Unemployment Insurance Take-up Rates in an Equilibrium Search Model

Stéphane Auray, David L. Fuller, Damba Lkhagvasuren

PII: S0014-2921(18)30185-5

DOI: https://doi.org/10.1016/j.euroecorev.2018.11.005

Reference: EER 3200

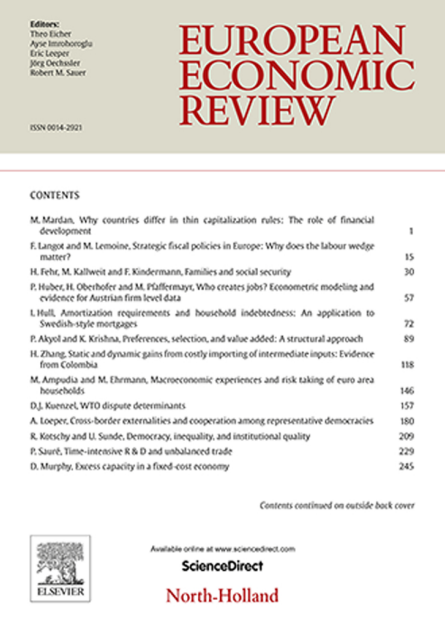

To appear in:

European Economic Review

Received date:

14 July 2017

Accepted date:

15 November 2018

Please cite this article as: Stéphane Auray, David L. Fuller, Damba Lkhagvasuren, Unemployment Insurance Take-up Rates in an Equilibrium Search Model, European Economic Review (2018), doi: https://doi.org/10.1016/j.euroecorev.2018.11.005

This is a PDF file of an unedited manuscript that has been accepted for publication. As a service to our customers we are providing this early version of the manuscript. The manuscript will undergo copyediting, typesetting, and review of the resulting proof before it is published in its final form. Please note that during the production process errors may be discovered which could affect the content, and all legal disclaimers that apply to the journal pertain. 


\title{
Unemployment Insurance Take-up Rates in an Equilibrium Search Model *
}

\author{
Stéphane Auray ${ }^{\dagger}$ \\ David L. Fuller ${ }^{\ddagger}$ \\ Damba Lkhagvasuren ${ }^{\S}$
}

November 24, 2018

\begin{abstract}
From $1989-2012$, on average $23 \%$ of those eligible for unemployment insurance (UI) benefits in the US did not collect them. To understand the implications of these "unclaimed" benefits, we develop a directed search model with an endogenous UI takeup rate. In equilibrium, UI collectors have longer unemployment durations relative to non-collectors. The difference results from two forces, a consumption effect and a private information effect, as UI collection histories are unobservable. We characterize both effects analytically and quantitatively. With an endogenous take-up rate, the unemployment rate and average duration of unemployment respond significantly slower to changes in the UI benefit level, relative to the standard model with a $100 \%$ takeup rate. The private information effect on non-collector job finding rates plays an important role in this result.
\end{abstract}

Keywords: unemployment insurance, take-up, calibration, matching frictions, search JEL classification: E61, J32, J64, J65

${ }^{*}$ We are grateful to the Editor, Ayse Imrohoroglu, an associate Editor, and two anonymous referees for comments that greatly improved the paper. We thank Pierre Cahuc, Yongsung Chang, Paul Gomme, B. Ravikumar, and Steve Williamson, and many conference and seminar participants. This paper was written while David Fuller was visiting Ensai, and he would like to thank them for their hospitality. Finally, we would like to thank financial support from the Chaire "Sécurisation des Parcours Professionnels at Sciences Po and GENES"

${ }^{\dagger}$ CREST-Ensai and ULCO; stephane.auray@ensai.fr

$\ddagger$ Corresponding author; University of Wisconsin-Oshkosh; 800 Algoma Blvd., Oshkosh, WI 54901; (262)424-1679; fullerd@uwosh.edu

${ }^{\S}$ Concordia University and CIREQ; damba.lkhagvasuren@concordia.ca 


\section{Introduction}

The unemployed not collecting benefits they are eligible for may represent the most important issue in the U.S. unemployment insurance system. The existing literature on unemployment insurance (UI) has focused primarily on incentive problems, such as moral hazard; however, much less attention has been devoted to understanding the issue of unclaimed UI benefits. Moreover, while many statistics and data on the labor market are readily available for public use, there exists little information on take-up rates of UI benefits. Our contribution includes a calculation of the fraction of eligible unemployed collecting UI (hereafter "take-up rate"), an equilibrium model incorporating the take-up decision, and an exploration of the implications of unclaimed benefits.

Building on the methodology of Blank and Card (1991), an estimate of the UI take-up rate is calculated from 1989 - 2012. The calculation uses the March supplement of the Current Population Survey (CPS) along with detailed eligibility criteria by U.S. state. Over the $1989-2012$ time period, the take-up rate averaged $77 \%$. An accurate measure of the UI take-up rate is essential on several dimensions.

First, changes in new UI claims represents an important and often used labor market and business cycle indicator (https://oui.doleta.gov/). Accurately accounting for changes in this measure requires an accurate measure of the UI take-up rate. Second, the efficacy of the UI system depends on how many/workers actually collect benefits, so knowing the take-up rate is an important first step towards developing policies that improve the provision of UI benefits. Finally, an accurate measure of the UI take-up rate is essential to study the effect of UI benefits on labor market outcomes. Any change in UI benefits alters not only the behavior and outcomes of UI collectors, but it may also impact how many collect benefits and the behayior and outcomes of the non-collectors. The analysis in this paper shows this to be an important consideration.

The take-up decision is captured using a search model with matching frictions, where risk-averse workers direct their search to the optimal wage and arrival rate combinations offered by risk-neutral firms (see Rogerson, Shimer, and Wright (2005) for an overview of a 
directed search environment and the related literature). Workers are heterogenous in their direct utility cost of collecting UI benefits. Assuming a utility cost of collecting is consistent with the work of Auray and Fuller (2018), who examine cross-state differences in UI takeup to identify the nature of the costs of collecting UI benefits. Indeed, the authors find a significant role for UI collection costs in the determination of the UI take-up rate. In our analysis, these costs, along with past UI collections, are private information for the worker. This informational structure, combined with an experience rated UI finaneing scheme have implications for the differences between UI collector and non-collector outcomes.

In the model, firms maximize profits by offering different wages depending on whether or not the worker prefers to collect UI benefits in the event of a future separation. They know the distribution of workers across UI collection costs, but do not observe whether or not the worker has collected in the past. In general, this is not problematic for the firm. They simply offer wages that maximize each type of worker's expected lifetime utility given the expected queue lengths associated with each wage. This would imply a natural "separating" equilibrium. The natural separation arises from the effects of different consumption levels with risk-averse workers. All else equal, UI collectors enjoy higher consumption while unemployed relative to a UI non-collector. Thus, UI collectors search for jobs offering relatively high wages, but longer unemployment durations (i.e. slower job arrival rates).

With experience rated taxes, however, this natural separation is distorted. With the UI tax accumulating only to those firms hiring a future UI collector, for an equivalent arrival rate, the UI non-collector has a higher wage than a collector. Thus, for some range of UI collection costs, a collector may find it beneficial to collect benefits but search for the non-collector wage, Indeed, we show that this is true in the private information equilibrium.

The differences in equilibrium between collectors and non-collectors arise from two sources. The first is a standard consumption effect. Since UI collectors have higher flow consumption while unemployed, they are willing to wait longer for higher wage jobs. This is a similar effect to the finding in Acemoglu and Shimer (1999) that an increase in UI benefits causes workers to accept longer unemployment durations in exchange for higher wage jobs, which 
may increase aggregate productivity. Second, the private information about past UI collections pushes non-collector durations down further. To understand the role played by each force, we characterize the features of collector and non-collector outcomes under equilibrium with private information, and equilibrium with observable UI collection histories.

Calibrating the model to the observed take-up rate allows us to quantify the collector and non-collector differences, as well as the relative contribution of the consumption and private information effects driving these differences. Non-collectors find jobs around 3 months sooner than UI collectors. Of that difference, around half is attributable to the effects of private information. Under private information non-collectors have an average unemployment duration of 2.44 months, compared to an average duration of 4 months under full information. UI collectors have an average duration of unemployment equal to 5.15 and 5.4 months under private and full information, respectively.

Interestingly, our analytical and quantitative results show the take-up rate is lower with full information relative to private information. When past UI collections are observable, to avoid paying the experience rated tax, firms prefer to dissuade some workers from collecting UI benefits by offering more appealing wages. Under private information, however, firms have fewer options to provide an attractive alternative to collecting UI; as a result, the take-up rate remains higher in the private information economy.

We also examine how incorporating an endogenous UI take-up rate affects the impact of UI benefits on equilibrium outcomes. That is, how does an increase in UI benefits affect moments such as the unemployment rate and average duration of unemployment? We find that allowing for an endogenous take-up rate has important implications. Specifically, while an increase in UI benefits does imply an increase in both the unemployment rate and average duration of unemployment, these two moments respond slower relative to a standard search model with a fixed $100 \%$ take-up rate. This occurs in part because the average duration of unemployment actually decreases for non-collectors when UI benefits increase, an effect driven by the private information distortion on non-collector wages and job finding rates.

The remainder of the paper proceeds as follows. In Section 2 we present information on 
the U.I. system in the U.S. and our estimates of the take-up rate. Section 3 describes the model and the key properties of equilibrium. Section 4 presents the calibration and policy experiments, and Section 5 concludes.

\section{Evidence on take-up rates}

This section has two objectives: a description of the relevant features of the U.S. system and a description of our take-up rate estimation and its key features.

\subsection{Unemployment Insurance System in the U.S.}

There are two features of the U.S. UI system relevant for the analysis below. First, UI in the U.S. is administered at the state-level. Each state has autonomy to set its own eligibility criteria and benefit levels. In addition, UI benefits have a fixed "Potential Duration," that each state controls. The typical U.S. state provides benefits equal to $50 \%$ of previous earnings that last for a maximum of 26 weeks. These 26 weeks are referred to as "Regular Program" benefits. In periods of high unemployment, states may choose to offer "Extended" benefits lasting an additional 13 or 20 weeks, depending on the state's current unemployment rate.

Second, UI benefits in the U.S. are financed by a tax levied on firms, and this tax is "Experience Rated." A particular firm's tax rate depends on the UI benefits collected by former employees. Note, the firm's UI tax rate does not depend on how frequently they separate from workers, but rather how frequently they separate from workers who collect UI benefits, and the total amount of benefits collected by these former employees. Firms that frequently send workers to unemployment who collect UI benefits face a relatively high tax rate. A firm may have a low tax rate as the result of very few separations, or as the result of rarely send workers to unemployment who actually collect UI benefits. 


\subsection{Take-up rate estimates}

The take-up rate is defined as the ratio of the number of unemployed collecting UI to the number of unemployed eligible to collect. The unemployed individuals that have/are collecting UI benefits are referred to as the "Insured Unemployed." Denote by FIU the ratio of Insured to Total Unemployed, or Fraction of Insured Unemployed: FIU $=\frac{\text { Insured Unemployed }}{\text { Total Unemployed }}$. The particular tabulation of the FIU we utilize includes only those unemployed collecting Regular Program benefits. This series is available via the U.S. Department of Labor at: http://workforcesecurity.doleta.gov/. On average, from 1989-2012, the FIU is $35 \%$.

While the FIU provides some characterization of the take-up rate, it does not control for eligibility. That is, many of the uninsured unemployed are in fact not eligible to collect benefits. To calculate the take-up rate, we must determine the fraction of unemployed individuals who are currently eligible to collect. We refer to the "Fraction of Eligible Unemployed" for UI benefits as FEU. The take-up rate is then the ratio of FIU to FEU, which is the number of insured unemployed divided by the number of eligible unemployed.

Since the FIU data are ready and tabulated, the key component of estimating the UI take-up rate is determining the FEU. Eligibility depends primarily on three factors, all of which are determined at the state level. The three factors are (i) monetary criteria, (ii) the duration of unemployment, and (iii) the nature of the separation. Below we describe the nature of the different eligibility criteria and how we evaluate these for individuals in the March CPS data.

\subsection{Monetary Criteria}

Monetary eligibility requires that an individual has accumulated sufficient earnings, or worked a minimum number of weeks in their previous employment. These previous earnings are measured in a specified "base-period." The base-period differs across states. Many use a year, while others use two quarters. The base-period is used both to determine monetary eligibility and to calculate the specific benefit an individual is entitled to. Given the March CPS supplement only covers the total earnings of an individual in the previous year, similarly 
to Blank and Card (1991), we only use a one-year base period. To estimate monetary eligibility, we use the earnings information contained in the March CPS, along with the state-level monetary eligibility requirements.

The monetary requirements vary significantly across states. Requiring base period earnings that exceed some multiple of the "weekly benefit amount," or WBA, represents the most common monetary criterion. For example, in 1989, Colorado required base period earnings to exceed 40 times the WBA. In this case, an individual with a WBA of $\$ 200$ per week would need total base period earnings of at least $\$ 8,000$. Other states simply set a fixed amount that must be earned in the base period. For example, in 1989, California required base period earnings of at least $\$ 1,200$. Finally, some states set a minimum number of weeks that must be worked in the base period. Michigan in 1989 represents an example of this, as they required 20 weeks of employment at a minimum of 30 times the state minimum hourly wage.

In general, the monetary criteria are the most heterogenous eligibility requirement across the U.S. states. Appendix E provides a list of each U.S. state and their eligibility requirements in 2012. We also discuss some drawbacks of using the CPS to determine eligibility that are similarly noted by Blank and Card (1991). We now turn to the next eligibility criterion, the duration of unemployment.

\subsection{Potential Duration of Benefits and Waiting Weeks}

The duration of the unemployment spell directly impacts an individual's eligibility for UI benefits. First, in certain states, there exists a "waiting week(s)," where a newly unemployed individual must wait at least 1 week before collecting. Second, as discussed above, UI benefits have a fixed potential duration, typically 26 weeks. There do exist a few states with potential durations longer than the standard 26 weeks (see MA, WA, and MT in Appendix E). Thus, if an individual collects benefits for 26 total weeks, but remains unemployed, they are no longer eligible to collect. Such an individual is said to have "Exhausted" their benefits. Since the March CPS does not ask whether the individual is currently collecting UI benefits, or the 
duration collected, an exhaustion must be inferred. Of course, being unemployed for longer than 26 weeks does not necessarily make an individual ineligible. The key issue is whether or not the individual exhausted their regular program benefits.

For example, suppose that at the time of the March CPS survey, an individual has been unemployed for 34 weeks; however, they did not apply until the 10th week of the spell. If any unemployment duration above 26 weeks is counted as an exhaustion, this individual is counted as such and classified as ineligible for UI benefits. Notice, however, this individual has only collected for 24 weeks and thus did not exhaust benefits. In general, as long as the individual still meets the aforementioned Monetary requirements for their previous earnings in a Base Period that starts from the date they apply, there are no other restrictions on when in the unemployment spell the individual can file. A worker could decide to file their first claim during the 27th week of the unemployment spell.

To control for this eligibility criterion, rather than rely exclusively on the duration of the unemployment spell, we also use the information in the March CPS about whether or not an individual collected benefits in the previous year. If an individual is unemployed in March of a given year and has expired regular program benefits, then they have been unemployed for longer than 26 weeks (accounting for differences in MA, WA, and MT where applicable) and must have collected benefits in the previous year. Thus, we classify an individual as ineligible via Exhaustion if they have been unemployed longer than 26 weeks, and they collected UI benefits in the previous year. This treatment of Exhaustions represents a departure from the methodology of Blank and Card (1991). Blank and Card (1991) classify individuals as ineligible via Exhaustions if they have been unemployed longer than 26 weeks, which suffers from the aforementioned issues. Below in Table 1 we compare our estimates with those obtained using the Blank and Card (1991) Exhaustion criterion. Finally, we also control for the waiting week where applicable. 


\subsection{Separation Criteria}

The nature of the separation leading to the spell of unemployment represents the final eligibility criterion. Unemployment insurance is designed to provide temporary income to those workers who have lost their job through no fault of their own; i.e., an individual must be involuntarily unemployed to be eligible for UI benefits. This implies that individuals who entered unemployment because they quit or were fired for cause are ineligible for UI benefits. In certain years, Georgia is an exception and does allow job leavers (quits) to collect benefits, but they face an increased waiting period. We can eliminate quits in the CPS dáta; however, we cannot determine whether or not the individual was fired for cause. As in Blank and Card (1991), we also eliminate postal workers, federal public administration workers, and ex-service persons, as this group is not eligible for UI benefits.

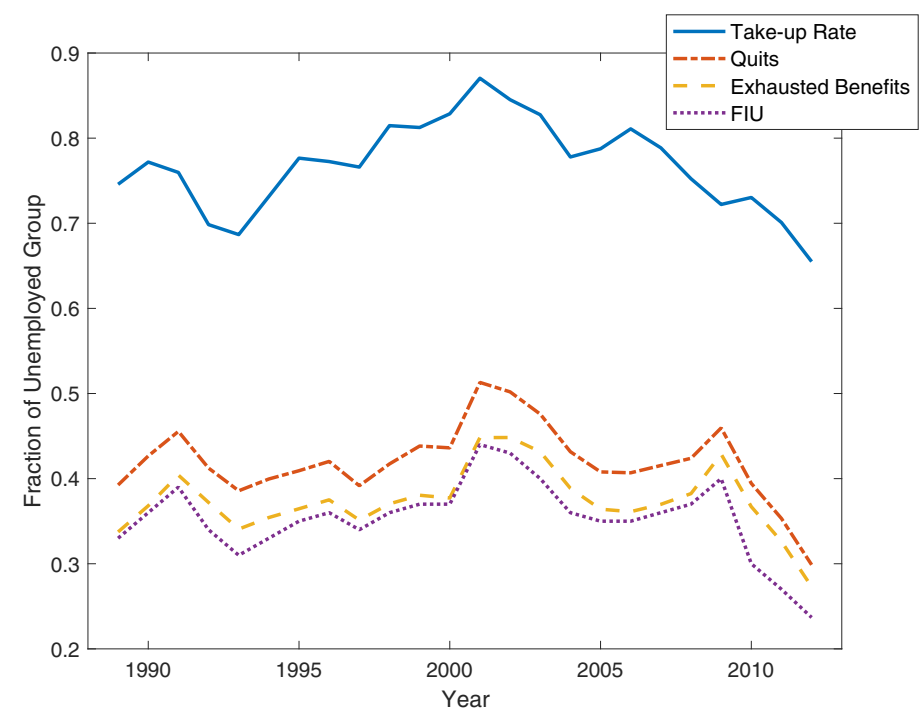

Figure 1: Take-up Rates by Eligibility Criteria Over Time

The bottom line labeled "FIU" is the ratio of insured unemployed to total unemployed. As the lines progress, unemployed individuals are eliminated from the denominator based on different eligibility criterion. Thus, the gap between lines illustrates how many unemployed are ineligible by each criterion. A larger gap between lines indicates a larger number of unemployed ineligible for a certain criterion. "Exhaustions" removes to those ineligible because they exhausted their benefits and "Quits" removes those who are ineligible because they quit the job. The jump from the "Quits" line to the "Take-up Rate" line occurs when those ineligible because of monetary requirements are removed. Finally, the "Take-up Rate" line plots the fraction of eligible unemployed collecting benefits. 


\subsection{Take-up Rates: Results}

Figure 1 presents the results of the take-up rate calculations from 1989-2012. The solid line is our estimate of the UI take-up rate. Starting with the lowest line, the FIU, we progressively remove ineligible unemployed by each of the aforementioned criterion. Moving from the lowest line to the next one, we remove those individuals that are ineligible because they exhausted benefits. The next line removes those ineligible because of quits, meaning the move from the third line to the highest line represents how many individuals are ineligible because they failed the monetary requirements.

We also present this information in Table 1. Here we provide the FIUfor each year, the take-up rate in each year, and the fraction of unemployed who are ineligible. We then show what fraction of the ineligible unemployed are ineligible by each criterion. For example, in 1989, the FIU is $33 \%$, and $56 \%$ of the unemployed are ineligible for UI benefits; this implies a take-up rate of $75 \%: T U R=\frac{0.33}{1-0.56}=0.75$. Of the $56 \%$ of unemployed ineligible, $71 \%$ are ineligible because they fail the monetary criteria, $25 \%$ from quits, and $4 \%$ from exhaustions. As expected, the exhaustion criterion has a cyclical contribution, with more individuals exhausting benefits during periods of high unemployment. For example, in 2010, $31 \%$ of those ineligible were due to exhausted benefits.

The final three columns of Table 1 show the take-up rate, fraction of unemployed ineligible, and the fraction of ineligible via exhaustions if we alternatively use the exhaustion criterion applied by Blank and Card (1991). Recall, they count any unemployed individuals with durations longer than 26 weeks as ineligible. As expected, this increases the number of unemployed ineligible, which in turn increases the estimated take-up rate. Of note is 2009, where we estimate) a take-up rate of $118 \%$ under the Blank and Card (1991) methodology. During this period, the average duration of unemployment was well above normal, implying a large fraction of the unemployed had durations longer than 26 weeks; as a result, a much larger fraction are deemed ineligible. It is important to note that the FIU used to compute the take-up rate includes only those collecting Regular Program benefits. In 2009 the U.S. Federal Government passed legislation that activated "Extended Benefits" covering workers 
from weeks 27 to as much as 99 weeks in certain states. Thus, the $118 \%$ take-up rate does not obtain because the FIU includes those on extended benefits, but rather from the improper accounting of exhaustions we detail above.

We also present a state-level breakdown of the take-up rate, FIU, FEU, and impact of eligibility criteria in Appendix C. This offers some insight into the variation across states in UI take-up rates.

\subsection{Examining Changes Over Time}

Figure 1 and Table 1 show there does exist some variation in the U.S. take-up rate over time. The general pattern looks as if there is an upward trend from 1989-2002, with a downward trend thereafter. It is useful to ask what factors may be contributing to these patterns. Mechanically, the take-up rate changes because either the FIU and/or the FEU changes. While changes in the FIU are more difficult to explain without individual-level data, we can examine some possible factors changing the FEU.

The FEU changes if either the eligibility rules change, or there is a change in the composition of the unemployed. To examine the effect of changes in eligibility rules, we perform the following experiment. We fix eligibility rules in each state as written in 1989. Changes are made to monetary criteria to adjust for inflation where relevant. Given the 1989 Eligibility Rules, we re-estimate the FEU and calculate the resulting take-up rate. This gives an alternative take-up rate that would have obtained had there been no changes in eligibility. Table 2 presents the results. The first column displays the FIU, the second column shows the FEU under the actual eligibility rules in each year, with the third column ("TUR") displaying the original TUR. The next two columns present the alternative "FEU 1989 Rules" and the corresponding take-up rate, "TUR 1989 Rules." The last column, "1989-Orig. Rules," takes the difference between the alternative TUR and the actual TUR.

Overall the results suggest that changes in eligibility had minimal impact on the take-up rate. Moreover, in most years from 1989-2002, the take-up rate would have been slightly higher under 1989 rules, while they would have been slightly lower in most years from 2003- 
Table 1: Take-up Rate and Ineligibility by Cause

\begin{tabular}{l|ccccccccc}
\hline Year & FIU & TUR & Inelig. & Mon. & Quits & Exhaust & TUR BCE & Inelig. BCE & Exhaust BCE \\
\hline 1989 & 0.330 & 0.746 & 0.558 & 0.714 & 0.246 & 0.039 & 0.800 & 0.588 & 0.174 \\
1990 & 0.360 & 0.772 & 0.534 & 0.707 & 0.251 & 0.041 & 0.819 & 0.560 & 0.173 \\
1991 & 0.390 & 0.760 & 0.487 & 0.705 & 0.224 & 0.072 & 0.806 & 0.516 & 0.215 \\
1992 & 0.340 & 0.698 & 0.513 & 0.658 & 0.174 & 0.168 & 0.768 & 0.557 & 0.344 \\
1993 & 0.310 & 0.687 & 0.549 & 0.642 & 0.193 & 0.164 & 0.755 & 0.590 & 0.352 \\
1994 & 0.330 & 0.732 & 0.549 & 0.683 & 0.192 & 0.125 & 0.809 & 0.591 & 0.340 \\
1995 & 0.350 & 0.777 & 0.549 & 0.736 & 0.191 & 0.073 & 0.830 & 0.592 & 0.323 \\
1996 & 0.360 & 0.772 & 0.534 & 0.732 & 0.193 & 0.076 & 0.896 & 0.579 & 0.310 \\
1997 & 0.340 & 0.766 & 0.556 & 0.763 & 0.179 & 0.058 & 0.835 & 0.598 & 0.266 \\
1998 & 0.360 & 0.815 & 0.558 & 0.754 & 0.195 & 0.050 & 0.848 & 0.593 & 0.246 \\
1999 & 0.370 & 0.813 & 0.545 & 0.714 & 0.235 & 0.051 & 0.889 & 0.575 & 0.209 \\
2000 & 0.370 & 0.829 & 0.553 & 0.726 & 0.240 & 0.034 & 0.784 & 0.584 & 0.184 \\
2001 & 0.440 & 0.870 & 0.495 & 0.712 & 0.251 & 0.037 & 0.934 & 0.528 & 0.201 \\
2002 & 0.430 & 0.845 & 0.491 & 0.708 & 0.208 & 0.083 & 0.979 & 0.529 & 0.284 \\
2003 & 0.400 & 0.827 & 0.517 & 0.692 & 0.167 & 0.142 & 0.965 & 0.561 & 0.350 \\
2004 & 0.360 & 0.778 & 0.537 & 0.691 & 0.172 & 0.137 & 0.900 & 0.586 & 0.365 \\
2005 & 0.350 & 0.788 & 0.556 & 0.745 & 0.186 & 0.070 & 0.887 & 0.600 & 0.316 \\
2006 & 0.350 & 0.811 & 0.568 & 0.754 & 0.191 & 0.055 & 0.850 & 0.606 & 0.275 \\
2007 & 0.360 & 0.789 & 0.543 & 0.755 & 0.197 & 0.049 & 0.802 & 0.588 & 0.283 \\
2008 & 0.370 & 0.752 & 0.508 & 0.750 & 0.186 & 0.064 & 0.740 & 0.551 & 0.293 \\
2009 & 0.400 & 0.722 & 0.446 & 0.709 & 0.140 & 0.150 & 1.179 & 0.500 & 0.451 \\
2010 & 0.300 & 0.730 & 0.589 & 0.594 & 0.096 & 0.310 & 0.952 & 0.661 & 0.612 \\
2011 & 0.270 & 0.701 & 0.615 & 0.617 & 0.103 & 0.280 & 0.885 & 0.685 & 0.611 \\
2012 & 0.237 & 0.655 & 0.638 & 0.676 & 0.117 & 0.207 & 0.753 & 0.695 & 0.582 \\
\hline Average & 0.353 & 0.768 & 0.541 & 0.706 & 0.189 & 0.106 & 0.861 & 0.584 & 0.323 \\
\hline \hline
\end{tabular}

This table presents the Fraction of Insured Unemployed (FIU), the Take-up Rate (TUR), the fraction of unemployed ineligible for UI ("Inelig."), and then breaks down the reasons for ineligibility. "Mon." corresponds to the Monetary criteria, "Quits" to Quits, and "Exhaust" to "Exhaustions." For example, in 1989, $56 \%$ of the unemployed were ineligible for UI benefits, implying that $44 \%$ were eligible. With a FIU of $33 \%$, this gives the TUR of $\frac{0.33}{0.44}=0.75$. Then, of those ineligible for benefit, $71.4 \%$ were ineligible because of Monetary criteria, $24.6 \%$ because of Quits, and $4 \%$ had exhausted benefits. Note, due to rounding errors, in some rows the three criteria may not sum precisely to $100 \%$. The last three columns correspond to take-up rate (TUR BCE) estimates using the Blank and Card (1991) exhaustion criterion, as well as the fraction ineligible (Inelig. BCE) and fraction ineligible from exhaustion (Exhaust BCE) under this criterion. The last row in the table, labeled "Average," averages each column from 1989-2012. 
Table 2: Changes in Take-up Rates and Eligibility Over Time

\begin{tabular}{l|llllll}
\hline Year & FIU & FEU & TUR & $\begin{array}{l}\text { FEU } \\
1989 \text { Rules }\end{array}$ & $\begin{array}{l}\text { TUR } \\
1989 \text { Rules }\end{array}$ & $\begin{array}{l}1989 \text { - Orig. } \\
\text { Rules }\end{array}$ \\
\hline 1989 & 0.33 & 0.44 & 0.75 & 0.44 & 0.75 & 0.000 \\
1990 & 0.36 & 0.47 & 0.77 & 0.44 & 0.81 & 0.042 \\
1991 & 0.39 & 0.51 & 0.76 & 0.46 & 0.85 & 0.086 \\
1992 & 0.34 & 0.49 & 0.70 & 0.51 & 0.67 & -0.032 \\
1993 & 0.31 & 0.45 & 0.69 & 0.48 & 0.64 & -0.044 \\
1994 & 0.33 & 0.45 & 0.73 & 0.45 & 0.74 & 0.010 \\
1995 & 0.35 & 0.45 & 0.78 & 0.45 & 0.78 & 0.005 \\
1996 & 0.36 & 0.47 & 0.77 & 0.46 & 0.78 & 0.005 \\
1997 & 0.34 & 0.44 & 0.77 & 0.44 & 0.77 & 0.005 \\
1998 & 0.36 & 0.44 & 0.81 & 0.44 & 0.82 & 0.001 \\
1999 & 0.37 & 0.46 & 0.81 & 0.46 & 0.81 & -0.004 \\
2000 & 0.37 & 0.45 & 0.83 & 0.44 & 0.83 & 0.006 \\
2001 & 0.44 & 0.51 & 0.87 & 0.51 & 0.87 & -0.004 \\
2002 & 0.43 & 0.51 & 0.85 & 0.51 & 0.85 & 0.001 \\
2003 & 0.4 & 0.48 & 0.83 & 0.49 & 0.82 & -0.011 \\
2004 & 0.36 & 0.46 & 0.78 & 0.47 & 0.77 & -0.005 \\
2005 & 0.35 & 0.44 & 0.79 & 0.46 & 0.76 & -0.024 \\
2006 & 0.35 & 0.43 & 0.81 & 0.45 & 0.78 & -0.029 \\
2007 & 0.36 & 0.46 & 0.79 & 0.47 & 0.77 & -0.017 \\
2008 & 0.37 & 0.49 & 0.75 & 0.50 & 0.74 & -0.013 \\
2009 & 0.4 & 0.55 & 0.72 & 0.56 & 0.72 & -0.005 \\
2010 & 0.3 & 0.41 & 0.73 & 0.42 & 0.72 & -0.008 \\
2011 & 0.27 & 0.39 & 0.70 & 0.39 & 0.69 & -0.016 \\
2012 & 0.24 & 0.36 & 0.65 & 0.39 & 0.61 & -0.041 \\
\hline \hline
\end{tabular}

This table examines the impact of changes in eligibility rules since 1989 on the UI take-up rate. The first column presents the Fraction of Insured Unemployed, FIU, and the second the Fraction of Eligible Unemployed (FEU) under the actual eligibility rules for each year. The third column then displays the takeup rate (TUR) based on these two ratios, which is our original estimate of the take-up rate. The column labeled "FEU 1989 Rules" calculates the FEU assuming that eligibility is determined by the 1989 rules, updating for inflation where relevant. The resulting take-up rate from these alternative eligibility rules for each year is presented in the column labeled "TUR 1989 Rules." In the final column we simply calculate the difference between the TUR 1989 Rules and the TUR (under original eligibility rules). 
2012. Thus, the aforementioned trends do not appear to be the result of changes in eligibility criteria.

\subsection{Reasons for Non-collection}

The estimates above imply significant unclaimed UI benefits. One may ask, what are the reasons for non-collection? Given the eligibility criteria discussed above, there clearly exist some costs to applying for UI benefits associated with documenting one's eligibility. The exact nature of these costs and the exact reason(s) for non-collection, however, have not been determined or well-documented in the literature. Anderson and Meyer (1997) cite some survey results offering possible reasons for non-collection, but no particular reason dominates. Reasons presented in Anderson and Meyer (1997) include uncertain eligibility, too much hassle/work to apply, too much like charity, expect to be recalled soon, or other reasons. There is some evidence that collection costs affect the take-up of Food Stamp benefits (now referred to as SNAP in the U.S.). For example, Brien and Swann (1997) and Bitler, Currie, and Scholz (2003) examine take-up of SNAP benefits and both find that the transaction costs and state-level program administration differences play a significant role in determining the take-up rate. While this is not necessarily reflective of the costs in the UI system, it is suggestive that such costs play a role.

An individual does not collect UI benefits if they believe the net benefit to doing so is negative. Below we model this as a per-period utility cost of collecting UI benefits. While the survey cited in Anderson and Meyer (1997) does not provide solid evidence of collection costs or their nature, Auray and Fuller (2018) explore possible micro-foundations for the costs associated with participating in the UI system. The authors indeed find evidence indicating an important role of collection costs in the take-up decision. Specifically Auray and Fuller (2018) focus on two types of UI collection costs: (i) fixed administrative costs and (ii) costs associated with firm eligibility challenges. They find that administrative costs account for the majority $(60 \%)$ of collection costs. Examples include the time required to file the application each week, or to provide evidence of continued eligibility, such as showing 
evidence of job search activities. The second type of costs, firm eligibility challenges arise when firms dispute the eligibility of a UI applicant. The associated back and forth poses costs to both the worker and the firm. Auray and Fuller (2018) find that such costs account for around $40 \%$ of total UI collection costs for workers.

\section{Model}

The economy consists of a unit-measure of infinitely-lived, risk-averse workers, and a large measure of risk-neutral firms. Time is continuous and goes on forever, and both workers and firms discount the future at rate $r>0$. Workers have preferences over consumption, with flow utility given by $h(c)$, where $c$ represents consumption. Firms are composed of a single job, either filled or vacant. Vacant firms are free to enter and pay a flow cost, $\gamma>0$, to advertise a vacancy. Vacant firms produce no output. The flow output of a firm with a filled job is given by $y$. There are several components of the model to specify. We begin by describing the key features of how UI is modeled.

\subsection{Unemployment Insurance}

As discussed in Section 2.8, we assume that there is a flow utility cost associated with collecting UI benefits and verifying eligibility. Furthermore, we assume that this flow utility cost is additively separable and occurs each period the worker collects UI benefits. ${ }^{1}$ This mirrors the actual U.S. system, where workers must re-apply for benefits each week they are unemployed. Workers are heterogenous with respect to their costs of collecting UI benefits, which are denoted/by $\varepsilon$. The cost remains the same for their lifetime; i.e. $\varepsilon$ is permanent. Thus, the worker faces the same costs of collecting UI benefits each unemployment spell.

Let $F(\varepsilon)$ denote the distribution of workers over $\varepsilon$. If a worker collects UI benefits, they receive, flow consumption $b$ and incur their cost of collecting benefits, $\varepsilon$. UI benefits only

\footnotetext{
${ }^{1}$ Assuming a one-time, upfront cost of collecting UI benefits represents the alternative. Either assumption, per-period flow cost or one-time upfront cost deliver the same results, since we assume the cost is the same each period during the worker's lifetime.
} 
expire if the worker transitions to employment. Assuming that UI benefits never expire does not affect our results but simplifies the analysis. If the worker decides not to collect UI benefits, they receive flow consumption $d$, where $b>d$. Thus, each period of unemployment a UI-collector with collection cost $\varepsilon$ receives flow utility of $h(b)-\varepsilon$ while a non-collector receives $h(d)$.

Unemployment benefits are financed by lump-sum taxes levied on firms. Experience rating is captured in the following manner. If a firm separates from a worker who collects UI benefits, the firm pays a flow cost of $\tau$. The value of $\tau$ determines the marginal cost to a firm of sending a worker to insured unemployment.

Notice, we assume that all workers are UI eligible. We analyze the take-up decision, which applies only to this group. Indeed, while some unemployed are not eligible for UI benefits, adding this dimension to the model complicates the analysis without providing commensurate insights to the question at hand. In addition, we similarly exclude the possibility of UI fraud, where workers ineligible for UI benefits still collect them (see Appendix D for further discussion of UI fraud). While excluding these features from our analysis creates a gap between the model and the data versions of the take-up rate, the additional tractability and analytical insights are worth this trade-off.

We also assume there exists private information. Specifically, we assume that the firm does not observe the worker's previous history of UI collections. Given this assumption, we must also assume that the worker's UI collection cost, $\varepsilon$, is private information. Since $\varepsilon$ remains the same for the worker's lifetime, knowledge of $\varepsilon$ would enable the firm to infer the UI collection history. The firm does know the distribution of $\varepsilon, F(\varepsilon)$. The firm's lack of knowledge regarding past UI collections represents the key source of private information. If only $\varepsilon$ is private information, but UI collection histories are observable, then private information does not affect equilibrium outcomes. Below we discuss some features of equilibrium with full information regarding UI collection histories, but where $\varepsilon$ remains private information. Comparing this "full" information equilibrium to the one with private information illustrates the mechanisms driving differences in UI collector and non-collector outcomes. 
In the U.S. UI system, when a worker files a UI claim, the firm is notified to verify the worker's eligibility. Thus, the worker's previous firm knows their UI collection status. Future firms, however, do not have access to this information. In the U.S. system, the state UI office cannot share information about UI collectors with any firms (other than the separating firm to verify eligibility). Therefore, the assumption of private information regarding past UI collections represents the current state of U.S. law.

\subsection{Wages and Matching}

We assume directed search. Firms post wages and workers direct their search to the wage maximizing their expected lifetime utility (see Moen (1997) or Acemoglu and Shimer (1999) for a similar formulation of the environment).

There exists a matching function, denoted $m(u, \mathrm{v})$, describing the number of matches formed between the $\mathrm{v}$ vacancies and $u$ unemployed workers. We assume standard properties, i.e. $m$ is continuous, strictly increasing, strictly/concave (with respect to each of its arguments), and exhibits constant returns to scale. Furthermore, $m(0, \cdot)=m(\cdot, 0)=0$ and $m(\infty, \cdot)=m(\cdot, \infty)=\infty$. Let $q=\frac{u}{\mathrm{v}}$ denote the "queue" length

Given this matching technology, a vacancy is filled with Poisson arrival rate $m\left(\frac{u}{\mathrm{v}}, 1\right)$. Similarly, an unemployed worker finds a job according to a Poisson process with arrival rate $m\left(1, \frac{\mathrm{v}}{u}\right)$. Let $\alpha_{E}(q)=m\left(\frac{\mathrm{u}}{\mathrm{v}}, 1\right)$ and $\alpha_{W}(q)=m\left(1, \frac{\mathrm{v}}{u}\right)$ denote the vacancy filling and job finding rates, respectively. Filled jobs receive negative idiosyncratic productivity shocks rendering the match unprofitable with a Poisson arrival rate $\lambda$.

\subsection{Value Functions}

We begin by describing the firm and worker value functions for a general wage function, $w$. After defining the equilibrium concept we then show that wages are a function of $\varepsilon$, and describe how the market naturally separates UI collectors and non-collectors. 


\subsubsection{Firms}

Denote the value of a vacancy and the value of a matched firm by $V$ and $J$, respectively. For any given $w$,

$$
r V=-\gamma+\alpha_{E}[q(w)][J-V]
$$

According to Equation (1), the firm pays the flow cost $\gamma$ to open the vacancy, and at rate $\alpha_{E}[q(w)]$ the vacancy is filled. For the value of a filled vacancy, $J$, denote the expected probability a worker collects UI benefits if separated (or the expected proportion of workers collecting) by $p$. Then,

$$
r J=y-w+\lambda[-p \tau+(V-J)]
$$

That is, the firm earns flow profits $y-w$. At rate $\lambda$ the job is destroyed, and whether or not the firm pays the experience rated tax, $\tau$, depends on if the worker collects UI benefits or not. Since the firm expects a worker to collect with probability $p, p \tau$ is the expected flow cost of experience rated taxes, which the firm pays upon separation. Given free entry, $V=0$, we have,

$$
J=\frac{y-w}{r+\lambda}-\lambda p \tau
$$

Plugging Equation (3) into Equation (1) under free entry, and solving for $w$ yields,

$$
w=y-\frac{\gamma(r+\lambda)}{\alpha_{E}(q(w))}-\lambda p \tau
$$

Equation (4) represents the zero-profit curve (alternatively iso-profit curve), describing the relationship between $w$ and $q$ for the firm. 


\subsubsection{Workers}

Unemployed workers can be in two possible states depending on whether or not they collect unemployment benefits. Denote unemployed collecting UI by $i=C$ and not-collecting by $i=N C$. The worker decides which unemployment state to enter the instant a separation occurs, when the worker transitions from employment to unemployment.

Let $C(\varepsilon)$ denote the expected value of searching for a job with wage and expected queue length combination $(w, q(w))$, for an unemployed worker collecting UI with cost of collecting $\varepsilon$. Similarly, let $N C(\varepsilon)$ denote the lifetime utility for the worker if not collecting UI, and $E(\varepsilon)$ the lifetime utility of employment. Given this, the value functions are given by:

$$
\begin{aligned}
r C(\varepsilon) & =h(b)-\varepsilon+\alpha_{W}(q(w))[E(\varepsilon)-C(\varepsilon)] \\
r N C(\varepsilon) & =h(d)+\alpha_{W}(q(w))[E(\varepsilon)-N C(\varepsilon)] \\
r E(\varepsilon) & =h(w)+\lambda(\max \{C(\varepsilon), N C(\varepsilon)\}-E(\varepsilon))
\end{aligned}
$$

Equation (5) implies that an unemployed worker collecting benefits receives instantaneous flow utility $h(b)$ from unemployment compensation, pays the cost of collecting $\varepsilon$, and with arrival rate $\alpha_{W}(q(w))$, the worker matches with a firm and transitions to employment. Equation (6) has a similar interpretation for an unemployed worker not collecting. Finally, Equation (7) states that an employed worker receives instantaneous flow utility from the wage, $h(w)$, and with Poisson arrival rate $\lambda$ the job dissolves. If the job dissolves, the worker decides whether or not to collect unemployment benefits. Notice, since the costs of collecting are the same for the worker's lifetime, in the steady state, if a worker prefers to collect UI benefits once, he always prefers to.

The following expressions for $C(\varepsilon)$ and $N C$ are useful in the analysis below. Using 
Equations (5) to (7) to solve for $C(\varepsilon)$ and $N C$, respectively, gives,

$$
\begin{aligned}
& r C(\varepsilon)=\left(\frac{1}{r+\lambda+\alpha_{W}(q(w))}\right)\left((r+\lambda)(h(b)-\varepsilon)+\alpha_{W}(q(w)) h(w)\right) \\
& r N C=\left(\frac{1}{r+\lambda+\alpha_{W}(q(w))}\right)\left((r+\lambda) h(d)+\alpha_{W}(q(w)) h(w)\right)
\end{aligned}
$$

To ensure that the worker's indifference curves in $(q, w)$ space are strictly convex requires the following assumption:

Assumption 1 The matching function satisfies:

$$
2\left[\alpha_{W}^{\prime}(q)\right]^{2} \alpha_{W}(q)>\alpha_{W}^{\prime \prime}(q)\left[\alpha_{W}(q)\right]^{2}
$$

This condition is generally true for large enough $q$, and was satisfied in the relevant range for all of the numerical examples computed in Section 4. Another way to view this assumption is as a sufficient condition for the value functions $C(\varepsilon)$ and $N C$ to be strictly concave in $q$.

\subsubsection{Definition of Equilibrium}

In this section we define equilibrium for the economy described above. An allocation is defined as a set $\{\mathbb{W}, Q, \mathbf{C}, \mathbf{E}, \mathbb{N} \mathbf{C}, \mathcal{T}\}$. This consists of a set of wages, $\mathbb{W}$, a queue length associated with each wage $Q(w)$, indirect utilities, E, C, NC for workers in each possible employment state, and a take-up decision rule, $\mathcal{T}$. An equilibrium is then defined as follows:

Definition 1 An equilibrium is an allocation $\{\mathbb{W}, Q, \mathbf{C}, \mathbf{E}, \mathbf{N C}, \mathcal{T}\}$ such that:

1. Profit maximization: for all $w$ and all $\varepsilon$,

$$
y-w-\frac{\gamma(r+\lambda)}{\alpha_{E}[q(w)]}-\lambda p \tau \geq 0
$$

with equality if $w \in \mathbb{W}$,

2. Optimal job application: for all $w$ and all $\varepsilon$,

$$
\begin{aligned}
\mathbf{C}(\varepsilon) & \geq C(w, Q(w), \varepsilon) \\
\mathbf{N C} & \geq N(w, Q(w))
\end{aligned}
$$


for $Q(w)>0$, where

$$
\begin{aligned}
\mathbf{C}(\varepsilon) & =\sup _{w^{\prime} \in \mathbb{W}} C\left(w^{\prime}, Q\left(w^{\prime}\right), \varepsilon\right) \\
\mathbf{N C} & =\sup _{w^{\prime} \in \mathbb{W}} N\left(w^{\prime}, Q\left(w^{\prime}\right)\right)
\end{aligned}
$$

3. Optimal Take-up: A worker $i \in \mathcal{T}$ if and only if $\mathbf{N C} \leq \mathbf{C}(\varepsilon)$

4. Consistency: The firm's expected $p$ in Equation (11) is consistent with $\mathcal{T}$.

This represents a standard definition of equilibrium in a directed search environment, adjusted for the take-up decision. Profit maximization states that firms choose the $w$ that maximizes profits, taking the expected queue length, $q$, and expected proportion of UI collectors, $p$ as given. Free entry ensures that firms earn zero profits in equilibrium. Optimal application requires that unemployed workers direct their search to the wage offering the highest expected lifetime utility. Note, it is possible that search behavior remains different for UI collectors and non-collectors; equilibrium is a set of wages, and workers direct their search appropriately within that set. The Optimal Táke-up condition specifies the set of workers that find it optimal to collect UI benefits upon separation. Finally, this optimal takeup condition must be consistent with the firm's expected $p$; if more or less workers collect UI benefits than the firm expects, either profit maximization or the zero profit condition are violated.

\subsubsection{Endogenous market segmentation}

Showing that equilibrium involves endogenous separation on two dimensions represents the next step. Specifically, we show that markets endogenously separate (i) between UI collectors and non-collectors and (ii) along $\varepsilon$ for UI collectors. Towards this end, consider the following result:

Lemma 1 For any active equilibrium (i.e. $Q(w)>0$ ), there exists a unique $\varepsilon^{*}$ such that

$\mathbf{C}(\varepsilon) \geq \mathbf{N C}$, for all $\varepsilon \leq \varepsilon^{*}$ and $\mathbf{N C}>\mathbf{C}(\varepsilon)$ for all $\varepsilon>\varepsilon^{*}$.

Lemma 1 establishes a unique cut-off value for the costs of collecting UI benefits, denoted $\varepsilon^{*}$. If a worker's $\varepsilon$ is below this cut-off, they prefer to collect UI benefits if separated. The 
existence of a unique cut-off $\varepsilon^{*}$ is true of any equilibrium, which creates two "types" of workers the firm encounters. Moreover, which type of worker the firm encounters affects the profits earned; a worker with $\varepsilon \leq \varepsilon^{*}$ collects UI benefits if separated, implying the firm pays a higher flow cost upon separation, $\tau$. Thus, the expected proportion of workers collecting benefits in equilibrium, $p$, is either $p=1$ for $\varepsilon \leq \varepsilon^{*}$ or $p=0$ for all $\varepsilon>\varepsilon^{*}$. Next we show that any equilibrium involves endogenous separation along this cut-off, $\varepsilon^{*}$, and also involves a wage function, $w(\varepsilon)$ for $\varepsilon \leq \varepsilon^{*}$.

Proposition 1 Any equilibrium allocation, $\{\mathbb{W}, \mathbb{Q}, \mathbf{C}, \mathbf{E}, \mathbf{N C}, \mathcal{T}\}$, involves a wage function, $w(\varepsilon)$, with $w_{C}(\varepsilon)$ for $\varepsilon \leq \varepsilon^{*}$ and $w_{N C}$ for $\varepsilon>\varepsilon^{*}$.

Given this endogenous separation, firms post two different types of wages: $w_{C}(\varepsilon)$ targeted to UI collectors and $w_{N C}$ to non-collectors. This in turn implies potentially different queue lengths, which we denote by $q_{C}(\varepsilon)$ and $q_{N C}$ for UI collectors and non-collectors, respectively. Notice that equilibrium rules out any "pooling" contracts. That is, by definition of equilibrium, it is always optimal for firms to offer different wage contracts to different workers.

\subsubsection{Labor market flows and stocks}

Our description of equilibrium also requires the flow equations associated with the measures of workers in the different employment and unemployment states. Let $j \in\{E, U\}$ denote the worker's employment state: $j=E$ for employed and $j=U$ for unemployed. Denote the number of workers in employment state $j \in\{E, U\}$ and UI collection state $i \in\{C, N C\}$ by $n_{j}^{j}$. Thus, unemployed workers collecting UI benefits (for each $\varepsilon$ ) are denoted by $n_{C}^{U}(\varepsilon)$, and the number of unemployed not collecting UI are denoted by $n_{N C}^{U}$. Similarly, $n_{C}^{E}(\varepsilon)$ denotes the number of employed workers in state $i=C$ (i.e. collects UI if separated) and $n_{N C}^{E}$ the number of employed workers in state $i=N$ (i.e. does not collect UI if separated).

To obtain a steady state equilibrium, for each $\varepsilon$ the flows of workers into and out of employment must be equal. Since the market segments along $\varepsilon$, with $\varepsilon \leq \varepsilon^{*}$ collecting UI 
benefits and all others not, we can characterize these equilibrium flow equations as:

$$
\begin{gathered}
\lambda n_{C}^{E}(\varepsilon)=\alpha_{W}\left[q_{C}(\varepsilon)\right] n_{C}^{U}(\varepsilon) \\
f(\varepsilon)=n_{C}^{E}(\varepsilon)+n_{C}^{U}(\varepsilon)
\end{gathered}
$$

Equation (16) states that for UI collectors, the flow of workers in and out of employment is equal and Equation (17) ensures that the total measure of workers across the two employment states adds up to the population fraction, or $f(\varepsilon)$. Similarly, for $\varepsilon>\varepsilon^{*}$ :

$$
\begin{aligned}
& \lambda n_{N C}^{E}=\alpha_{W}\left(q_{N C}\right) n_{N C}^{U} \\
& 1-F\left(\varepsilon^{*}\right)=n_{N C}^{E}+n_{N C}^{U}
\end{aligned}
$$

Given these flow equations, further denote the total number of employed (unemployed) with $\varepsilon \leq \varepsilon^{*}$ by $N_{C}^{j}=\int_{0}^{\varepsilon^{*}} n_{C}^{j}(\varepsilon) d \varepsilon, j=E, U$. Further let $N_{N C}^{j} \equiv n_{N C}^{j}, j=E, U$. Then, for $\varepsilon \leq \varepsilon^{*}$, Equations (16) and (17) give

$$
N_{C}^{U}=\int_{0}^{\varepsilon^{*}} \frac{f(\varepsilon) \lambda}{\lambda+\alpha_{W}\left[q_{C}(\varepsilon)\right]} d \varepsilon
$$

Similarly we have:

$$
N_{N C}^{U}=\frac{[1-F(\varepsilon)] \lambda}{\lambda+\alpha_{W}\left(q_{N C}\right)}
$$

Thus, the unemployment rate for this economy is given by $u=N_{C}^{U}+N_{N C}^{U}$. The takeup rate is the fraction of eligible unemployed who collect UI benefits. Since we assume all workers are eligible for UI benefits, this is given by:

$$
\mathrm{TUR}=\frac{N_{C}^{U}}{u}
$$

Equation (22) helps illustrate important equilibrium relationships determining the UI take-up rate. The take-up rate depends on $\varepsilon^{*}$ and $q_{C}(\varepsilon)$ which are determined endogenously in equilibrium, as well as exogenous factors such as $\lambda$ (the separation rate) and the distribu- 
tion $F(\varepsilon)$. Thus, the firm interactions we characterize below, that determine the equilibrium objects $\varepsilon^{*}$ and $q_{C}(\varepsilon)$, are essential to understand the determination of the UI take-up rate.

\subsection{Properties of Equilibrium}

This section characterizes the key properties of equilibrium in the economy described above. The goal is to characterize the differences between UI collector and non-collector outcomes, and then to characterize what aspects of these differences are the result of private information. The latter is accomplished by comparing the private information equilibrium with a full information equilibrium, where past UI collection histories are always known. We begin with the properties of the private information equilibrium.

Proposition 1 shows that equilibrium involves segmentation of markets by collectors and non-collectors; firms offer separate wages for collectors, $w_{C}(\varepsilon)$, and for non-collectors, $w_{N C}$. Workers then optimally direct their search to these wages. Since the worker's previous UI collection status is unobservable by a firm, there is no way to prevent a current UI collector from searching for the non-collector wage. This creates an "incentive" problem for a firm offering a non-collector wage. Define $\tilde{C}(\&)$ as the expected lifetime utility for a UI collector who deviates and searches for the non-collector job. From Equation (8) this is given by,

$$
\tilde{C}(\varepsilon)=\frac{1 \lambda}{r\left(r+\lambda+\alpha_{W}\left(q_{N C}\right)\right)}\left[(r+\lambda)(h(b)-\varepsilon)+\alpha_{W}\left(q_{N C}\right) h\left(w_{N C}\right)\right]
$$

In Equation (23), the worker receives the flow utility from collecting UI benefits, $h(b)-\varepsilon$, but searches for the $\left(q_{N C}, w_{N C}\right)$ job, with employment at wage $w_{N C}$ arriving at rate $\alpha_{W}\left(q_{N C}\right)$.

In order for wages (and associated queue lengths) $w_{C}(\varepsilon)$ and $w_{N C}$ to be viable in equilibrium, they must satisfy the constraint:

$$
C(\varepsilon) \geq \tilde{C}(\varepsilon), \text { for all } \varepsilon \leq \varepsilon^{*}
$$

If this constraint is violated, a UI collector prefers to search for the non-collector job. As a result, $q_{N C}$ and the firm's expected $p$ are not consistent with the firm's expectations. 
The firm offering the non-collector wage receives more applications than expected, and they expect $p=0$ but $p>0$ obtains. Thus, to be an equilibrium allocation, the non-collector job must be altered to satisfy this constraint. ${ }^{2}$ Since $\varepsilon$ is unobservable, the possibility of workers pretending to be higher or lower $\varepsilon$ types and searching for other UI collector wages is in one sense another dimension of incentive compatibility. These deviations are prevented by the Optimal Application condition of Definition 1. This condition implies that firms offer wages that maximize expected lifetime utility for each "type" of worker. We present this constraint formally in the next result.

Proposition 2 Assume that $\varepsilon$ and past UI collections are unobservable. If $\{\mathbb{W}, Q, \mathbf{C}, \mathbf{E}, \mathbf{N C}, \mathcal{T}\}$ is an active equilibrium allocation, then any $w_{C}(\varepsilon) \in \mathbb{W}, w_{N} \in \mathbb{W}, q_{C}(\varepsilon)=Q\left(w_{C}(\varepsilon)\right)$, and $q_{N C}=Q\left(w_{N C}\right)$ must solve:

$$
\begin{aligned}
& \mathbf{C}(\varepsilon)=\max _{w_{C}(\varepsilon), q_{C}(\varepsilon)}\left(\frac{1}{r\left(r+\lambda+\alpha_{W}\left(q_{C}(\varepsilon)\right)\right)}\right)\left((r+\lambda)(h(b)-\varepsilon)+\alpha_{W}\left(q_{C}(\varepsilon)\right) h\left(w_{C}(\varepsilon)\right)\right) \\
& \text { s.t. } \left.w_{C}(\varepsilon)=y-\frac{\gamma(r+\lambda)}{\alpha_{E}\left(q\left(w_{C}(\varepsilon)\right)\right)}\right) \lambda \\
& \mathbf{N C}=\max _{w_{N C}, q_{N C}}\left(\frac{1}{r\left(r+\lambda+\alpha_{W}\left(q_{N C}\right)\right)}\right)\left((r+\lambda) h(d)+\alpha_{W}\left(q_{N C}\right) h\left(w_{N C}\right)\right) \\
& \text { s.t. } w_{N C}=y-\frac{\gamma(r+\lambda)}{\alpha_{E}\left(q\left(w_{N C}\right)\right)} \text { and, } \\
& C(\varepsilon) \geq \tilde{C}(\varepsilon), \text { for all } \varepsilon \leq \varepsilon^{*}
\end{aligned}
$$

This represents a standard determination of equilibrium in a directed search environment, with the exception of Equation (28), which represents the "incentive constraint" for firms

\footnotetext{
${ }^{2}$ Potentjally, one may consider altering the UI collector jobs, $\left(q_{C}(\varepsilon), w_{C}(\varepsilon)\right)$ to ensure the constraint is satisfied; however, this remains infeasible. This is true because the firm posting $w_{C}(\varepsilon)$ ) has no control over a worker's utility when they deviate. That is, this firm does not control $w_{N C}$ (and thus $q_{N C}$ ) and therefore can only alter the utility a worker receives from applying to their job. Since $w_{C}(\varepsilon)$ already maximizes a type $\varepsilon$ worker's utility, no other possible $w_{C}(\varepsilon)$ can increase $C(\varepsilon)$ to satisfy the constraint. As a result, $w_{N C}$ must be altered.
} 
in the non-collecting market. The addition of this incentive constraint, however, alters key aspects of equilibrium. Let $\tilde{w}_{N C}$ and $\tilde{q}_{N C}$ denote the solution to the non-collector problem in the private information equilibrium given by Equations (26) to (28). This equilibrium has the following properties:

Proposition 3 In the private information equilibrium with $\tau>0$ :

(i). $\varepsilon^{*}=h(b)-h(d)$,

(ii). The constraint in Equation (28) binds at $\varepsilon=\varepsilon^{*}$,

(iii). The job arrival rate $\alpha_{W}\left[q_{C}(\varepsilon)\right]$ is increasing in $\varepsilon$ and the wage $w_{C}(\varepsilon)$ is decreasing in $\varepsilon$,

(iv). There are two possible equilibrium values of $\tilde{q}_{N G}$ satisfying $\tilde{q}_{N C}^{L}<q_{N C}^{*}<\tilde{q}_{N C}^{H}$. Moreover, $\tilde{q}_{N C}^{L}<q_{C}(\varepsilon)$ and $w_{N C}\left(\tilde{q}_{N C}^{L}\right)<w_{C}(\varepsilon)$ for all $\varepsilon \leq \varepsilon^{*}$ implying that non-collectors have a shorter unemployment duration and lower wage than UI collectors.

Figure 2 shows the determination of equilibrium with private information. Recall, an equilibrium has two essential features: optimal application and profit maximization. Profit maximization implies that firms offer a wage lying on their zero-profit curve. Optimal application requires that this wage must also maximize the worker's utility. Figure 2 shows two zero-profit curves, one for firms hiring UI collectors and one for firms hiring non-collectors. This obtains because of the experience rated tax, which is only paid by the firms hiring UI collectors, shifting the zero-profit curve down. A standard determination of wages and queue lengths are those that put the worker's indifference curve tangent to the zero-profit curve. In the case of non-collectors, however, this does not obtain.

The non-collector wage, $w_{N C}$, must maximize non-collector utility, subject to the incentive constraint in Equation (28). Suppose instead that $w_{N C}$ is determined at the point maximizing non-collector utility, ignoring the incentive constraint. This point is labeled in Figure 2 as $\left(q_{N C}^{*}, w_{N C}^{*}\right)$. At this point, however, the non-collector wage exceeds the UI collector wage (at 


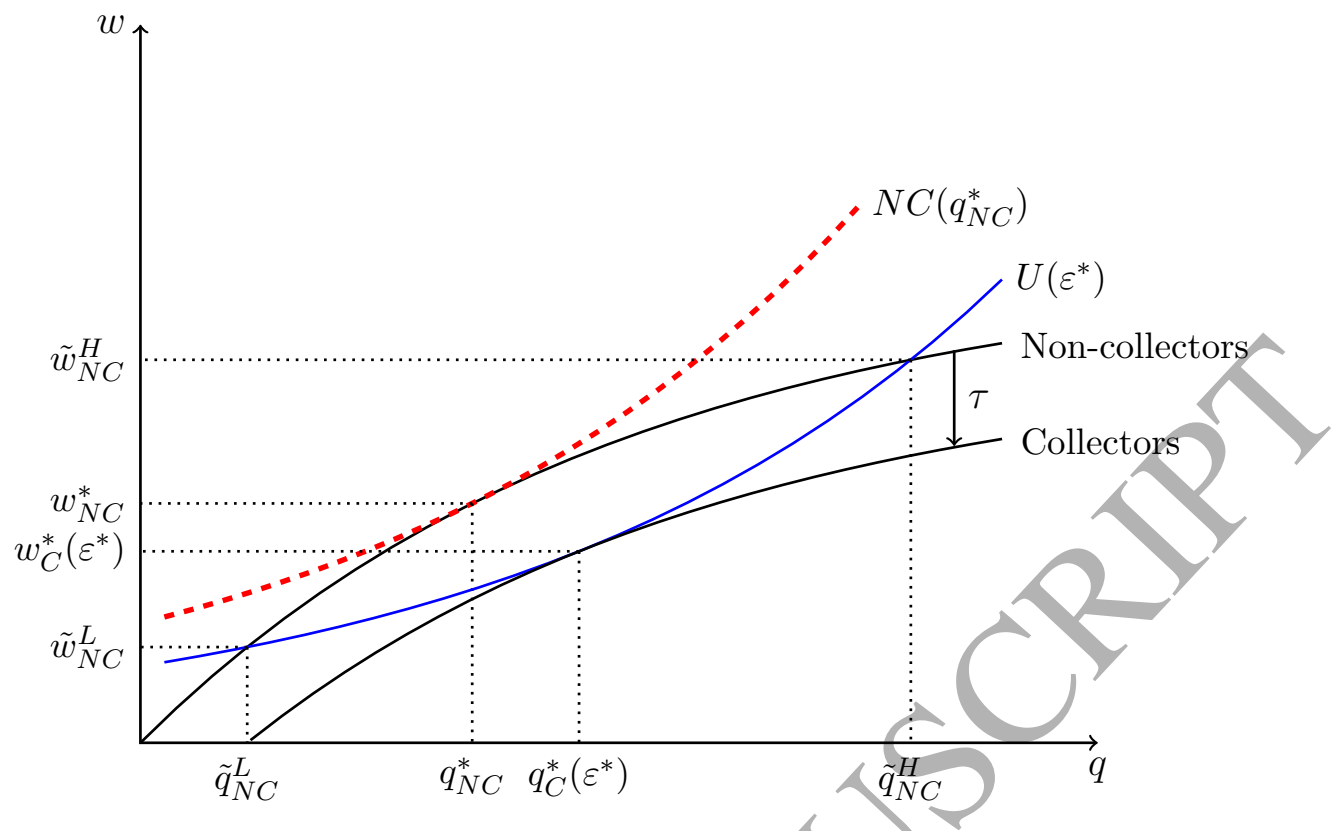

Figure 2: Determination of Equilibrium, Private Information

The graph shows the determination of $\left(q_{C}(\varepsilon), w_{C}(\varepsilon)\right), \varepsilon \leq \varepsilon^{*}$ and $\left(\tilde{q}_{N C}, \tilde{w}_{N C}\right)$ when $\varepsilon$ is private information. Since a UI collector can search for $\left(q_{N C}^{*}, w_{N C}^{*}\right)$, and receives higher utility doing so, $\left(q_{N C}^{*}, w_{N C}^{*}\right)$ is not a feasible equilibrium for non-collectors. To solve this incentive problem, firms offer a $\left(\tilde{q}_{N C}, \tilde{w}_{N C}\right)$ where the UI collectors indifference curve intersects the non-collector zero-profit curve. Given a strictly convex indifference curve, there thus exist two possible equilibrium values, $\tilde{q}_{N C}^{L}$ and $\tilde{q}_{N C}^{H}$.

$\left.\varepsilon=\varepsilon^{*}\right)$, and it arrives faster since $q_{N C}<q_{C}\left(\varepsilon^{*}\right)$. This strictly dominates the $\left(q_{C}\left(\varepsilon^{*}\right), w_{C}\left(\varepsilon^{*}\right)\right)$ job; as a result, UI collectors will prefer to search for this job, violating Equation (28).

To satisfy the combination of zero-profits, optimal application, and incentive compatibility, firms offering $w_{N C}$ must make it such that the marginal collector (i.e. with $\varepsilon=\varepsilon^{*}$ ) is indifferent between this job and the $w_{C}\left(\varepsilon^{*}\right)$ job. As shown in Figure 2, this is accomplished by setting $\tilde{w}_{N C}$ at the point where the collector's (with $\varepsilon=\varepsilon^{*}$ ) indifference curve intersects the non-collector zero-profit curve. At this point, zero-profits, optimal application, and incentive compatibility are all satisfied. Notice, with strictly convex indifference curves, there exist two possible equilibria for the non-collector job. In Figure 2 these are labeled as $\left(\tilde{q}_{N C}^{L}, \tilde{w}_{N C}^{L}\right)$ and $\left(\tilde{q}_{N C}^{H}, \tilde{w}_{N C}^{H}\right)$.

While indeed there exist two possible $\tilde{q}_{N C}$ 's, our empirical analysis below rules out $\tilde{q}_{N C}^{H}$. Specifically, under $\tilde{q}_{N C}^{H}$, the job-arrival rate for UI collectors exceeds that of non-collectors. 
This is contrary to the empirical evidence on the effects of UI benefits, which suggests a UI collector has a longer average duration of unemployment relative to a non-collector (for example see Katz and Meyer (1990) or Braun, Engelhardt, Griffy, and Rupert (2016)).

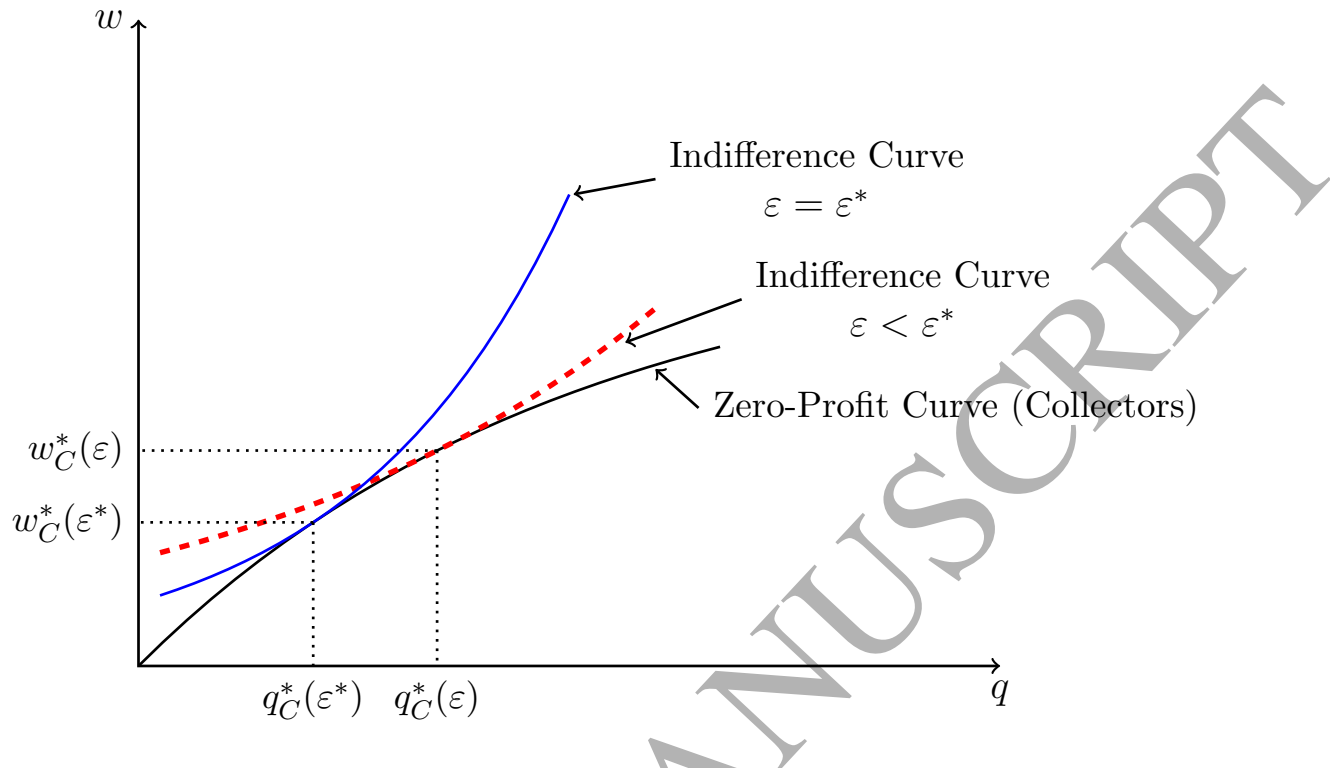

Figure 3: Effect of UI collection costs

The graph shows the determination of $\left(q_{C}(\varepsilon), w_{C}(\varepsilon)\right), \varepsilon \leq \varepsilon^{*}$. As $\varepsilon$ decreases, the UI collector's indifference curve gets "flatter," as the net gain from UI benefits increases. This pushes the queue length and wage higher. These UI collectors are willing to wait longer for higher wage jobs.

For UI collectors optimal application is straightforward. Firms offer a wage, $w_{C}(\varepsilon)$, that lies on the zero profit curve and maximizes utility for a worker with collection $\operatorname{costs} \varepsilon$. This implies the worker's indifference curve is tangent to the zero-profit curve. In Figure 2 we show the case of $\varepsilon=\varepsilon^{*}$, the highest value of $\varepsilon$ a worker is still willing to collect at. In Proposition 2, (iii) describes how UI collector wages and queue lengths change with $\varepsilon$ for all $\varepsilon \leq \varepsilon^{*}$. As $\varepsilon$ decreases, the worker's indifference curve "flattens" out, and the wage increases along the zero-profit curve, also increasing the queue length, $q_{C}(\varepsilon)$. Thus, UI collectors with lower costs of collecting have higher wages but longer unemployment durations.

Figure 3 shows this feature of equilibrium. Intuitively, as $\varepsilon$ decreases, the net benefit provided by UI increases, which acts similarly to an increase in actual UI benefits. Hence, workers with lower $\varepsilon$ are willing to wait longer for higher wages because they are more 
comfortable in unemployment. This represents a similar result to the effect of increasing UI benefits characterized by Acemoglu and Shimer (1999), who show that an economy with higher UI benefits has longer durations and higher wages.

Figure 2 also allows a comparison of UI collector and non-collector wages and arrival rates. In equilibrium with private information, UI collectors have longer average unemployment durations and higher wages relative to non-collectors. There are two effects leading to these differences. The first is a "consumption" effect. As discussed above, UI collectors accept the longer unemployment durations in exchange for higher wages, because they have higher consumption $b>d$, ultimately leading to a higher net (of UI collection costs) flow utility while unemployed. Relative to non-collectors, the consumption effect is represented by the difference between the $\left(q_{C}\left(\varepsilon^{*}\right), w_{C}\left(\varepsilon^{*}\right)\right)$ job and the $\left(q_{N C}^{*}, w_{N C}^{*}\right)$ job. The latter represents the non-collector job that obtains when past UI collection histories are observable. In this case, the consumption effect represents the only difference between non-collector and collector outcomes.

UI collector and non-collector equilibrium outcomes also differ as a result of the distortion from private information about UI collection histories. This effect is represented by the difference between $\left(q_{N C}^{*}, w_{N C}^{*}\right)$ and $\left(\tilde{q}_{N C}^{L}, \tilde{w}_{N C}^{L}\right)$. Thus, our analysis shows that non-collectors have shorter unemployment durations relative to UI collectors, and part of this difference is the result of private information. Having analytically characterized the key differences between UI collector and non-collector outcomes in an equilibrium with endogenous take-up rates, we now turn towards quantifying these implications.

Before proceeding to the quantitative analysis, we would like to briefly discuss the differences between the private information equilibrium, $\left(\tilde{q}_{N C}^{L}, \tilde{w}_{N C}^{L}\right)$, and the equilibrium with "full" information, $\left(q_{N C}^{*}, w_{N C}^{*}\right)$. Full information refers to the firm's knowledge of a worker's past UI collections; we still maintain the assumption that $\varepsilon$ remains private information. When $\varepsilon$ is private information, but collection histories are observable, firms offer the same wages as if both $\varepsilon$ and collection histories were observable. Thus, unobservable UI collection histories represents the key information friction distorting non-collector outcomes. In 
Appendix A we present the derivation of the full information equilibrium and its properties.

\section{Quantitative analysis}

In this section, we present a quantitative analysis of the aforementioned model and equilibrium. Our calibration focuses on the time period from $1989-2012$.

\subsection{Calibration}

We now calibrate the private information economy presented in Section 3. This model leaves the following parameters to be determined: $r, b, d, \lambda, \gamma, F(\varepsilon), \tau$, and functional forms for the matching function, $m$, and the utility function, $h$.

The time period is set to one month, so a per-annum risk-free interest rate of $4 \%$ implies $r=0.0033$. The utility function is given by $h(c)=\log (c)$. The distribution $F(\varepsilon)$ is assumed to be exponential and we set the mean of this distribution equal to 1 . For the matching function, $m$, we use the standard constant returns to scale form given by $m(u, \mathrm{v})=u^{\eta} \mathrm{v}^{1-\eta}$. As in Fredriksson and Holmund (2001), we use a value of 0.5 for $\eta$.

The job separation rate is set to match the average unemployment rate from 1989-2012, which is $6.0 \%$. This implies a value of $\lambda=0.0157$. This value of $\lambda$ is consistent with Shimer (2005), who finds a quarterly job separation rate of 0.035 . The value of $\gamma$ (vacancy creation costs) is set to match the observed average unemployment duration from 1989-2012. According to the BLS tabulations from the CPS, the average unemployment duration from $1989-2012$ was 18.1 weeks, or 4.53 months, implying $\gamma=22.14$.

We parameterize the UI system setting $b=0.444$ (the value of output, $y$ is normalized to $y=1$ ), consistent with an average replacement rate of 0.50 . The replacement rate is calculated as $b$ divided by the average wage for UI collectors, $\frac{b}{\overline{w_{C}}}$. The average wage for UI collectors is $\bar{w}_{C}=\int_{0}^{\varepsilon^{*}} w_{C}(\varepsilon) \phi_{E}(\varepsilon) d \varepsilon$, where $\phi_{E}(\varepsilon)=\frac{n_{C}^{E}(\varepsilon)}{N_{C}^{E}}$. For the minimum level of consumption (among UI non-collectors), we set $d$ to match the observed take-up rate. For the $1989-2012$ period, the take-up rate averaged $77 \%$, requiring $d=0.1661$. Again it is 
Table 3: Parameters

\begin{tabular}{ccr}
\hline$r$ & 0.0033 & Discount rate \\
$\eta$ & 0.5 & Elasticity of matching function \\
$\lambda$ & 0.0157 & Job separation rate \\
$b$ & 0.444 & UI benefit level \\
$d$ & 0.1661 & Minimum consumption level \\
$\gamma$ & 22.14 & Vacancy cost \\
$\tau$ & 1.83 & Experience rating parameter \\
\hline \hline
\end{tabular}

worth noting that since we do not model the UI eligibility process, all workers in the model remain UI eligible implying a "gap" between the model and data take-up rates.

Finally, the value of $\tau$ is set to match data on experience rating in the U.S. system. Topel (1983) examines the specific experience rating system in a number of states finding an average marginal cost of a separation to a firm of approximately $80 \%$ of the implied UI expenditures. In the model, the average worker who collects UI induces benefit expenditures equal to the UI benefit, $b$, times the average duration of unemployment for UI collectors (since benefits do not expire). We set $\tau$ to be $80 \%$ of this average benefit expenditure, implying $\tau=1.83$ (average duration for collectors is 5.15 months from Table 5).

Table 3 lists the parameters and their values, and Table 4 presents the results from our calibration showing the key moments in the model and data.

\subsection{Results}

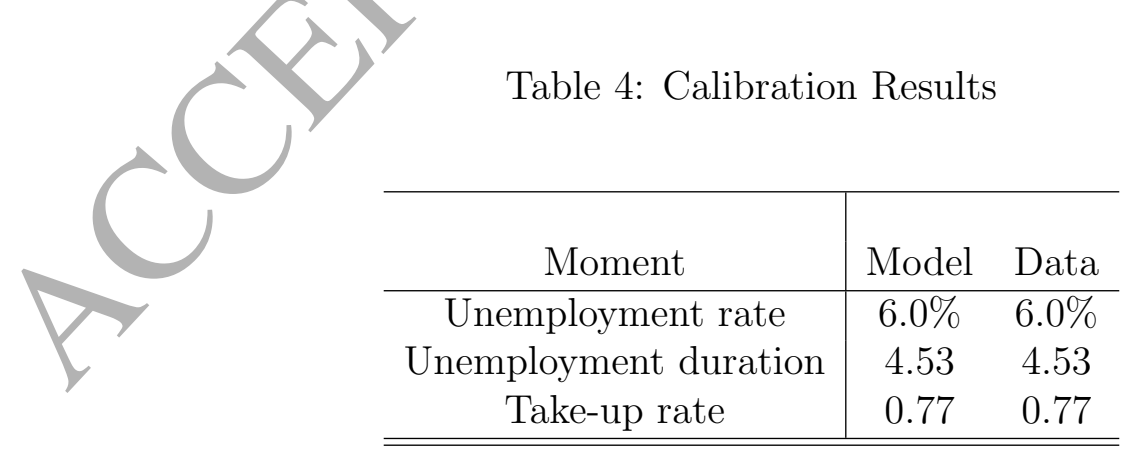


The empirical literature on UI benefits has found that UI non-collectors have shorter unemployment durations relative to an equivalent collector. In our model, this difference is the result of two factors: (i) a consumption effect and (ii) private information. Figure 2 displays the qualitative effect of private information on non-collector wages and arrival rates. Our calibrated model now allows us to decompose these effects quantitatively. Recall, in the full information equilibrium, the differences between collectors and non-collectors are due only to the consumption effect.

Table 5: Full Information vs. Private Information

\begin{tabular}{l||c|c} 
Moment & Full Info & Private Info \\
\hline Average Duration, UI Collectors & 5.42 & 5.15 \\
Average Duration, UI Non-collectors & 3.98 & 2.44 \\
Average Duration (overall) & 4.72 & 4.53 \\
Average Wage, UI Collectors & 0.89 & 0.89 \\
Wage, UI Non-collectors & 0.89 & 0.83 \\
Unemployment rate & $6.73 \%$ & $6.00 \%$ \\
Take-up Rate & $51 \%$ & $77 \%$ \\
\hline \hline
\end{tabular}

For UI collectors, the unemployment duration and wage vary with $\varepsilon$. The table reports the respective averages across $\varepsilon$. Specifically, $\bar{w}_{C}=\int_{0}^{\varepsilon^{*}} w_{C}(\varepsilon) \phi_{E}(\varepsilon) d \varepsilon$ and DUR $=\int_{0}^{\varepsilon^{*}} \frac{1}{\alpha_{W}\left[q_{C}(\varepsilon)\right]} \phi_{C}(\varepsilon) d \varepsilon$, where $\phi_{j}(\varepsilon)=$ $\frac{n_{U}^{j}(\varepsilon)}{N_{U}^{j}}, j \in\{E, U\}$

Table 5 displays these differences. In the calibrated private information economy, noncollectors transition to employment 2.71 months, or 10.84 weeks, faster relative to UI collectors. To quantify the role of the consumption effect consider the column labeled "Full Info." Here we see that non-eollectors transition to employment 1.44 months, or 5.76 weeks sooner than UI collectors) Thus, roughly half of the nearly 11 week difference in UI collector and non-collector average unemployment durations stems from the standard consumption effect of UT benefits. The remaining half of the difference is the result of private information.

The difference in UI take-up rates between the two equilibria represents another interesting feature. From Table 5 the "Full Info" equilibrium has a take-up rate of $51 \%$ compared to the calibrated "Private Info" take-up rate of $77 \%$. This is the result of several forces. First, 
recall from Proposition 3 that in the private information equilibrium, $\varepsilon^{*}=h(b)-h(d)$. In the full information equilibrium, however, $\varepsilon^{*}<h(b)-h(d)$ (see Appendix A for the derivation of this result). This leaves a smaller mass of workers with $\varepsilon \leq \varepsilon^{*}$ in the full information equilibrium, driving the UI take-up rate down. Second, with full information, the market is able to provide some "natural" insurance to non-collectors in the form of shorter unemployment durations. Since they do not pay the UI tax, these firms can also offer a much higher wage under full information. These features make the non-collector wage more appealing, reducing the UI take-up rate.

\subsection{Effects of UI Benefits}

In this section we consider the equilibrium impact of changing the level of unemployment benefits. In the experiments below, we increase the UI replacement rate while setting $\tau$ to maintain the initial level of experience rating. That is, we maintain $\frac{\tau}{b * D U R_{C}}=0.80$ as the replacement rate changes.

Figures 4(a) to 4(c) display the effects of an increase in $b$ on the key equilibrium outcomes. First consider Figure 4(a). The take-up rate is increasing and concave in the UI replacement rate. Take-up increases from a low of $9.97 \%$ to a maximum of $94.06 \%$ as the replacement rate changes from $20 \%$ to $98 \%$. Next, in Figures 4(b) and 4(c), the unemployment rate and average duration of unemployment are also increasing in the UI replacement rate. While indeed both moments increase with the replacement rate, they do so relatively slowly. A replacement rate of almost $100 \%$ is associated with an unemployment rate of $8.98 \%$. Typically the unemployment rate and duration explode as the replacement rate approaches $100 \%$. To understand the significance of these results, we compare them to a simple economy with a fixed $100 \%$ take-up rate.

Consider a standard directed search model with no UI collection costs (i.e. $\varepsilon=0$ for all workers) and assume that all unemployed workers collect UI benefits. Thus, the take-up rate is fixed at $100 \%$. We simulated the economy under different replacement rates, maintaining the same parametrization as the baseline case (with the exception that $\varepsilon=0$ ). 


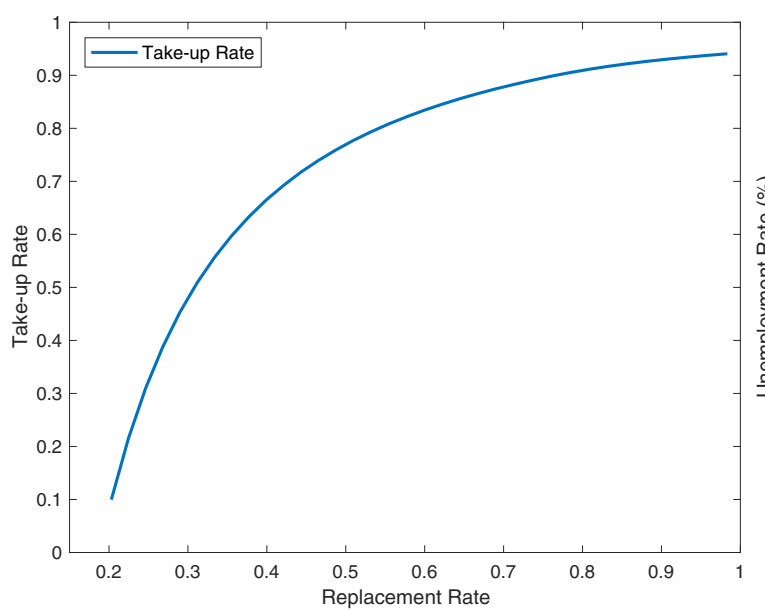

(a) Take-up Rate

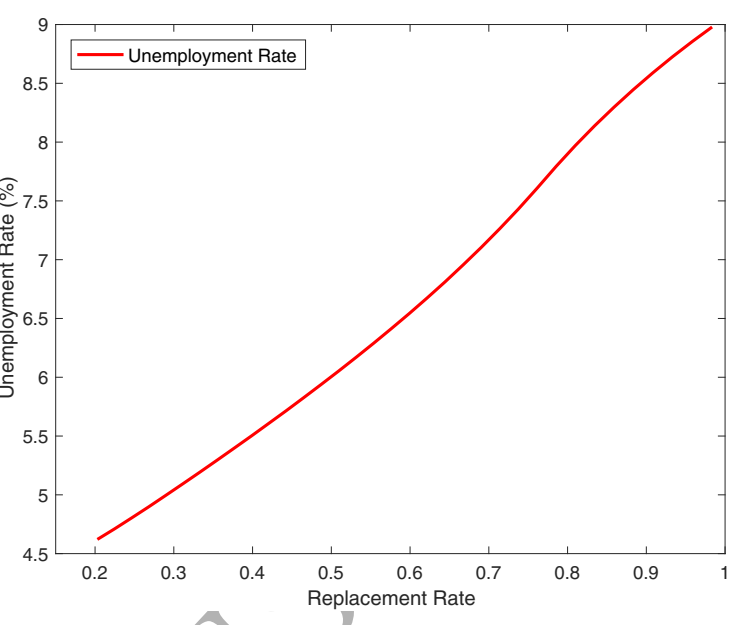

(b) Unèmployment Rate

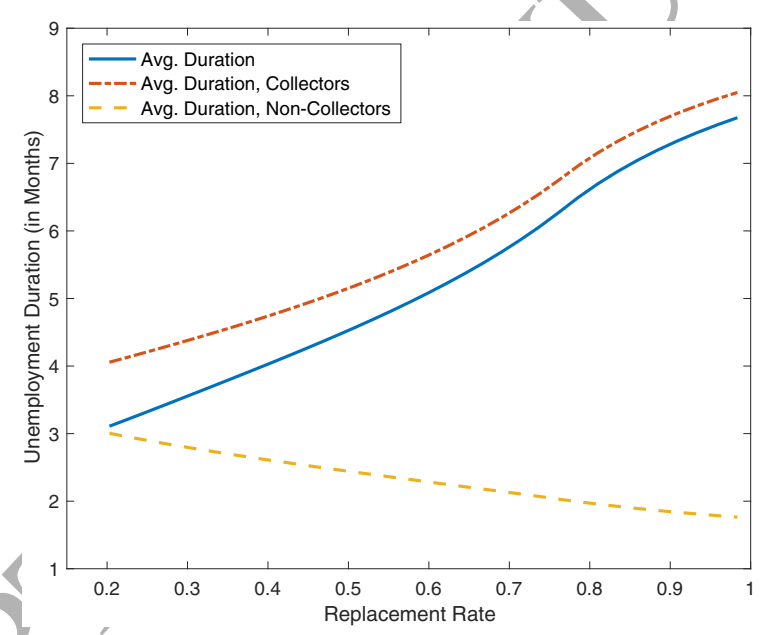

(c) Unemployment Durations

Figure 4: Effects of UI Benefits

This figure plots the effects of UI benefits on equilibrium outcomes. The top two graphs plot the take-up and unemployment rates, respectively. The bottom graph plots the effect of $b$ on unemployment durations. It plots the overall average unemployment duration, as well as for collectors and non-collectors separately. In all figures, the horizontal axis corresponds to the average replacement ratio for that particular $b$, or $\frac{b}{w_{C}}$, where $\bar{w}_{C}=\int_{0}^{\varepsilon^{*}} w_{C}(\varepsilon) \phi_{E}(\varepsilon) d \varepsilon$ is the average wage for UI collectors. 


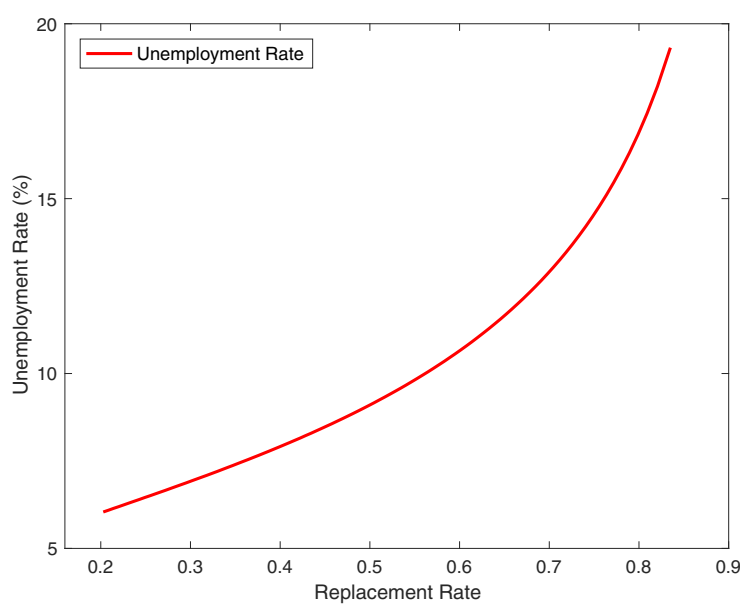

(a) Unemployment Rate

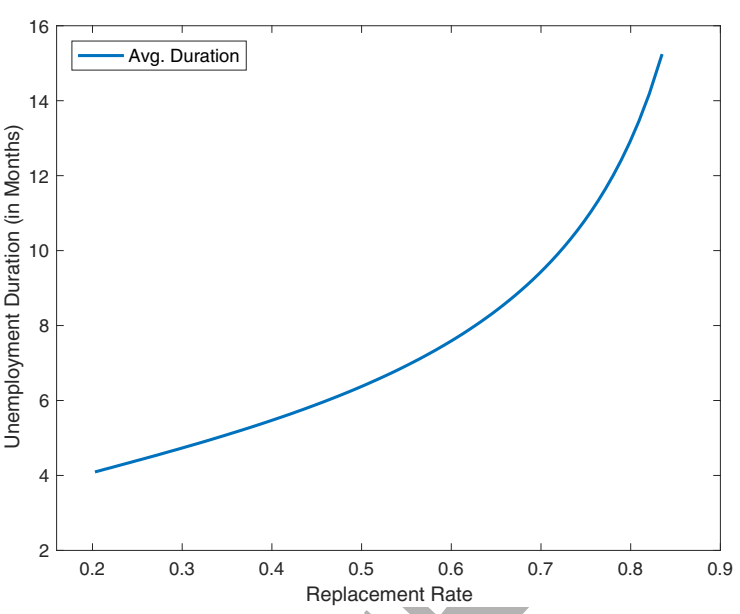

(b) Unemployment Durations

Figure 5: Effects of UI Benefits: 100\% Take-up Model

This figure plots the effects of UI benefits on equilibrium outcomes for a standard model with $100 \%$ take-up. The two graphs plot the responses of the Unemployment Rate and Average Unemployment Duration for the $100 \%$ take-up rate economy.

Figures 5(a) and 5(b) plot the response of the unemployment rate and average duration of unemployment, respectively. As one expects, as the replacement rate approaches 100\%, both of the aforementioned moments begin to explode. At a replacement rate of $83.5 \%$ the unemployment rate is $19.32 \%$ and the average unemployment duration is 15.24 months. This is a significantly faster response rélative to our baseline model in Figures 4(b) and 4(c). Indeed, the endogenous take-up rate represents the key difference between the two models.

The difference in responses of the unemployment rate and average duration of unemployment derives in part from the following. As UI benefits increase, the average duration of unemployment for UI collectors indeed increases; however, it decreases for non-collectors. This effect is displayed in Figure 4(c), which plots the average duration for all workers, and the average duration for collectors and non-collectors separately. Recall, the non-collector duration is determined by the queue length where the indifference curve of a collector with $\varepsilon=\varepsilon^{*}$ intersects the non-collector zero-profit curve (see Figure 2). When UI benefits increase, there are several effects impacting the equilibrium queue length $\tilde{q}_{N C}^{L}$. First, $\varepsilon^{*}$ increases, which tends to increase $\tilde{q}_{N C}^{L}$, increasing the non-collector duration. Second, the 
increase in $b$ flattens the UI collector indifference curve, for any $\varepsilon$; this represents a similar effect to that displayed in Figure 3. This also pushes the non-collector duration higher. The resulting increase in $\tau$ represents third and most dominant effect. Although $\tau$ is still set at $80 \%$ of the expected UI bill for a separated worker, this bill is now higher when $b$ increases. When $\tau$ increases, the UI collector zero-profit curve shifts down, causing $\tilde{q}_{N C}^{L}$ to decrease and thus non-collector durations to decrease.

Finally, in the equilibrium with an endogenous take-up rate, the take-up rate increases at a decreasing rate with UI benefits. Put together with the aforementioned effects, the average duration of unemployment (economy-wide), which is the average between collectors and non-collectors, eventually levels off similarly to the take-up rate.

\section{Conclusion}

We estimate the UI take-up rate for the U.S. economy from 1989 - 2012. An equilibrium directed search model is developed to explain this empirical fact and explore its implications for the provision of UI benefits. We characterize the differences between UI collector and noncollector outcomes. Non-collectors have shorter unemployment durations, caused by both a consumption effect, and the effects of private information about UI collection histories.

After calibrating the model, we find that the distortion imposed by private information accounts for around half of the difference between UI collector and non-collector unemployment durations. Finally, we also show that incorporating the take-up decision matters when examining the effects of UI benefits on equilibrium outcomes. The analysis indicates that the unemployment rate and average duration of unemployment respond slower to changes in UI benefits than the standard search model with a fixed $100 \%$ take-up rate. The private information effect on non-collector durations drives this result.

Given the importance of UI collection costs for our analysis, we would like to briefly discuss our assumption that workers are unable to save. Workers simply consume their entire flow income each period and do not have access to a technology that allows them to transfer this income across periods. Generating unclaimed UI benefits is a first requirement 
of our model given the question we study. This requires heterogeneity in the net benefits of collecting UI. We generate this heterogeneity with differences in UI collection costs. If workers were allowed to save, this generates a second source of heterogeneity that would certainly impact the UI take-up decision.

Savings would have two primary effects on the model. First, this additional source of heterogeneity would have to be reflected in the wages posted by firms, since workers with different levels of savings would have different values of searching and employment. Second, savings could increase or decrease the importance of $\varepsilon$, depending on the worker. For example, consider a worker with a relatively large amount of accumulated assets. This implies the worker has resources outside of UI benefits with which to smooth consumption during a spell of unemployment. All else equal, this worker would have a lower cut-off value of $\varepsilon^{*}$, potentially reducing the role of UI collection costs in the take-up decision. On the other hand, consider a worker with negative accumulated savings (borrower). This worker must rely exclusively on UI benefits to smooth consumption during the spell of unemployment. This results in a larger cut-off, $\varepsilon^{*}$, magnifying the role of UI collection costs. Thus, the full impact of savings would depend on the distribution of liquid savings among the unemployed. In general, these examples illustrate that incorporating savings into a similar model represents an important direction for future research on UI take-up rates. 


\section{References}

Acemoglu, D., And R. Shimer (1999): "Efficient Unemployment Insurance," Journal of Political Economy, 107, 893-928.

Anderson, P., And B. Meyer (1997): "Unemployment Insurance Takeup Rates and the After-Tax Value of Benefits," The Quarterly Journal of Economics, 112, 913-937.

Auray, S., AND D. L. Fuller (2018): "Eligibility, Generosity, and Take-up: A State Level Analysis of Unemployment Insurance in the U.S.," Working paper, CREST-ENSAI.

Bitler, M. P., J. Currie, And J. K. Scholz (2003): "WIC eligibility and participation," Journal of Human resources, pp. 1139-1179.

Blank, R., And D. CARD (1991): "Recent Trends in Insured and Uninsured Unemployment: Is There an Explanation?," The Quarterly Journal of Economics, 106, 1157-1189.

Braun, C., B. Engelhardt, B. Griffy, and P. Rupert (2016): "Do Workers Direct Their Search?," Working paper, UC-Santa Barbara.

Brien, M. J., AND C. A. SWANN (1997): Prenatal WIC participation and infant health: Selection and maternal fixed effects. Thomas Jefferson Center for Political Economy, University of Virginia.

Fredriksson, P., AND B. Holmund (2001): "Optimal Unemployment Insurance in Search Equilibrium," Journal of Labor Economics, 19, 370-399.

Fuller, D. L., B. Ravikumar, and Y. Zhang (2015): "Unemployment Insurance Fraud and Optimal Monitoring," American Economic Journal: Macroeconomics, 7, 249-290.

KatZ, L, F., And B. D. Meyer (1990): "The Impact of the Potential Duration of Unemployment Benefits on the Duration of Unemployment," Journal of Public Economics, 41, $45-72$. 
Moen, E. R. (1997): "Competitive Search Equilibrium," Journal of Political Economy, 105, 385-411.

Rogerson, R., R. Shimer, and R. Wright (2005): "Search Theoretic Models of the Labor Market: A Survey," Journal of Economic Literature, 43, 959-988.

Shimer, R. (2005): "The Cyclical Behavior of Equilibrium Unemployment and Vacancies," American Economic Review, 95, 25-49.

Topel, R. H. (1983): "On Layoffs and Unemployment Insurance," American Economic Review, 83, 541-559. 


\section{A Full Information Equilibrium}

Above we compare equilibrium under both full and private information in order to understand differences in collector and non-collector outcomes. This section formally presents the case of "full" information.

In the full information economy, we assume firms observe a worker's history of UI collections, and they can throw away applications at no cost. We still assume $\varepsilon$ is private information. Thus, if a firm expects to hire a non-collector $\left(\varepsilon>\varepsilon^{*}\right)$, but receives an application from a worker who has collected in the past, although the firm does not observe the specific value of $\varepsilon$ the past UI collections imply $\varepsilon \leq \varepsilon^{*}$. In such a cáse, the firm may disregard the application. This prevents UI collectors from applying to the wages posted for non-collectors and vice versa.

Equilibrium with full information is determined similarly to the private information case. Formally,

Proposition 4 Assume that firms observe past UI collections. If $\{\mathbb{W}, Q, \mathbf{C}, \mathbf{E}, \mathbf{N C}, \mathcal{T}\}$ is an active equilibrium allocation, then any $w_{C}(\varepsilon) \in \mathbb{W}, w_{N} \in \mathbb{W}, q_{C}(\varepsilon)=Q\left(w_{C}(\varepsilon)\right)$, and $q_{N}=Q\left(w_{N}\right)$ must solve:

$$
\begin{aligned}
& \mathbf{C}(\varepsilon)=\max _{w_{C}(\varepsilon), q_{C}(\varepsilon)}\left(\frac{1}{r\left(r+\lambda+\alpha_{W}\left(q_{C}(\varepsilon)\right)\right)}\right)\left((r+\lambda)(h(b)-\varepsilon)+\alpha_{W}\left(q_{C}(\varepsilon)\right) h\left(w_{C}(\varepsilon)\right)\right) \\
& \text { s.t. } w_{C}(\varepsilon) \neq y-\frac{\gamma(r+\lambda)}{\alpha_{E}\left(q\left(w_{C}(\varepsilon)\right)\right)}-\lambda \tau \\
& \mathbf{N C}=\max _{w_{N C}, q_{N C}}\left(\frac{1}{r\left(r+\lambda+\alpha_{W}\left(q_{N C}\right)\right)}\right)\left((r+\lambda) h(d)+\alpha_{W}\left(q_{N C}\right) h\left(w_{N C}\right)\right) \\
& \text { s.t. } w_{N C}=y-\frac{\gamma(r+\lambda)}{\alpha_{E}\left(q\left(w_{N C}\right)\right)}
\end{aligned}
$$

Proposition 4 represents the same formulation of equilibrium as in Proposition 2, only there is no longer an incentive constraint. Firms post equilibrium wages that maximize 
worker's utility, subject to the zero profit condition. Figure 6 shows this equilibrium graphically. The equilibrium values of $(q, w)$ occur at the point where the worker's indifference curve is tangent to the zero-profit curve in $(q, w)$ space. This ensures both optimal application and profit-maximization. Since firms hiring UI collectors pay an experience rated tax with certainty at separation (i.e. $p=1$ ), their zero profit curve is shifted down by $\tau$. Next we characterize some important features of the full information allocation.

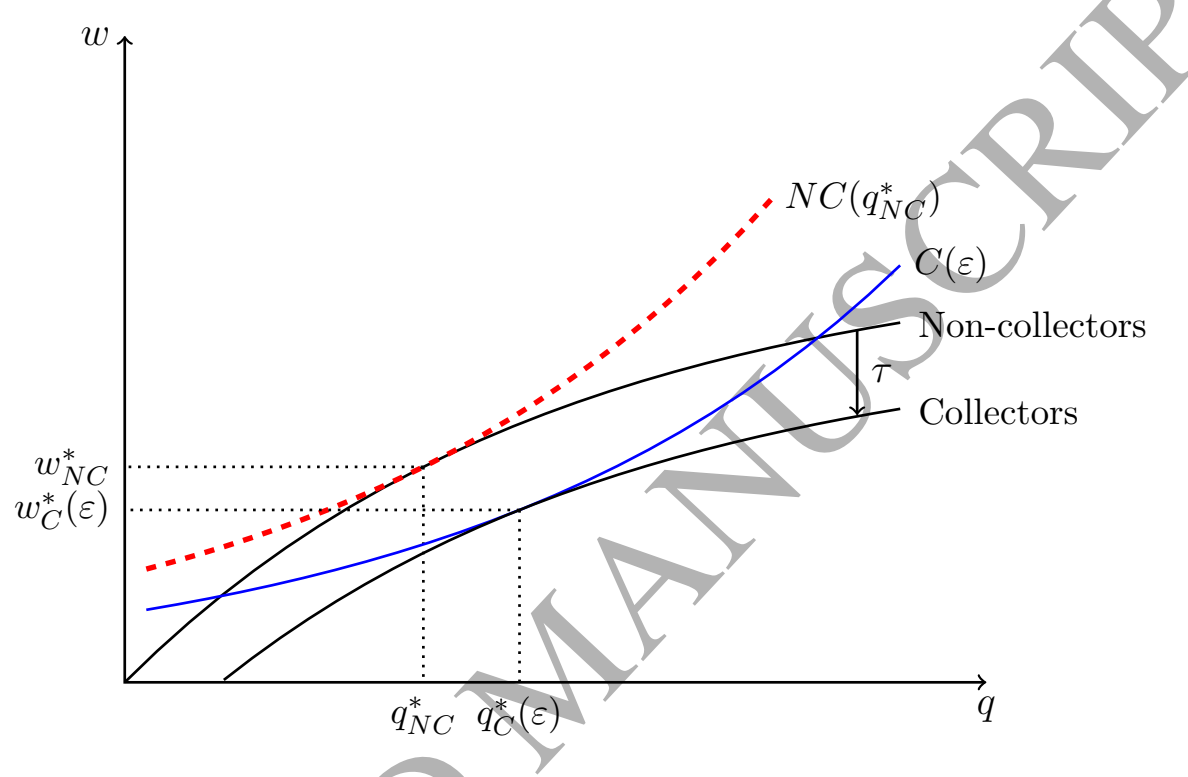

Figure 6: Determination of Equilibrium, Full Information

The graph shows the determination of $\left(q_{C}(\varepsilon), w_{C}(\varepsilon)\right), \varepsilon \leq \varepsilon^{*}$ and $\left(q_{N C}^{*}, w_{N C}^{*}\right)$ when there is full information. Wages offered by firms occur where the worker's indifference curve intersects the appropriate zero-profit curve. Since firms hiring UI collectors pay higher UI taxes, their zero-profit curve is shifted down by the tax, $\tau$.

Proposition 5 In the full information equilibrium, the following is true:

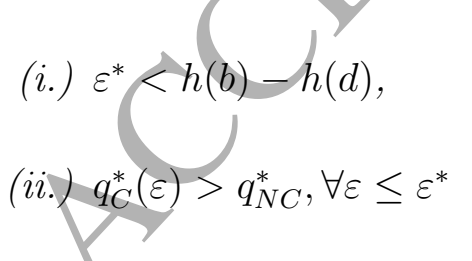

Proposition 5 illustrates some interesting features of the full information equilibrium. First, the value of $\varepsilon^{*}$, the point where the worker prefers to collect UI benefits for any 
$\varepsilon \leq \varepsilon^{*}$, has implications for the UI take-up rate. Recalling Equations (20) to (22), the takeup rate is generally increasing with $\varepsilon^{*}$. Denote the $\varepsilon^{*}$ under full information as $\varepsilon_{F I}^{*}$ and the value in the private information equilibrium as $\varepsilon_{P I}^{*}$.

Second, according to property (ii), UI collectors have longer unemployment durations, on average, relative to non-collectors. This follows from (iii) in Proposition 3 (see Figure 3), where we show the queue length is inversely related to $\varepsilon$. Notice, a UI non-collector is equivalent (in flow utility) to a worker with $\varepsilon=h(b)-h(d)$. Since $\varepsilon^{*}<h(b)-h(d)$, all UI collectors lie below this point, and from (ii) of Proposition 3, must have a higher queue length and longer average duration of unemployment. This is intuitive: non-collectors have lower flow utility in unemployment relative to a collector, and as a result they prefer shorter unemployment durations.

\section{B Proofs}

The following Lemma is used in the Proof of Lemma 1.

Lemma 2 The value function, $C(\varepsilon)$ is strictly decreasing in $\varepsilon$; i.e. $\frac{\partial C(\varepsilon)}{\partial \varepsilon}<0$.

Proof: This follows immediately from Equation (8) and the envelope theorem.

\section{Proof of Lemma 1:}

Proof: To prove Lemma 1, define the function $\Gamma(\varepsilon)=C(\varepsilon)-N C$. Let $w \in \mathbb{W}$ and $q=Q(w)$ be an equilibrium wage and associated queue length, with $q>0$. Consider first $\Gamma(0)$. Since $b>d$, we have:

$$
\begin{gathered}
\mathbf{N C}=\sup _{w^{\prime}}\left(\frac{1}{r\left(r+\lambda+\alpha_{W}\left(q\left(w^{\prime}\right)\right)\right)}\right)\left((r+\lambda) h(d)+\alpha_{W}\left(q\left(w^{\prime}\right)\right) h\left(w^{\prime}\right)\right)< \\
\gamma \sup _{w^{\prime}}\left(\frac{1}{r\left(r+\lambda+\alpha_{W}\left(q\left(w^{\prime}\right)\right)\right)}\right)\left((r+\lambda) h(b)+\alpha_{W}\left(q\left(w^{\prime}\right)\right) h\left(w^{\prime}\right)\right)=\mathbf{C}(0)
\end{gathered}
$$

which implies that $\Gamma(0)>0$. Next consider $\lim _{\varepsilon \rightarrow \infty} \Gamma(\varepsilon)$. Notice, from Lemma $2, C(\varepsilon)$ is decreasing in $\varepsilon$. Specifically, $\lim _{\varepsilon \rightarrow \infty} C(\varepsilon)=-\infty$; therefore, there exists some $\underline{\varepsilon}$ such that 
$\Gamma(\underline{\varepsilon})<0$. From Lemma 2, $\Gamma(\varepsilon)$ is strictly decreasing (and continuous); therefore, there exists a unique $\varepsilon^{*}$ such that $C\left(\varepsilon^{*}\right)=N C$.

The following Lemma is useful in the proof of Proposition 1.

Lemma 3 Any equilibrium $w \in \mathbb{W}$ and $q(w)=Q(w)$ must satisfy: $B(w)+C(q)=0$ for all $\varepsilon \leq \varepsilon^{*}$, where

$$
\begin{aligned}
B(w) & =\frac{\alpha_{W}[q(w)] h^{\prime}(w)}{r \Theta} \\
C(q) & =\frac{\alpha_{W}^{\prime}(q) q^{\prime}(w)(r+\lambda)[h(w)-(h(b)-\varepsilon)]}{r \Theta^{2}}
\end{aligned}
$$

and $\Theta=\left(r+\lambda+\alpha_{W}[q(w)]\right)$.

Proof: For $w \in \mathbb{W}$ and $q(w)=Q(w)$ to be equilibrium wages and queue lengths, they must satisfy Equation (12); that is, they must be optimal for a UI collector. Thus, there does not exist another $w^{\prime}$ such that the worker has higher lifetime expected utility. Suppose instead that $B(w)+C(q) \neq 0$, and take the case where $B(w)+C(q)>0$. This is without loss of generality, as the $B(w)+C(q)<0$ case follows by reversing the direction of the proof. Now, suppose we increase $w$ by any small amount. Let $q^{\prime}(w)$ denote the associated increase in $q$ required to remain on the firm's zero-profit curve in Equation (25) (or Equation (30) in the full information equilibrium). The increase in $w$ increases an unemployed worker's utility by $\frac{\partial C(\varepsilon)}{\partial w}=\frac{r \alpha_{W}(q) h^{\prime}(w)}{r\left(r+\lambda+\alpha_{W}(q)\right)}=B(w)$. When $q$ increases by $q^{\prime}(w)$, utility changes by:

$$
\begin{gathered}
\frac{\partial C(\varepsilon)}{\partial q} q^{\prime}(w)=q^{\prime}(w)\left[\frac{\alpha_{W}^{\prime}(q) h(w)\left(r\left(r+\lambda+\alpha_{W}(q)\right)\right)-\left((r+\lambda)(h(b)-\varepsilon)+\alpha_{W}(q)\right) r \alpha_{W}^{\prime}(q)}{r^{2}\left(r+\lambda+\alpha_{W}(q)\right)^{2}}\right] \\
=q^{\prime}\left[\frac{\gamma(r+\lambda) \alpha_{W}^{\prime}(q) h(w)-r(r+\lambda) \alpha_{W}^{\prime}(q)(h(b)-\varepsilon)}{r^{2}\left(r+\lambda+\alpha_{W}(q)\right)^{2}}\right] \\
=\frac{\alpha_{W}^{\prime}(q) q^{\prime}(w)(r+\lambda)[h(w)-(h(b)-\varepsilon)]}{r\left(r+\lambda+\alpha_{W}(q)\right)^{2}}=C(q)
\end{gathered}
$$

Thus, the worker's utility changes by $B(w)+C(q)$. Recall, $B(w)+C(q)>0$ so this increases $C(\varepsilon)$. Since the changes maintained profit maximization, this is a contradiction to $w \in \mathbb{W}$ and $q(w)=Q(w)$ as an equilibrium wage and queue length. 
For the remaining proofs, it is useful to work with the worker's indifference curve. This is derived using Equation (8). Specifically, for any level of utility $\bar{C}$, an unemployed UI collector's indifference curve is given by:

$$
\mathcal{W}(q)=h^{-1}\left\{\frac{1}{\alpha_{W}(q)}\left[r \bar{C}\left(r+\lambda+\alpha_{W}(q)\right)-(r+\lambda)[h(b)-\varepsilon]\right]\right\}
$$

To ease the notation, define $T(q)$ as:

$$
T(q)=\frac{1}{\alpha_{W}(q)}\left[r \bar{C}\left(r+\lambda+\alpha_{W}(q)\right)-(r+\lambda)[h(b)-\varepsilon]\right]
$$

Given this, we have $\mathcal{W}(q)=h^{-1}[T(q)]$, so

$$
\frac{\partial \mathcal{W}(q)}{\partial q}=\frac{T^{\prime}(q)}{h^{\prime}\left(h^{-1}(T(q))\right)}
$$

where

$$
T^{\prime}(q)=\frac{-\alpha_{W}^{\prime}(q)}{\left[\alpha_{W}(q)\right]^{2}}(r q-[h(b)-\varepsilon])
$$

Note that in equilibrium, since we restrict attention to $q(\varepsilon)$ such that $w(q) \geq \max \{h(b)-$ $\varepsilon, h(d)\}$ (depending on whether or not the worker collects UI), $\bar{C} \geq h(b)-\varepsilon$; as a result, since $\alpha_{W}^{\prime}(q)<0, T^{\prime}(q)>0$. That is, the worker's indifference curve is strictly increasing in $(q, w)$ space. Related, define the zero profit function defined in Equation (25) (or Equation (30) for the full information case) as:

$$
\mathcal{P}(q)=y-\frac{\gamma(r+\lambda)}{q_{C}(\varepsilon) \alpha_{W}\left(q_{C}(\varepsilon)\right)}-\lambda \tau
$$

Viewed in this way, the problem of determining the optimal $q$ becomes one of finding the indifference curve tangent to the firm's zero profit curve. The next Lemma shows that $\mathcal{P}(q)$ is strictly increasing and strictly concave.

Lemma 4 The wage defined in Equation (25) (and Equation (39)) is such that $\mathcal{P}^{\prime}(q)>0$ and $\mathcal{P}^{\prime \prime}(q)<0$. 
Proof: First, recall that our matching function is assumed to be such that $\alpha_{E}^{\prime}(q)>0$ and $\alpha_{E}^{\prime \prime}(q)<0$. Differentiating Equation (39) with respect to $q$ gives,

$$
\mathcal{P}^{\prime}(q)=\frac{\gamma(r+\lambda) \alpha_{E}^{\prime}(q)}{\left[\alpha_{E}(q)\right]^{2}}
$$

which is $>0$ given the properties of $\alpha_{E}(q)$. Differentiating again with respect to $q$ yields,

$$
\mathcal{P}^{\prime \prime}(q)=\frac{\gamma(r+\lambda) \alpha_{E}^{\prime \prime}(q)\left[\alpha_{E}(q)\right]^{2}-2 \gamma(r+\lambda) \alpha_{E}^{\prime}(q) \alpha_{E}(q)}{\left[\alpha_{E}(q)\right]^{2}}
$$

which is $<0$ since $\alpha_{E}^{\prime \prime}(q)<0$ and $\alpha_{E}^{\prime}(q)>0$.

\section{Proof of Proposition 1:}

We begin by showing that there must exist a wage function $w(\varepsilon)$ for UI collectors, and then show there exists a distinct wage for non-collectors, $w_{N} C$. Suppose that there exists only one equilibrium wage, $\hat{w}$ that all employed workers receive if matched with a firm. Denote the expected queue length associated with this wage by $q(\hat{w})$. Next, consider any $\varepsilon_{1} \leq \varepsilon^{*}$, where $\varepsilon^{*}$ is the unique cut-off value given by Lemma 1. By definition of equilibrium, $\hat{w}$ must satisfy $C\left(\varepsilon_{1}\right)=\sup _{w^{\prime}} C\left(\varepsilon_{1}, w^{\prime}\right)$. Then consider any $\varepsilon_{2}<\varepsilon_{1}$. Notice that $B(w)$ from Equation (33) does not depend on $\varepsilon$ and $C(q)$ from Equation (34) is decreasing in $\varepsilon$. Thus, $B\left(\hat{w} ; \varepsilon_{1}\right)=B\left(\hat{w} ; \varepsilon_{2}\right)$ and $C\left(q(\hat{w}) ; \varepsilon_{1}\right)>C\left(q(\hat{w}) ; \varepsilon_{2}\right)$. From Lemma $3, \hat{w}$ and $q(\hat{w})$ satisfy $0=B\left(\hat{w} ; \varepsilon_{1}\right)+C\left(q(\hat{w}) ; \varepsilon_{1}\right)>B\left(\hat{w} ; \varepsilon_{2}\right)+C\left(q(\hat{w}) ; \varepsilon_{2}\right)$. This implies, however, that the marginal cost of decreasing $\hat{w}$ exceeds the gain (of decreasing $q$ along the zero-profit curve), increasing utility for a worker with $\varepsilon=\varepsilon_{2}$, a contradiction to $\hat{w}$ being an equilibrium wage. Therefore, any equilibrium wage must be a function of $\varepsilon$ for $\varepsilon \leq \varepsilon^{*}$. Call this function $w_{C}(\varepsilon)$.

The final step in the proof is to verify a distinct wage for non-collectors. The alternative is that all non-collectors receive the wage $w_{C}\left(\varepsilon^{*}\right)$. Notice, then, at this wage, some workers prefer to collect UI benefits (those with $\varepsilon=\varepsilon^{*}$ while the rest $\left(\varepsilon>\varepsilon^{*}\right)$ do not collect. Thus, for a firm opening this job, the expected probability a separated worker collects is $0<p<1$. Suppose this is true.

Again, by assumption all $\varepsilon \geq \varepsilon^{*}$ search for the $w_{C}\left(\varepsilon^{*}\right)$ job, at the expected queue length 
$q_{C}\left(\varepsilon^{*}\right)$. Notice that $p>0$ for this job since both some collectors and non-collectors apply, but $p=1$ for all $\varepsilon<\varepsilon^{*}$ as only collectors apply to these jobs. We will show that in this case there exits a $\delta>0$ such that $w_{C}\left(\varepsilon^{*} ; 1>p>0\right)>w_{C}\left(\varepsilon^{*}-\delta ; p=1\right)$ and $q_{C}\left(\varepsilon^{*} ; 1>p>0\right)<$ $q_{C}\left(\varepsilon^{*}-\delta ; p=1\right)$. This would imply a neighborhood around $\varepsilon^{*}$ where optimal application is violated, since for those $\varepsilon \in\left[\varepsilon^{*}-\delta, \varepsilon^{*}\right)$, the $w_{C}\left(\varepsilon^{*} ; 1>p>0\right)$ job would pay a higher wage and arrive faster, strictly dominating the $w_{C}\left(\varepsilon^{*}-\delta ; p=1\right)$ job. To show this, we use the fact that optimal application and profit maximization imply equilibrium wages and queue lengths must be such that the worker's indifference curve is tangent to the zero profit curve (in $(q, w)$ space). That is, they must satisfy,

$$
\mathcal{P}^{\prime}\left(q_{C}^{*}(\varepsilon)\right)=\frac{\partial \mathcal{W}}{\partial q}=\frac{T^{\prime}\left(q_{C}^{*}(\varepsilon)\right)}{h^{\prime}\left(h^{-1}\left(q_{C}(\varepsilon)\right)\right)}
$$

Now, begin with the claim that $w_{C}\left(\varepsilon^{*} ; 1>p>0\right)>w_{C}\left(\varepsilon^{*}-\delta ; p=1\right)$. We first show that $w_{C}\left(\varepsilon^{*} ; 1>p>0\right)>w_{C}\left(\varepsilon^{*} ; p=1\right)$ and then a standard continuity argument delivers the desired result. Suppose instead that $w_{C}\left(\varepsilon^{*} ; 1>p>0\right) \leq w_{C}\left(\varepsilon^{*} ; p=1\right)$. Given the zero profit curves for each $p$, profit maximization implies that $q_{C}(p<1)<q_{C}(p=1)$. Then, Assumption 1 implies $T^{\prime \prime}(q)>0$ so that $T^{\prime}\left(q_{C}(p=1)\right)>T^{\prime}\left(q_{C}(p<1)\right.$. Moreover, strict convexity of the utility function $h(\cdot)$ implies that $\frac{1}{h^{\prime}\left(w_{C}(p=1)\right)} \geq \frac{1}{h^{\prime}\left(w_{C}(p<1)\right)}$. Combining these inequalities along with $P^{\prime \prime}(q)<0$ and Equation (40) we have:

$$
\begin{gathered}
y \frac{T^{\prime}\left(q_{C}(p=1)\right)}{h^{\prime}\left(w_{C}(p=1)\right)}>\frac{T^{\prime}\left(q_{C}(p<1)\right)}{h^{\prime}\left(w_{C}(p<1)\right)} \\
\Rightarrow P^{\prime}\left(q_{C}(p=1)\right)>P^{\prime}(p<1) \\
\Rightarrow q_{C}(p<1)>q_{C}(p=1)
\end{gathered}
$$

which is a contradiction to the argument above that $q_{C}(p<1)<q_{C}(p=1)$. Thus, $w_{C}\left(\varepsilon^{*} ; 1>\right.$ $p>0)>w_{C}\left(\varepsilon^{*} ; p=1\right)$.

Now, given this, we can then show that $q_{C}(p<1)<q_{C}(p=1)$. Suppose instead $q_{C}(p<1) \geq q_{C}(p=1)$. Then, from the properties of $T(\cdot)$ discussed above, $T^{\prime}\left(q_{C}(p<1)\right) \geq$ $T^{\prime}\left(q_{C}(p=1)\right.$. Since $w_{C}\left(\varepsilon^{*} ; 1>p>0\right)>w_{C}\left(\varepsilon^{*} ; p=1\right)$, the strict concavity of $h(\cdot)$ implies 
$\frac{1}{h^{\prime}\left(w_{C}(p<1)\right)} \geq \frac{1}{h^{\prime}\left(w_{C}(p=1)\right)}$. Combining these inequalities again with Equation $(40)$ yields:

$$
\begin{aligned}
\frac{T^{\prime}\left(q_{C}(p<1)\right)}{h^{\prime}\left(w_{C}(p<1)\right)}>\frac{T^{\prime}\left(q_{C}(p=1)\right)}{h^{\prime}\left(w_{C}(p=1)\right)} \\
\Rightarrow P^{\prime}\left(q_{C}(p<1)\right)>P^{\prime}(p=1) \\
\Rightarrow q_{C}(p=1)>q_{C}(p<1)
\end{aligned}
$$

a contradiction. Thus, $q_{C}(p<1)<q_{C}(p=1)$. Combining these results, if all non-collectors search for the wage $w_{C}\left(\varepsilon^{*}\right)$, then this wage is such that $w_{C}\left(\varepsilon^{*} ; 1>p>0\right)>w_{C}\left(\varepsilon^{*} ; p=1\right)$ and $q_{C}\left(\varepsilon^{*} ; p<1\right)<q_{C}\left(\varepsilon^{*} ; p=1\right)$. Then, since the policy functions, $\omega_{C}(\varepsilon)$ and $q_{C}(\varepsilon)$ are continuous functions of $\varepsilon$ (for a given $p$ ), there exists a $\delta>0$ such that $w_{C}\left(\varepsilon^{*} ; 1>p>0\right)>$ $w_{C}\left(\varepsilon^{*}-\delta ; p=1\right)$ and $q_{C}\left(\varepsilon^{*} ; p<1\right)<q_{C}\left(\varepsilon^{*}-\delta ; p=1\right)$. Notice, however, that this implies the $w_{C}\left(\varepsilon^{*}\right)$ job has a higher wage and lower job arrival rate than the jobs offered to UI collectors with $\varepsilon \in\left[\varepsilon^{*}-\delta, \varepsilon^{*}\right)$. As a result, those workers with $\varepsilon \in\left[\varepsilon^{*}-\delta, \varepsilon^{*}\right)$ have higher utility from searching for the $w_{C}\left(\varepsilon^{*}\right)$ job, violating optímal application. Therefore, there must exist a distinct wage $w_{N}$ for $\varepsilon>\varepsilon^{*}$.

We now turn towards the proof of Proposition 2. Towards this end, the following Lemma is used:

Lemma 5 The function defined by $G(q)=\frac{\alpha_{W}(q)}{r+\lambda+\alpha_{W}(q)}$ is such that $G^{\prime}(q)<0$.

Proof: Differentiating with respect to $q$ yields,

$$
G^{\prime}(q)=\frac{\alpha_{W}^{\prime}(q)(r+\lambda)}{\left(r+\lambda+\alpha_{W}(q)\right)^{2}}<0
$$

where the inequality follows from the properties of the matching function that imply $\alpha_{W}^{\prime}(q)<$ 0 .

\section{Proof of Proposition 2:}

We show that any equilibrium must satisfy the optimization problems in Equations (24) to (27). Suppose that $\{\mathbb{W}, Q, \mathbf{C}, \mathbf{E}, \mathbf{N C}, \mathcal{T}\}$ is an equilibrium with $w_{C}^{*} \in \mathbb{W}$ and $q_{C}^{*}\left(w_{C}^{*}\right)=$ 
$Q\left(w_{C}^{*}\right)>0$, for all $\varepsilon$. Furthermore, suppose there exists another $w_{C}^{\prime}$ and $q_{C}^{\prime}\left(w_{C}^{\prime}\right)$ that achieves a higher value of the objective function in Equation (24) (it is without loss of generality that we use $w_{C}, q_{C}$, as the case for $q_{N}, w_{N}$ and the objective in Equation (26) follows analogously). That is, suppose that for any $\varepsilon \leq \varepsilon^{*}, q_{C}^{\prime}$ and $w_{C}^{\prime}$ satisfy

$$
\left(\frac{1}{r+\lambda+\alpha_{W}\left(q_{C}^{\prime}(\varepsilon)\right)}\right)\left((r+\lambda)(h(b)-\varepsilon)+\alpha_{W}\left(q_{C}^{\prime}(\varepsilon)\right) h\left(w_{C}^{\prime}(\varepsilon)\right)\right)>\mathbf{C}(\varepsilon)
$$

Then, by definition of $Q(w)$ in equilibrium, for the wage $w_{C}^{\prime}$ it must satisfy optimal application, which implies

$$
\left(\frac{1}{r+\lambda+\alpha_{W}\left(Q\left(w_{C}^{\prime}\right)\right)}\right)\left((r+\lambda)(h(b)-\varepsilon)+\alpha_{W}\left(Q\left(w_{C}^{\prime}\right)\right) h\left(w_{C}^{\prime}(\varepsilon)\right)\right) \leq \mathbf{C}(\varepsilon)
$$

Combining Equations (41) and (42) implies that

$$
\frac{\alpha_{W}\left(Q\left(w_{C}^{\prime}\right)\right)}{r+\lambda+\alpha_{W}\left(Q\left(w_{C}^{\prime}\right)\right)}<\frac{\alpha_{W}\left(q_{C}^{\prime}\left(w_{C}^{\prime}\right)\right)}{r+\lambda+\alpha_{W}\left(q_{C}^{\prime}\left(w_{C}^{\prime}\right)\right)}
$$

From Lemma 5, this inequality implies that $q_{C}^{\prime}\left(w_{C}^{\prime}\right)<Q\left(w_{C}^{\prime}\right)$. Now, profit maximization in equilibrium implies that $w_{C}^{*}$ and $Q\left(w_{C}^{*}\right)$ satisfy Equation (25) with equality. Furthermore, this profit maximization implies that any other $w_{C}$ cannot earn greater than this. Combining $q_{C}^{\prime}\left(w_{C}^{\prime}\right)<Q\left(w_{C}^{\prime}\right)$, the fact that $\alpha_{E}(q)$ is increasing in $q$, along with the profit maximization just discussed implies that

$$
y=w_{C}^{\prime}-\frac{\gamma(r+\lambda)}{\alpha_{E}\left(q_{C}^{\prime}\right)}-\lambda \tau<y-w_{C}^{\prime}-\frac{\gamma(r+\lambda)}{\alpha_{E}\left(Q\left(w_{C}^{\prime}\right)\right)}-\lambda \tau \leq 0
$$

Thus, $q_{C}^{\prime}, w_{C}^{\prime}$ do not satisfy profit maximization, and thus are not feasible in equilibrium. Therefore, any equilibrium allocation must satisfy Equations (24) to (28).

The following two Lemmas are needed in the proof of Proposition 3:

Lemma 6 When $\tau=0, \mathbf{C}(\hat{\varepsilon} ; \tau=0)=\mathbf{N C}\left(q_{N C}^{*}\right)$, where $q_{N C}^{*}$ is defined as the solution to Equations (31) to (32), $\mathbf{C}(\varepsilon)$ is given by Equations (24) to (25), and $\hat{\varepsilon}=h(b)-h(d)$.

Proof: When $\tau=0$, from Equations (25) and (27), the zero-profit curves for firms hiring 
collectors and for firms hiring non-collectors coincide. Moreover, at $\hat{\varepsilon}=h(b)-h(d)$, a UI collector and non-collector have identical flow utility, and thus identical indifference curves in $(q, w)$ space. As a result, the utility maximizing $(q, w)$ combination must also coincide, implying that $\mathbf{C}(\hat{\varepsilon} ; \tau=0)=\mathbf{N C}\left(q_{N C}^{*}\right)$.

Lemma 7 The value function $C(\varepsilon ; \tau)$ is decreasing in $\tau$.

Proof: Differentiating $C(\varepsilon)$ in Equation (8) with respect to $\tau$ (using the Envelope Theorem) gives:

$$
\frac{\partial C}{\partial \tau}=\left(\frac{\alpha_{W}\left(q_{C}(\varepsilon)\right)}{r+\lambda+\alpha_{W}\left(q_{C}(\varepsilon)\right)}\right)\left(h^{\prime}\left(w_{C}(\varepsilon)\right)\right)\left(\frac{\partial w_{C}}{\partial \tau}\right)
$$

The first two terms in parenthesis are positive, and from Equation (25) (or Equation (30)), $\frac{\partial w_{C}}{\partial \tau}<0$.

\section{Proof of Proposition 3:}

Proof: To show property (i), denote $\varepsilon^{*}$ as the unique cut-off value such that $\mathbf{C}(\varepsilon) \geq \mathbf{N C}$ for all $\varepsilon \leq \varepsilon^{*}$, with equality at $\varepsilon=\varepsilon^{*}$. This simply represents the unique crossing point of $C(\varepsilon)$ and $N C$ identified in Lemma 1. Further let $\hat{\varepsilon}=h(b)-h(d)$. Property (i) says $\varepsilon^{*}=\hat{\varepsilon}$. Suppose instead this is not true. Then there are two possibilities: Case $1: \varepsilon^{*}<\hat{\varepsilon}$. In this case, notice that since $h(b)-\hat{\varepsilon}=h(d)$, it must be that $\tilde{C}(\hat{\varepsilon})=\mathrm{NC}\left(\tilde{q}_{N C}\right)$, for any equilibrium $\tilde{q}_{N C}$. Moreover, by definition, $\mathbf{C}\left(\varepsilon^{*}\right)=\mathbf{N C}\left(\tilde{q}_{N C}\right)$. Using this along with Lemma 2, given $\hat{\varepsilon}>\varepsilon^{*}:$

$$
\tilde{C}\left(\varepsilon^{*}\right)=\mathbf{N C}\left(\tilde{q}_{N C}\right)=\mathbf{C}\left(\varepsilon^{*}\right)>\mathbf{C}(\hat{\varepsilon})
$$

a contradiction to equilibrium conditions, as the constraint in Equation (28) is violated. The other possibility then is Case 2: $\varepsilon^{*}>\hat{\varepsilon}$. In this case, using the definitions of $\hat{\varepsilon}$ and $\varepsilon^{*}$, the fact that $\tilde{\mathbb{C}}(\varepsilon)$ (given by Equation (23)) is decreasing in $\varepsilon$, and the constraint in Equation (28) implies:

$$
\operatorname{NC}\left(\tilde{q}_{N C}\right)=\mathbf{C}\left(\varepsilon^{*}\right) \geq \tilde{C}\left(\varepsilon^{*}\right)>\tilde{C}(\hat{\varepsilon})=\operatorname{NC}\left(\tilde{q}_{N C}\right)
$$


a contradiction. Therefore, $\varepsilon^{*}=\hat{\varepsilon}=h(b)-h(d)$.

For property (ii), we need to show that Equation (28) binds at $\varepsilon=\varepsilon^{*}$. Suppose instead that Equation (28) remains slack at $\varepsilon=\varepsilon^{*}$. First, notice that since $C(\varepsilon)$ is increasing in $\varepsilon$, if Equation (28) is slack at $\varepsilon=\varepsilon^{*}$, then it is slack for all $\varepsilon \leq \varepsilon^{*}$. If Equation (28) does not bind, then the non-collector allocation is the solution to Equations (31) and (32); that is, $\tilde{q}_{N C}=q_{N C}^{*}$. It is sufficient to show that at $q_{N C}^{*}$ the constraint is violated at $\varepsilon=\varepsilon^{*}=$ $h(b)-h(d)$. That is, $\tilde{C}\left(\varepsilon^{*}\right)>C\left(\varepsilon^{*}\right)$. Towards this end, notice that by definition of $\tilde{C}(\varepsilon)$ and $\varepsilon^{*}, \tilde{C}\left(\varepsilon^{*}\right)=\mathbf{N C}\left(q_{N C}^{*}\right)$. Moreover, from Lemma $7 \mathbf{C}\left(\varepsilon^{*} ; \tau>0\right)<\mathbf{C}\left(\varepsilon^{*} ; \tau=0\right)$, and from Lemma $6 \mathbf{C}\left(\varepsilon^{*} ; \tau=0\right)=\mathbf{N C}\left(q_{N C}^{*}\right)$. Combining these relationships implies:

$$
\mathbf{C}\left(\varepsilon^{*} ; \tau>0\right)<\mathbf{C}\left(\varepsilon^{*} ; \tau=0\right)=\mathbf{N C}\left(q_{N C}^{*}\right)=\tilde{C}\left(\varepsilon^{*}\right)
$$

a contradiction to the equilibrium conditions. Thus, $\widetilde{q}_{N C} \neq q_{N C}^{*}$ in the private information equilibrium, and Equation (28) binds at $\varepsilon=\varepsilon^{*}$.

Next we show (iii), a feature of UI collector wages and arrival rates. Towards this end, consider $\varepsilon_{1}$ and $\varepsilon_{2}$ such that $\varepsilon_{2}>\varepsilon_{1}$. Denote $q_{C}^{*}(\varepsilon)$ the optimal choice of queue length (defined by Equation (24) or Equation (29)) for a given $\varepsilon$. Since $\alpha_{W}(q)$ is strictly decreasing in $q$, we need to show that $q_{C}^{*}\left(\varepsilon_{1}\right)>q_{C}^{*}\left(\varepsilon_{2}\right)$. Now, suppose instead that $q_{C}^{*}\left(\varepsilon_{2}\right) \geq q_{C}^{*}\left(\varepsilon_{1}\right)$. Notice, for a given $q, T^{\prime}(q)$ is increasing in $\varepsilon$; therefore, $T^{\prime}\left(q ; \varepsilon_{2}\right)>T^{\prime}\left(q ; \varepsilon_{1}\right)$. Since by assumption, $q_{C}^{*}\left(\varepsilon_{2}\right) \geq q_{C}^{*}\left(\varepsilon_{1}\right)$ and $T(q)$ is increasing in $q$, we also have that $T^{\prime}\left(q_{C}^{*}\left(\varepsilon_{2}\right)\right)>T^{\prime}\left(q_{C}^{*}\left(\varepsilon_{1}\right)\right)$. Moreover, since $\mathcal{P}(q)$ is increasing in $q$, we also have that $w_{C}\left(q_{C}\left(\varepsilon_{2}\right)\right) \geq w_{C}\left(q_{C}\left(\varepsilon_{1}\right)\right)$. Thus, the strictly concaye utility function implies $\frac{1}{h^{\prime}\left(h^{-1}\left(q_{C}\left(\varepsilon_{2}\right)\right)\right)} \geq \frac{1}{h^{\prime}\left(h^{-1}\left(q_{C}\left(\varepsilon_{1}\right)\right)\right)}$, implying that $\frac{T^{\prime}\left(q_{C}^{*}\left(\varepsilon_{2}\right)\right)}{h^{\prime}\left(h^{-1}\left(q_{C}\left(\varepsilon_{2}\right)\right)\right)}>\frac{T^{\prime}\left(q_{C}^{*}\left(\varepsilon_{1}\right)\right)}{h^{\prime}\left(h^{-1}\left(q_{C}\left(\varepsilon_{1}\right)\right)\right)}$.

Now, by definition of being an optimal solution, $q_{C}^{*}\left(\varepsilon_{1}\right)$ satisfies,

$$
\mathcal{P}^{\prime}\left(q_{C}^{*}\left(\varepsilon_{1}\right)\right)=\frac{\partial \mathcal{W}}{\partial q}=\frac{T^{\prime}\left(q_{C}^{*}\left(\varepsilon_{1}\right)\right)}{h^{\prime}\left(h^{-1}\left(q_{C}\left(\varepsilon_{1}\right)\right)\right)}
$$


Since $\mathcal{P}^{\prime \prime}(q)<0, \mathcal{P}^{\prime}\left(q_{C}^{*}\left(\varepsilon_{2}\right)\right) \leq \mathcal{P}^{\prime}\left(q_{C}^{*}\left(\varepsilon_{1}\right)\right)$, which combined with the results above implies,

$$
\frac{T^{\prime}\left(q_{C}^{*}\left(\varepsilon_{2}\right)\right)}{h^{\prime}\left(h^{-1}\left(q_{C}\left(\varepsilon_{2}\right)\right)\right)}>\frac{T^{\prime}\left(q_{C}^{*}\left(\varepsilon_{1}\right)\right)}{h^{\prime}\left(h^{-1}\left(q_{C}\left(\varepsilon_{1}\right)\right)\right)}=\mathcal{P}^{\prime}\left(q_{C}^{*}\left(\varepsilon_{1}\right)\right) \geq \mathcal{P}^{\prime}\left(q_{C}^{*}\left(\varepsilon_{2}\right)\right)
$$

which is a contradiction to $q_{C}^{*}\left(\varepsilon_{2}\right)$ being an optimal solution to Equation (29). Therefore, $q_{C}^{*}\left(\varepsilon_{2}\right)<q_{C}^{*}\left(\varepsilon_{1}\right)$.

Finally, consider (iv). For notation, denote the firm's zero profit curve from Equation (39) for workers collecting UI (with $\tau$ paid at separation) by $\mathcal{P}_{C}(q)$ and for a non-eollector as $\mathcal{P}_{N C}(q)$. Note, given $\tau>0$, Equation (39) implies that given any $q, \mathcal{P}_{N C}(q)>\mathcal{P}_{C}(q)$.

In equilibrium, the "incentive" constraint imposed by Equation (28) implies that a noncollector and a UI collector with $\varepsilon=\varepsilon^{*}$ must be on the same indifference curve. That is, $\mathcal{W}\left(\tilde{q}_{N C}\right)=\mathcal{W}\left(q_{C}^{*}\left(\varepsilon^{*}\right)\right)$. In addition, equilibrium requires the zero profit curve to intersect the indifference curve at the equilibrium $q$. For UI collectors this is a tangency, while for noncollectors (under private information) it is an intersection, which we show happens twice. To show this, we start by showing that at $q=q_{N C}^{*}, \mathcal{W}(q)-\mathcal{P}_{N C}(q)<0$ and crosses zero twice, once with $\tilde{q}_{N C}^{L}<q_{N C}^{*}$ and once with $\tilde{q}_{N C}^{H}>q_{N C}^{*}$.

From Lemmas 6 and $7, \mathbf{N C}\left(q_{N C}^{*}\right)=\mathbf{C}\left(\varepsilon^{*} ; \tau=0\right)>\mathbf{C}\left(\varepsilon^{*} ; \tau>0\right)=\mathbf{N C}\left(\tilde{q}_{N C}\right)$. As a result, $\mathcal{P}_{N C}\left(q_{N C}^{*}\right)=\mathcal{W}\left(q_{N C}^{*} ; \mathbf{N C}\left(q_{N C}^{*}\right)\right)>\mathcal{W}\left(\tilde{q}_{N C} ; \mathbf{N C}\left(\tilde{q}_{N C}\right)\right)=\mathcal{W}\left(q_{C}^{*}\left(\varepsilon^{*}\right) ; \mathbf{C}\left(\varepsilon^{*}\right)\right)=$ $\mathcal{P}_{C}\left(q_{C}^{*}\left(\varepsilon^{*}\right)\right)$. Thus, at $q_{N C}^{*}, \mathcal{W}\left(q_{N C}^{*}\right)-\mathcal{P}_{N C}\left(q_{N C}^{*}\right)<0$. Now, consider $\mathcal{W}(q)-\mathcal{P}_{N C}(q)$ as $q$ decreases. Towards this end, given the properties of the matching function, notice that $\lim _{q \rightarrow 0} \alpha_{W}(q)=\infty, \lim _{q \rightarrow \infty} \alpha_{W}(q)=0, \lim _{q \rightarrow 0} \alpha_{E}(q)=0$, and $\lim _{q \rightarrow \infty} \alpha_{E}(q)=\infty$.

$$
\begin{aligned}
& \lim _{q \rightarrow 0} \mathcal{W}(q)=C^{*}-(r+\lambda) h(d) \\
& \lim _{q \rightarrow \infty} \mathcal{W}(q)=h^{-1}[\infty]=\infty \\
& \lim _{q \rightarrow 0} \mathcal{P}(q)=-\infty \\
& \lim _{q \rightarrow \infty} \mathcal{P}(q)=y-\chi_{i} \lambda \tau
\end{aligned}
$$

where recall $\chi_{i}, i=C, N$ is an indicator variable with $\chi_{C}=1$ and $\chi_{N}=0$. Using Equa- 
tions (43) to (46) implies that $\lim _{q \rightarrow 0} \mathcal{W}(q)-\mathcal{P}_{N C}(q)>0$. Thus, it starts negative at $q=q_{N C}^{*}$ and is eventually positive. Since $\mathcal{W}(q)$ is strictly convex (and strictly increasing) and $\mathcal{P}(q)$ is strictly concave (and strictly increasing), this crossing only happens once. As a result, there exists an equilibrium $\tilde{q}_{N C}^{L}<q_{N C}^{*}$. We similarly show that there exists an equilibrium $\tilde{q}_{N C}^{H}>q_{N C}^{*}$. Specifically, Equations (43) to (46) imply that $\lim _{q \rightarrow \infty} \mathcal{W}(q)-\mathcal{P}_{N C}(q)>0$, which combined with the strict convexity of $\mathcal{W}(q)$ and strict concavity of $\mathcal{P}(q)$ yields a unique crossing above $q_{N C}^{*}$.

\section{Proof of Proposition 4:}

Proof: The proof follows the same logic as the proof of Proposition 2 above, and is thus omitted here..

\section{Proof of Proposition 5:}

Proof: First consider (i) $\varepsilon^{*}<h(b)-h(d)$. Define $\hat{\varepsilon}=h(b)-h(d)$. Suppose instead that $\varepsilon^{*} \geq \hat{\varepsilon}$. Notice that if $\varepsilon=\hat{\varepsilon}$, collectors and non-collectors have the same flow utility. Moreover, the set of feasible wages for a firm hiring non-collectors, given any $q$, includes as a subset the wages available to a firm hiring collectors. This implies that by definition of $\mathbf{N C}, \mathbf{N C} \geq \mathbf{C}(\hat{\varepsilon})$. Then, if $\varepsilon^{*}>\hat{\varepsilon}$,

$$
\mathbf{N C} \geq \mathbf{C}(\hat{\varepsilon})>\mathbf{C}\left(\varepsilon^{*}\right)
$$

where the last inequality comes from Lemma 2. This is a contradiction to the definition of $\varepsilon^{*}$ where $\mathbf{C}\left(\varepsilon^{*}\right)=\mathbf{N C}$. Then, what if $\varepsilon^{*}=\hat{\varepsilon}$ ? Consider the determination of $(q, w)$ as the tangency point of the worker's indifference curve and the zero-profit curve. This implies that the equilibrium $q$ must satisfy $\mathcal{P}^{\prime}(q)=\mathcal{W}^{\prime}(q)$, or:

$$
\frac{\gamma(r+\lambda) \alpha_{E}^{\prime}(q)}{\left[\alpha_{E}(q)\right]^{2}}=\frac{-\alpha_{W}^{\prime}(q)}{\left[\alpha_{W}(q)\right]^{2}}[r \bar{C}-H(c)]
$$

where $H(c)=h(b)-\varepsilon$ for a UI collector and $H(c)=h(d)$ for a non-collector. Notice, for $\varepsilon=\hat{\varepsilon}$, Equation (47) is the same for UI collector's and non-collectors. Since $\mathcal{P}(q)$ and $\mathcal{W}(q)$ are strictly concave and convex, respectively, this has a unique solution. Therefore, 
$q_{C}(\hat{\varepsilon})=q_{C}\left(\varepsilon^{*}\right)=q_{N C}$. Since $p=1$ for $\varepsilon=\varepsilon^{*}$, the wage for a UI collector, from Equation (30), is such that $w_{C}\left(\varepsilon^{*}\right)<w_{N C}$. Given the same flow utility, however, $q_{C}\left(\varepsilon^{*}\right)=q_{N C}$ and $w_{C}\left(\varepsilon^{*}\right)<w_{N C}$ imply that $\mathbf{C}\left(\varepsilon^{*}\right)<\mathbf{N C}$, a contradiction to the definition of $\varepsilon^{*}$. Thus, $\varepsilon^{*}<\hat{\varepsilon}$.

To show property (ii), $q_{C}(\varepsilon)>q_{N C}$, for all $\varepsilon \leq \varepsilon^{*}$, we can start with the fact argued above that from Equation $(47), q_{C}(\hat{\varepsilon})=q_{N C}$. Combining this with $\varepsilon^{*}<\hat{\varepsilon}$ and (iii) of Proposition 3 yields the desired result.

\section{State Level Take-up Data}

In Section 2.2 we examine the U.S. take-up rate. This is accomplished by estimating eligible unemployed in each state according to their respective eligibility rules. This produces an FEU for the entire U.S. economy, which is used along with the FIU (tabulated by the BLS) for the entire U.S. to produce the take-up rate. The BLS also tabulates the FIU for each U.S. state individually. Given this, we can also estimate an FEU for each state, which is then combined with the FIU for that state to estimate the state's UI take-up rate. We have done this exercise and present the results in Table 6.

Table 6 provides the average value of each statistic for the entire 1989-2012 time period for each U.S. state. This table presents similar information to Table 1. Specifically we display the FIU, take-up rate (TUR), fraction of ineligible unemployed (Inelig.), and then the fraction of ineligible from monetary criteria (Mon.), quits (Quits), and exhaustions (Exhaust). Note, the sum of the state average take-up rates will not sum to the U.S. average take-up rate presented in Table 1. Thís is because of the different population sizes of each state, which implies a weighted average of the state take-up rates is required to arrive at the total U.S. take-up rate we ealculate in Table 1.

In the last two columns of Table 6 we examine the impact of changes in eligibility rules since 1989 for each state. Similarly to the exercise carried out in Table 2, here we fix eligibility rules in 1989, only updating for inflation where necessary. We then re-estimate the FEU in each state, each year under these hypothetical rules and calculate the associated take-up rate. The column labeled "TUR 1989 Rules" displays this alternative take-up rate and the column 
labeled "1989-Orig. Rules" takes the alternative take-up rate minus the original. A positive difference in this column indicates that actual eligibility rules have become more restrictive since 1989, while a negative difference indicates the rules have become more generous. In most states the difference remains relatively small (essentially 0 in several cases), but a few examples of large changes do exist. All of the calculations in the last two columns are based on the average in each state from 1989-2012.

Table 6: Take-up Rates by U.S. State

\begin{tabular}{|c|c|c|c|c|c|c|c|c|}
\hline State & FIU & TUR & Inelig. & Mon. & Quits & Exhaus & & $198 ?$ \\
\hline $\mathrm{AK}$ & 0.336 & 0.949 & 0.051 & 0.707 & 0.159 & 0.092 & & 0.000 \\
\hline $\mathrm{AL}$ & 0.774 & 0.383 & 0.617 & 0.051 & 0.577 & 0.311 & & 0.262 \\
\hline $\mathrm{AR}$ & 0.348 & 0.905 & 0.095 & 0.709 & 0.189 & & 0.892 & -0.013 \\
\hline $\mathrm{AZ}$ & 0.402 & 0.570 & 0.430 & 0.685 & 0.200 & 0.073 & 0.596 & 0.026 \\
\hline $\mathrm{CA}$ & 0.438 & 0.809 & 0.191 & 0.702 & & 0,111 & 0.826 & 0.017 \\
\hline $\mathrm{CO}$ & 0.372 & 0.610 & 0.390 & 0.653 & & 0.081 & 0.602 & -0.008 \\
\hline $\mathrm{CT}$ & 0.438 & 0.910 & 0.090 & 0.594 & 0.187 & 0.177 & 0.910 & -0.001 \\
\hline $\mathrm{DC}$ & 0.390 & 0.704 & 0.296 & 0.723 & 0.160 & 0.076 & 0.690 & -0.015 \\
\hline $\mathrm{DE}$ & 0.442 & 0.840 & & 0.619 & 0.239 & 0.100 & 0.834 & -0.006 \\
\hline $\mathrm{FL}$ & 0.369 & $0 \subset 0$ & (.J.5 & 0.683 & 0.186 & 0.089 & 0.615 & 0.008 \\
\hline GA & 0.619 & 0.418 & 0.582 & 0.330 & 0.510 & 0.129 & 0.308 & -0.110 \\
\hline $\mathrm{HI}$ & & & 0.054 & 0.700 & 0.196 & 0.063 & 0.931 & -0.015 \\
\hline IA & & 0.627 & 0.373 & 0.596 & 0.258 & 0.105 & 0.627 & 0.000 \\
\hline ID & 0.492 & 0.831 & 0.169 & 0.691 & 0.193 & 0.074 & 0.850 & 0.019 \\
\hline $1 \mathrm{~L}$ & 0.456 & 0.738 & 0.262 & 0.673 & 0.166 & 0.119 & 0.754 & 0.016 \\
\hline IN & 0.420 & 0.675 & 0.325 & 0.688 & 0.177 & 0.094 & 0.686 & 0.011 \\
\hline $\mathrm{KS}$ & 0.375 & 0.796 & 0.204 & 0.690 & 0.203 & 0.066 & 0.768 & -0.029 \\
\hline KY & 0.494 & 0.531 & 0.469 & 0.635 & 0.242 & 0.081 & 0.550 & 0.019 \\
\hline $\mathrm{LA}$ & 0.504 & 0.579 & 0.421 & 0.624 & 0.255 & 0.079 & 0.340 & -0.239 \\
\hline
\end{tabular}




\begin{tabular}{|c|c|c|c|c|c|c|c|c|}
\hline MA & 0.459 & 0.915 & 0.085 & 0.638 & 0.176 & 0.144 & 0.909 & -0.006 \\
\hline MD & 0.493 & 0.612 & 0.388 & 0.652 & 0.197 & 0.110 & 0.632 & 0.020 \\
\hline ME & 0.523 & 0.678 & 0.322 & 0.638 & 0.210 & 0.110 & 0.673 & -0.005 \\
\hline MI & 0.344 & 0.902 & 0.098 & 0.745 & 0.111 & 0.102 & 0.898 & -0.003 \\
\hline $\mathrm{MN}$ & 0.511 & 0.693 & 0.307 & 0.701 & 0.157 & 0.100 & 0.718 & 0.025 \\
\hline $\mathrm{MO}$ & 0.483 & 0.657 & 0.343 & 0.620 & 0.236 & 0.102 & 0.642 & \\
\hline MS & 0.333 & 0.757 & 0.243 & 0.757 & 0.146 & 0.055 & 0.758 & \\
\hline MT & 0.428 & 0.829 & 0.171 & 0.666 & 0.222 & 0.070 & 0.874 & \\
\hline $\mathrm{NC}$ & 0.384 & 0.797 & 0.203 & 0.643 & 0.221 & 0.095 & & 0.000 \\
\hline ND & 0.764 & 0.412 & 0.588 & 0.506 & 0.352 & 0.100 & & 0.000 \\
\hline $\mathrm{NE}$ & 0.411 & 0.768 & 0.232 & 0.624 & 0.259 & 0.075 & & -0.011 \\
\hline $\mathrm{NH}$ & 0.473 & 0.537 & 0.463 & 0.623 & 0.207 & & & 0.023 \\
\hline NJ & 0.438 & 0.910 & 0.090 & 0.640 & 0.148 & & 0.910 & 0.000 \\
\hline NM & 0.569 & 0.482 & 0.518 & 0.528 & 0.328 & 0.102 & 0.335 & -0.147 \\
\hline NV & 0.665 & 0.555 & 0.445 & 0.284 & & 0.204 & 0.445 & -0.110 \\
\hline NY & 0.432 & 0.823 & 0.177 & 0.714 & & 0.116 & 0.880 & 0.057 \\
\hline $\mathrm{OH}$ & 0.383 & 0.744 & 0.256 & & 0.149 & 0.085 & 0.775 & 0.031 \\
\hline $\mathrm{OK}$ & 0.303 & 0.745 & & 0.704 & 0.189 & 0.065 & 0.908 & 0.163 \\
\hline OR & 0.415 & & & 0.631 & 0.207 & 0.120 & 0.904 & -0.003 \\
\hline PA & 0.463 & & 07 & 0.686 & 0.156 & 0.116 & 0.925 & 0.003 \\
\hline RI & & & 0.092 & 0.688 & 0.144 & 0.127 & 0.924 & 0.016 \\
\hline $\mathrm{SC}$ & & 070 ? & 0.297 & 0.632 & 0.211 & 0.116 & 0.719 & 0.016 \\
\hline SD & & 0.518 & 0.482 & 0.744 & 0.187 & 0.027 & 0.521 & 0.004 \\
\hline & 0.406 & 0.692 & 0.308 & 0.696 & 0.188 & 0.074 & 0.689 & -0.004 \\
\hline & 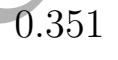 & 0.598 & 0.402 & 0.711 & 0.187 & 0.061 & 0.586 & -0.012 \\
\hline & 0.574 & 0.437 & 0.563 & 0.512 & 0.349 & 0.097 & 0.322 & -0.116 \\
\hline VA & 0.398 & 0.565 & 0.435 & 0.697 & 0.197 & 0.064 & 0.608 & 0.043 \\
\hline VT & 0.487 & 0.863 & 0.137 & 0.665 & 0.211 & 0.082 & 0.854 & -0.009 \\
\hline
\end{tabular}




\begin{tabular}{c|cccccccc} 
WA & 0.563 & 0.694 & 0.306 & 0.585 & 0.231 & 0.142 & 0.694 & 0.000 \\
WI & 0.501 & 0.890 & 0.110 & 0.680 & 0.194 & 0.084 & 0.863 & -0.028 \\
WV & 0.412 & 0.744 & 0.256 & 0.680 & 0.186 & 0.092 & 0.761 & 0.016 \\
WY & 0.597 & 0.454 & 0.546 & 0.593 & 0.289 & 0.077 & 0.454 & 0.000 \\
\hline \hline
\end{tabular}

\section{UI Fraud}

While the UI take-up rate examines eligibles who do not collect, there also exists the possibility of UI fraud: individuals who are ineligible for UI benefits still collect them. Indeed, UI fraud does occur in the U.S. system, with around $3 \%$ of UI benefits being collected fraudulently (see Fuller, Ravikumar, and Zhang (2015) for UI fraud facts and discussion). Thus, some of those in the numerator of the FIU are collecting UI benefits but are in fact ineligible. Ideally, we could either remove such cases from the numerator, or add them back in as "eligible" in the FEU. Unfortunately, the data does not exist to allow us to properly adjust for those committing UI fraud. This issue should not significantly affect the accuracy of our take-up rate estimates, however. While $3 \%$ of UI benefits are collected fraudulently, much of this obtains on the intensive, rather than extensive margin. That is, most UI fraud occurs as workers collect higher weekly benefit levels than they are entitled to, rather that workers collecting any amount who were not entitled to any UI benefits. The intensive margin of UI fraud does not create problems for the UI take-up rate, as these workers are eligible for some UT benefits.

To provide evidence that fraud occurs primarily along the intensive margin, we used UI fraud data available from the Benefit Accuracy Measurement (BAM) program run by the U.S. Department of Labor. The BAM program audits a random sample of weekly UI claims for accuracy, with the main goal to characterize any overpayments that may occur. BAM auditors also note if UI fraud has occurred. Fraud is defined as a UI collector intentionally misleading their state UI office to collect more benefits than they are entitled to. Fraud occurs on the extensive margin if individuals collect some benefits although they were not 
eligible for any. It occurs on the intensive margin if the individual collects a higher benefit amount then they were eligible for, but they were still entitled to collect some UI benefits.

Using this BAM data from 1989-2012, we calculated the difference between the actual WBA (weekly benefit amount) the individual received and the amount of overpayment determined in the BAM audit. For those deemed to have committed UI fraud, we classified them as an extensive margin fraud if the difference between WBA and overpayment was less than or equal to $\$ 0$. This implies the worker was not entitled to any UI benefits, but collected anyway. On average from 1989-2012, only $11 \%$ of fraud was along the extensive margin. To understand why this may be the case, it is useful to note that the majority of UI fraud is Concealed Earnings fraud: workers collect UI but work at the same time (see Fuller, Ravikumar, and Zhang (2015) for more details on concealed earnings fraud and its implications for the provision of UI). Workers are allowed to simultaneously work and collect UI, but any earnings above a threshold are met with a dollar for dollar reduction in the WBA. In many cases, the worker is still entitled to some benefits, but underreports their earnings to receive a larger UI benefit; this again implies the fraud is on the intensive margin.

\section{E State Laws: 2012}

In this section we present a detailed description of the eligibility laws in each state in 2012. As discussed in Blank and Card (1991), using the March CPS to estimate UI eligibility does have some drawbacks. These are most notable in the Monetary criteria, where High Quarter Earnings (HQE) represents an important quantity for monetary eligibility in some states. Since the March CPS only details earnings during the previous year, HQE cannot be determined. In some states, eligibility is based on earnings outside of the HQE. For example, in 1989, Georgia required base period earnings greater than 1.5 times the HQE. In such cases, we are unable to determine monetary eligibility. Using weeks worked represents one possible way to proxy for this type of eligibility. For example, in the case of Georgia above, we could require total weeks worked in the previous year to exceed $19.5(1.5 * 13)$. This assumes constant earnings over the year, and simply requires the individual to have 
worked more than one quarter. We have implemented this alternative and it has a negligible impact on the fraction of unemployed eligible for benefits.

Below we provide a table obtained at https://oui.doleta.gov/unemploy/statelaws.asp. This table lists the key features of each U.S. state's UI laws in 2012, including its eligibility criteria. 


\section{SIGNIFICANT PROVISIONS OF STATE UNEMPLOYMENT INSURANCE LAWS} EFFECTIVE JANUARY 2012

\begin{tabular}{|c|c|c|c|c|c|c|c|c|c|c|}
\hline & \multicolumn{7}{|c|}{ BENEFITS } & \multirow{3}{*}{$\begin{array}{l}\text { COVERAGE } \\
\text { Size of Payroll } \\
\text { (Length of } \\
\text { Employment/ } \\
\text { Wages Paid) }^{6}\end{array}$} & \multicolumn{2}{|c|}{ TAXES } \\
\hline & \multirow{2}{*}{$\begin{array}{c}\text { Earnings/ } \\
\text { Employment } \\
\text { Needed in Base } \\
\text { Period to Qualify }{ }^{1}\end{array}$} & \multirow{2}{*}{$\begin{array}{l}\text { Computation of } \\
\text { Weekly Benefit } \\
\text { Amount }\end{array}$} & \multicolumn{2}{|c|}{$\begin{array}{l}\text { Weekly Benefit } \\
\text { Amount }^{2}\end{array}$} & \multirow{2}{*}{$\begin{array}{c}\text { Weekly } \\
\text { Earnings } \\
\text { Disregarded }\end{array}$} & \multirow{2}{*}{$\begin{array}{l}\text { Calculation of } \\
\text { Number of } \\
\text { Benefit } \\
\text { Weeks }^{4}\end{array}$} & \multirow{2}{*}{$\begin{array}{l}\text { Number } \\
\text { of } \\
\text { Benefit } \\
\text { Weeks }^{5}\end{array}$} & & \multirow{2}{*}{$\begin{array}{c}2012 \\
\text { Wages } \\
\text { Subject } \\
\text { to Tax }\end{array}$} & \multirow{2}{*}{$\begin{array}{c}2011 \\
\text { Minimum \& } \\
\text { Maximum } \\
\text { Rates }^{7} \\
\text { New } \\
\text { Employer } \\
\text { Rate }^{8} \\
\end{array}$} \\
\hline & & & $\begin{array}{l}\text { Mini- } \\
\text { mum }\end{array}$ & $\begin{array}{l}\text { Maxi- } \\
\text { Mum }\end{array}$ & & & & & & \\
\hline $\mathrm{AL}$ & $\begin{array}{l}1 \frac{1}{2} \times \mathrm{HQW} \text {; } \\
\text { qualify for at least } \\
\text { minimum WBA }\end{array}$ & $\begin{array}{l}1 / 26 \text { avg of } 2 \\
\text { highest qtrs }\end{array}$ & $\$ 45$ & $\$ 265$ & $\$ 15$ & $\begin{array}{l}\text { Lesser of } 1 / 3 \\
\text { BPW or } 26 x \\
\text { WBA }\end{array}$ & $15-26$ & $\begin{array}{l}20 \text { weeks or } \\
\$ 1,500 \text { in any } \\
\text { qtr }\end{array}$ & $\$ 8,000$ & $\begin{array}{l}0.59 \% \\
6.74 \% \\
2.70 \%\end{array}$ \\
\hline AK & $\begin{array}{l}\$ 2,500 ; \text { wages in } \\
2 \text { qtrs }\end{array}$ & $\begin{array}{l}0.9-4.4 \% \text { of annual } \\
\text { wages }+\$ 24 \text { per } \\
\text { dep up to } \$ 72\end{array}$ & $\begin{array}{l}\$ 56- \\
128\end{array}$ & $\begin{array}{l}\$ 370- \\
442\end{array}$ & $\begin{array}{l}\$ 50 \text { and } 1 / 4 \\
\text { wages over } \\
\$ 50\end{array}$ & $\begin{array}{l}\text { Weighted } \\
\text { schedule of } \\
\text { BPW to HQW }\end{array}$ & $16-26$ & Any size & $\$ 34,600$ & $\begin{array}{l}1.00 \% \\
5.40 \% \\
3.40 \% \\
\end{array}$ \\
\hline$A Z$ & $\begin{array}{l}11 / 2 \times \mathrm{HQW} \text { and } \\
\$ 1,500 \text { in } 1 \text { qtr; or } \\
\text { wages in } 2 \text { qtrs } \\
\text { with wages in } 1 \\
\text { qtr sufficient to } \\
\text { qualify for } \\
\text { maximum WBA, } \\
\text { and total BPW } \geq \\
\text { taxable wage } \\
\text { base }\end{array}$ & 1/25 HQW & $\$ 60$ & $\$ 240$ & $\$ 30$ & $\begin{array}{l}\text { Lesser of } \\
\text { BPW or } 2 \\
\text { WBA }\end{array}$ & & $\begin{array}{l}20 \text { weeks or } \\
\$ 1,500 \text { in any } \\
\text { qtr }\end{array}$ & $\$ 7,000$ & $\begin{array}{l}0.02 \% \\
5.86 \% \\
2.00 \%\end{array}$ \\
\hline AR & $\begin{array}{l}35 \times \text { WBA; wages } \\
\text { in } 2 \text { qtrs }\end{array}$ & 1/26 HQW & $\$ 82$ & $\$ 457$ & $40 \%$ WBA & $\begin{array}{l}\text { Lesser of } 25 \\
\times \text { WBA or } 1 / 3 \\
\text { BPW }\end{array}$ & $9-25$ & $\begin{array}{l}\text { One } \\
\text { employee for } \\
10 \text { or more } \\
\text { days in a CY }\end{array}$ & $\$ 12,000$ & $\begin{array}{l}1.00 \% \\
6.90 \% \\
3.80 \%\end{array}$ \\
\hline CA & $\begin{array}{l}\$ 1,300 \text { in } \mathrm{HQ} \text {, or } \\
\$ 900 \text { in } \mathrm{HQ} \text { with } \\
\mathrm{BPW}=1 \frac{1}{4} \times \mathrm{HQ}\end{array}$ & $1 / 23$ to $1 / 26 \mathrm{HQW}$ & $\$ 40$ & $\$ 450$ & $\begin{array}{l}\text { Greater of } \\
\$ 25 \text { or } 1 / 4 \\
\text { wages }\end{array}$ & $\begin{array}{l}\text { Lesser of } 26 \\
x \text { WBA or } 1 / 2 \\
\text { BPW }\end{array}$ & $14-26$ & $\begin{array}{l}\text { Over } \$ 100 \text { in } \\
\text { any qtr }\end{array}$ & $\$ 7,000$ & $\begin{array}{l}1.50 \% \\
6.20 \% \\
3.40 \% \\
\end{array}$ \\
\hline $\mathrm{CO}$ & $\begin{array}{l}40 \times \text { WBA or } \\
\$ 2,500 \text {, } \\
\text { whichever is } \\
\text { greater }\end{array}$ & $\begin{array}{l}\text { Higher of } 60 \% \text { of } \\
1 / 26 \text { of } 2 \text { consecu- } \\
\text { tive HQW, capped } \\
\text { by } 50 \% \text { of State } \\
\text { avg weekly earn- } \\
\text { ings or } 50 \% \text { of } 1 / 52 \\
\text { BP earnings } \\
\text { capped by } 55 \% \text { of } \\
\text { State avg weekly } \\
\text { earnings }\end{array}$ & $\$ 25$ & & $1 / 4$ WBA & $\begin{array}{l}\text { Lesser of } 26 \\
x \text { WBA or } 1 / 3 \\
\text { BPW }\end{array}$ & $13-26$ & $\begin{array}{l}20 \text { weeks or } \\
\$ 1,500 \text { in any } \\
\text { qtr }\end{array}$ & $\$ 11,000$ & $\begin{array}{l}1.00 \% \\
5.40 \% \\
1.70 \%\end{array}$ \\
\hline CT & $40 \times$ WBA & $\begin{array}{l}1 / 26 \text { avg of } 2 \\
\text { highest qtrs } \\
+\$ 15 \text { per dep, up } \\
\text { to } 5 \text {; DA capped at } \\
\text { WBA (For } \\
\text { construction } \\
\text { workers, } 1 / 26 \mathrm{HQ} \text { ) }\end{array}$ & $\$ 15-30$ & $\begin{array}{l}\$ 573- \\
648 \\
\text { Eff. } \\
10 / 2 / \\
11\end{array}$ & $1 / 3$ wages & $\begin{array}{l}\text { Uniform } \\
\text { duration }\end{array}$ & 26 & $\begin{array}{l}20 \text { weeks or } \\
\$ 1,500 \text { in any } \\
\text { qtr }\end{array}$ & $\$ 15,000$ & $\begin{array}{l}1.90 \% \\
6.80 \% \\
3.70 \%\end{array}$ \\
\hline DE & $36 \times$ WBA & $\begin{array}{l}1 / 46 \text { total wages in } \\
2 \text { highest qtrs }\end{array}$ & $\$ 20$ & $\$ 330$ & $\begin{array}{l}\text { Greater of } \\
\$ 10 \text { or } 50 \% \\
\text { WBA }\end{array}$ & $1 / 2 \mathrm{BPW}$ & $24-26$ & $\begin{array}{l}20 \text { weeks or } \\
\$ 1,500 \text { in any } \\
\text { qtr }\end{array}$ & $\$ 10,500$ & $\begin{array}{l}0.10 \% \\
8.00 \% \\
2.60 \% \\
\end{array}$ \\
\hline DC & $\begin{array}{l}11 / 2 \times \text { HQW or } \\
\text { within } \$ 70 ; \text { not } \\
\text { less than } \$ 1,950 \\
\text { in } 2 \text { qtrs; } \$ 1,300 \\
\text { in } 1 \text { qtr }\end{array}$ & $1 / 26 \mathrm{HQW}$ & $\$ 50$ & $\$ 359$ & $\begin{array}{l}1 / 5 \text { of wages } \\
\text { plus } \$ 20\end{array}$ & $\begin{array}{l}\text { Lesser of } 26 \\
\times \text { WBA or } 1 / 2 \\
\text { BPW }\end{array}$ & $19-26$ & Any size & $\$ 9,000$ & $\begin{array}{l}1.60 \% \\
7.00 \% \\
2.70 \%\end{array}$ \\
\hline $\mathrm{FL}$ & $\begin{array}{l}1 \frac{1}{2} \times \mathrm{HQW} \\
\text { minimum } \$ 3,400 \\
\text { wages in } 2 \text { gtrs }\end{array}$ & 1/26 HQW & $\$ 32$ & $\$ 275$ & $\begin{array}{l}8 \times \text { federal } \\
\text { hourly mini- } \\
\text { mum wage }\end{array}$ & $25 \%$ BPW & $9-23$ & $\begin{array}{l}20 \text { weeks or } \\
\$ 1,500 \text { in any } \\
\text { qtr }\end{array}$ & $\$ 8,500$ & $\begin{array}{l}1.03 \% \\
5.40 \% \\
2.70 \%\end{array}$ \\
\hline GA & $\begin{array}{l}\text { Wages in } 2 \text { qtrs \& } \\
150 \% \times \text { HQW } \text { or } \\
\text { HQW divided by } \\
21 \text { for WBA w/ } \\
\text { total earnings at } \\
\text { least } 40 \times \text { WBA }\end{array}$ & $\begin{array}{l}1 / 42 \text { of wages in } \\
\text { highest } 2 \text { qtrs or } \\
1 / 21 \mathrm{HQW}\end{array}$ & $\$ 44$ & $\$ 330$ & $\$ 50$ & $\begin{array}{l}\text { Lesser of } 26 \\
\times \text { WBA or } 1 / 4 \\
\text { BPW }\end{array}$ & $6-26$ & $\begin{array}{l}20 \text { weeks or } \\
\$ 1,500 \text { in any } \\
\text { qtr }\end{array}$ & $\$ 8,500$ & $\begin{array}{l}0.025 \% \\
5.40 \% \\
2.62 \%\end{array}$ \\
\hline $\mathrm{HI}$ & $\begin{array}{l}26 \times \text { WBA; wages } \\
\text { in } 2 \text { qtrs }\end{array}$ & 1/21 HQW & $\$ 5$ & $\$ 523$ & $\$ 150$ & $\begin{array}{l}\text { Uniform } \\
\text { duration }\end{array}$ & 26 & Any size & $\$ 38,800$ & $\begin{array}{l}1.20 \% \\
5.40 \% \\
4.00 \% \\
\end{array}$ \\
\hline
\end{tabular}




\begin{tabular}{|c|c|c|c|c|c|c|c|c|c|c|}
\hline & \multicolumn{7}{|c|}{ BENEFITS } & \multirow{3}{*}{$\begin{array}{l}\text { COVERAGE } \\
\text { Size of Payroll } \\
\text { (Length of } \\
\text { Employment/ } \\
\text { Wages Paid) }^{6}\end{array}$} & \multicolumn{2}{|c|}{ TAXES } \\
\hline & \multirow{2}{*}{$\begin{array}{l}\text { Earnings/ } \\
\text { Employment } \\
\text { Needed in Base } \\
\text { Period to Qualify }\end{array}$} & \multirow{2}{*}{$\begin{array}{l}\text { Computation of } \\
\text { Weekly Benefit } \\
\text { Amount }\end{array}$} & \multicolumn{2}{|c|}{$\begin{array}{l}\text { Weekly Benefit } \\
\text { Amount }^{2}\end{array}$} & \multirow{2}{*}{$\begin{array}{l}\text { Weekly } \\
\text { Earnings } \\
\text { Disregarded }^{3}\end{array}$} & \multirow{2}{*}{$\begin{array}{l}\text { Calculation of } \\
\text { Number of } \\
\text { Benefit } \\
\text { Weeks }^{4}\end{array}$} & \multirow{2}{*}{$\begin{array}{l}\text { Number } \\
\text { of } \\
\text { Benefit } \\
\text { Weeks }^{5}\end{array}$} & & \multirow{2}{*}{$\begin{array}{l}2012 \\
\text { Wages } \\
\text { Subject } \\
\text { to Tax }\end{array}$} & \multirow{2}{*}{$\begin{array}{c}2011 \\
\text { Minimum \& } \\
\text { Maximum } \\
\text { Rates }^{7} \\
\text { New } \\
\text { Employer }^{\text {Rate }}{ }^{8} \\
\end{array}$} \\
\hline & & & $\begin{array}{l}\text { Mini- } \\
\text { mum }\end{array}$ & $\begin{array}{l}\text { Maxi- } \\
\text { Mum }\end{array}$ & & & & & & \\
\hline ID & $\begin{array}{l}11 / 4 \times \mathrm{HQW} \text {; not } \\
\text { less than the } \\
\text { minimum } \\
\text { qualifying wages } \\
\text { in } 1 \text { qtr } \$ 1,872\end{array}$ & 1/26 HQW & $\$ 72$ & $\$ 343$ & $1 / 2$ WBA & $\begin{array}{l}\text { Weighted } \\
\text { schedule of } \\
\text { BPW to HQW }\end{array}$ & $10-26$ & $\begin{array}{l}20 \text { weeks or } \\
\$ 1,500 \text { in any } \\
\text { qtr }\end{array}$ & & $\begin{array}{l}0.96 \% \\
6.80 \% \\
3.36 \% \\
\end{array}$ \\
\hline IL & $\begin{array}{l}\$ 1,600 ; \$ 440 \\
\text { outside HQ }\end{array}$ & $\begin{array}{l}47 \% \text { of claimant's } \\
\text { AWW in } 2 \text { highest } \\
\text { qtrs }\end{array}$ & $\$ 51-77$ & $\begin{array}{l}\$ 403- \\
549\end{array}$ & $1 / 2$ WBA & $\begin{array}{l}\text { Uniform } \\
\text { duration }\end{array}$ & 25 & $\begin{array}{l}20 \text { weeks or } \\
\$ 1,500 \text { in any } \\
\text { qtr }\end{array}$ & & $\begin{array}{l}0.70 \% \\
8.40 \% \\
3.80 \%\end{array}$ \\
\hline IN & $\begin{array}{l}11 / 2 \times H Q W \\
\text { totaling at least } \\
\$ 2,500 \text { in last } 2 \\
\text { qtrs; not less than } \\
\$ 4,200 \text { in BP }\end{array}$ & $\begin{array}{l}5 \% \text { of } 1^{\text {st }} \$ 2,000 \text { of } \\
\text { wage credits in } \mathrm{HQ} \text {, } \\
4 \% \text { of remaining } \\
\mathrm{HQW} \text { credits; wage } \\
\text { credits limited to } \\
\$ 9,250\end{array}$ & $\$ 50$ & $\$ 390$ & $\begin{array}{l}\text { Greater of } \\
\$ 3 \text { or } 20 \% \\
\text { WBA from } \\
\text { other than } \\
\text { BP } \\
\text { employers }\end{array}$ & $\begin{array}{l}\text { Lesser of } \\
28 \% \text { BPW or } \\
26 \times \text { WBA }\end{array}$ & $8-26$ & $\begin{array}{l}20 \text { weeks or } \\
\$ 1,500 \text { in any } \\
\text { qtr }\end{array}$ & $\$ 9,500$ & $\begin{array}{l}0.70 \% \\
9.50 \% \\
2.50 \%\end{array}$ \\
\hline IA & $\begin{array}{l}11 / 4 \times \mathrm{HQW} ; 3.5 \% \\
\text { of the statewide } \\
\mathrm{AAW} \text { in } \mathrm{HQ} ; 1 / 2 \\
\mathrm{HQW} \text { in qtr not } \\
\text { the HQ }\end{array}$ & $\begin{array}{l}1 / 23 \mathrm{HQW} \text { or } 1 / 19 \\
-1 / 22 \mathrm{HQW} \text { for } \\
\text { claimants with deps }\end{array}$ & $\$ 57-70$ & $\begin{array}{l}\$ 385- \\
473\end{array}$ & $1 / 4$ WBA & 1/3 BPW & & $\begin{array}{l}20 \text { weeks or } \\
\$ 1,500 \text { in any } \\
\text { qtr }\end{array}$ & $\$ 25,300$ & $\begin{array}{l}0.00 \% \\
9.00 \% \\
1.90 \%\end{array}$ \\
\hline KS & $\begin{array}{l}30 \times \text { WBA; wages } \\
\text { in } 2 \text { qtrs }\end{array}$ & $4.25 \% \mathrm{HQW}$ & $\$ 111$ & $\$ 444$ & $25 \%$ WBA & $1 / 3 \mathrm{~B}$ & $10-$ & $\begin{array}{l}20 \text { weeks or } \\
\$ 1,500 \text { in any } \\
\text { qtr }\end{array}$ & $\$ 8,000$ & $\begin{array}{l}0.11 \% \\
7.40 \% \\
4.00 \%\end{array}$ \\
\hline KY & $\begin{array}{l}11 / 2 \times \text { HQW; } 8 \times \\
\text { WBA in last } 2 \\
\text { qtrs; } \$ 750 \text { outside } \\
\mathrm{HQ}\end{array}$ & $1.923 \% \mathrm{BPW}$ & $\$ 39$ & $\$ 415$ & $1 / 5$ wages & 1/3 BPW & $15-26$ & $\begin{array}{l}20 \text { weeks or } \\
\$ 1,500 \text { in any } \\
\text { qtr }\end{array}$ & $\$ 9,000$ & $\begin{array}{l}1.00 \% \\
10.00 \% \\
2.70 \%\end{array}$ \\
\hline LA & $\begin{array}{l}\$ 1,200 \text { total } \\
\text { BPW; wages in } 2 \\
\text { qtrs; } 1 \frac{1}{2} \times \mathrm{HQW}\end{array}$ & $\begin{array}{l}1 / 25 \text { of the avg of } \\
\text { wages in } 4 \text { qtrs of } \\
\text { BP } \times 1.05 \times 1.15\end{array}$ & $\$ 10$ & $\$ 247$ & $\begin{array}{l}\text { Lesser of } 1 / 2 \\
\text { WBA or } \$ 50\end{array}$ & $\begin{array}{l}\text { Uniform } \\
\text { duration }\end{array}$ & 26 & $\begin{array}{l}20 \text { weeks or } \\
\$ 1,500 \text { in any } \\
\text { qtr }\end{array}$ & $\$ 7,700$ & $\begin{array}{l}0.11 \% \\
6.20 \% \\
\text { InAvg } \%\end{array}$ \\
\hline ME & $\begin{array}{l}2 \times \text { AWW in } 2 \\
\text { different BP qtrs; } \\
\text { total BPW = } 6 x \\
\text { AWW }\end{array}$ & $\begin{array}{l}1 / 22 \text { avg wages } \\
\text { paid in } 2 \text { highest } \\
\text { qtrs of } B P+\$ 10 \\
\text { per dep up to } 1 / 2 \\
\text { WBA }\end{array}$ & $\$ 64-96$ & $\begin{array}{l}\$ 366- \\
549\end{array}$ & $\$ 25$ & 1/3 BPW & $22-26$ & $\begin{array}{l}20 \text { weeks or } \\
\$ 1,500 \text { in any } \\
\text { qtr }\end{array}$ & $\$ 12,000$ & $\begin{array}{l}0.86 \% \\
7.95 \% \\
3.02 \%\end{array}$ \\
\hline MD & $\begin{array}{l}11 / 2 \times \mathrm{HQW} ; \\
\$ 576.01 \text { in } \mathrm{HQ} \\
\$ 1,776.01 \text { in } \mathrm{HQ} \\
\text { Eff. } 3 / 4 / 12\end{array}$ & $\begin{array}{l}1 / 24 \mathrm{HQW}+\$ 8 \text { per } \\
\text { dep up to } 5 \text { deps }\end{array}$ & & $\$ 430$ & $\leq \$ 50$ & $\begin{array}{l}\text { Uniform } \\
\text { duration }\end{array}$ & 26 & Any size & $\$ 8,500$ & $\begin{array}{l}2.20 \% \\
13.50 \% \\
2.60 \%\end{array}$ \\
\hline MA & $\begin{array}{l}30 \times \text { WBA; } \\
\$ 3,500 \text { minimum }\end{array}$ & $\begin{array}{l}50 \% \text { AWW }+\$ 25 \\
\text { per dep up to } 1 / 2 \\
\text { WBA }\end{array}$ & $\$ 33-49$ & $\begin{array}{l}\$ 653- \\
979\end{array}$ & 1/3 WBA & $36 \%$ BPW & $10-30$ & $\begin{array}{l}13 \text { weeks or } \\
\$ 1,500 \text { in any } \\
\text { qtr }\end{array}$ & $\$ 14,000$ & $\begin{array}{l}1.26 \% \\
12.27 \% \\
2.83 \%\end{array}$ \\
\hline MI & $\begin{array}{l}11 / 2 \times \mathrm{HQW} \text {; at } \\
\text { least } \$ 2,871 \text { in } \\
\mathrm{HQ} \text {; or wages in } 2 \\
\text { or more BP qtrs } \\
\text { totaling at least } \\
\$ 17,206.80 \text { ( } 20 \times \\
\text { State AWW of } \\
\$ 860,34)\end{array}$ & $\begin{array}{l}\text { 4.1\% HQW }+\$ 6 \text { for } \\
\text { each dep up to } 5\end{array}$ & $\begin{array}{l}\$ 117- \\
147\end{array}$ & $\$ 362$ & $\begin{array}{l}\text { WBA } \\
\text { reduced by } \\
40 \phi \text { for } \\
\text { every } \$ 1 \\
\text { earned. } \\
\text { Earnings } \\
\text { and benefits } \\
\text { limited to } 1.6 \\
x \text { WBA } \\
\end{array}$ & $\begin{array}{l}43 \% \text { BP } \\
\text { wages }\end{array}$ & $14-20$ & $\begin{array}{l}20 \text { weeks or } \\
\$ 1,000 \text { in CY }\end{array}$ & $\$ 9,500$ & $\begin{array}{l}0.06 \% \\
10.30 \% \\
2.70 \%\end{array}$ \\
\hline $\mathrm{MN}$ & $\begin{array}{l}\text { At least } \$ 1,000 \text { in } \\
\mathrm{HQ} ; \$ 250 \text { outside } \\
\mathrm{HQ}\end{array}$ & $\begin{array}{l}\text { Higher of } 50 \% \text { of } \\
1 / 13 \mathrm{HQW} \text { up to } \\
43 \% \text { of State AWW } \\
\text { or } 50 \% \text { of } 1 / 52 \\
\text { BPW up to } 662 / 3 \% \\
\text { of State AWW }\end{array}$ & $\$ 38$ & $\begin{array}{l}\$ 385- \\
597\end{array}$ & $\begin{array}{l}\text { WBA } \\
\text { reduced by } \\
55 \phi \text { for } \\
\text { every } \$ 1 \\
\text { earned }\end{array}$ & $\begin{array}{l}\text { Lesser of } 1 / 3 \\
\text { BPW or } 26 x \\
\text { WBA }\end{array}$ & $11-26$ & Any size & $\$ 28,000$ & $\begin{array}{l}0.50 \% \\
9.40 \% \\
2.91 \%\end{array}$ \\
\hline MS & $\begin{array}{l}40 \times \text { WBA; } \$ 780 \\
\text { in HQ; wages in } 2 \\
\text { qtrs }\end{array}$ & 1/26 HQW & $\$ 30$ & $\$ 235$ & $\$ 40$ & $\begin{array}{l}\text { Lesser of } 1 / 3 \\
\text { BPW or } 26 x \\
\text { WBA }\end{array}$ & $13-26$ & $\begin{array}{l}20 \text { weeks or } \\
\$ 1,500 \text { in any } \\
\text { qtr }\end{array}$ & $\$ 14,000$ & $\begin{array}{l}0.85 \% \\
5.40 \% \\
2.70 \%\end{array}$ \\
\hline
\end{tabular}




\begin{tabular}{|c|c|c|c|c|c|c|c|c|c|c|}
\hline & \multicolumn{7}{|c|}{ BENEFITS } & \multirow{3}{*}{$\begin{array}{l}\text { COVERAGE } \\
\text { Size of Payroll } \\
\text { (Length of }^{\text {Employment/ }} \\
\text { Wages Paid) }^{6}\end{array}$} & \multicolumn{2}{|c|}{ TAXES } \\
\hline & \multirow{2}{*}{$\begin{array}{c}\text { Earnings/ } \\
\text { Employment } \\
\text { Needed in Base } \\
\text { Period to Qualify }\end{array}$} & \multirow{2}{*}{$\begin{array}{l}\text { Computation of } \\
\text { Weekly Benefit } \\
\text { Amount }\end{array}$} & \multicolumn{2}{|c|}{$\begin{array}{l}\text { Weekly Benefit } \\
\text { Amount }^{2}\end{array}$} & \multirow{2}{*}{$\begin{array}{c}\text { Weekly } \\
\text { Earnings } \\
\text { Disregarded }^{3}\end{array}$} & \multirow{2}{*}{$\begin{array}{l}\text { Calculation of } \\
\text { Number of } \\
\text { Benefit } \\
\text { Weeks }^{4}\end{array}$} & \multirow{2}{*}{$\begin{array}{l}\text { Number } \\
\text { of } \\
\text { Benefit } \\
\text { Weeks }^{5}\end{array}$} & & \multirow{2}{*}{$\begin{array}{c}2012 \\
\text { Wages } \\
\text { Subject } \\
\text { to Tax }\end{array}$} & \multirow{2}{*}{$\begin{array}{c}2011 \\
\text { Minimum \& } \\
\text { Maximum } \\
\text { Rates }^{7} \\
\text { New } \\
\text { Employer } \\
\text { Rate }^{8}\end{array}$} \\
\hline & & & $\begin{array}{l}\text { Mini- } \\
\text { mum }\end{array}$ & $\begin{array}{l}\text { Maxi- } \\
\text { Mum }\end{array}$ & & & & & & \\
\hline MO & $\begin{array}{l}11 / 2 \times \mathrm{HQW} ; \\
\$ 1,500 \text { in } 1 \mathrm{qtr} \text {; or } \\
\text { wages in } 2 \text { qtrs } \\
\text { of } \mathrm{BP}=1 \frac{1}{2} \\
\text { maximum taxable } \\
\text { wage base }\end{array}$ & $\begin{array}{l}4 \% \text { of the avg of } \\
\text { the } 2 \mathrm{HQWs}\end{array}$ & $\$ 35$ & $\$ 320$ & $\begin{array}{l}\text { Greater of } \\
20 \% \text { WBA or } \\
\$ 20\end{array}$ & $\begin{array}{l}\text { Lesser of } 20 \\
\times \text { WBA or } 1 / 3 \\
\text { BPW }\end{array}$ & $8-20$ & $\begin{array}{l}20 \text { weeks or } \\
\$ 1,500 \text { in any } \\
\text { qtr }\end{array}$ & & $\begin{array}{l}0.00 \% \\
9.75 \% \\
3.51 \%\end{array}$ \\
\hline MT & $\begin{array}{l}\text { BPW }=11 / 2 \times \\
\text { HQW and total } \\
\text { wages } \geq 7 \% \text { of } \\
\text { AAW or BPW } \geq \\
50 \% \text { of AAW }\end{array}$ & $\begin{array}{l}1 \% \text { BPW or } 1.9 \% \\
\text { wages in } 2 \mathrm{HQs}\end{array}$ & $\$ 123$ & $\$ 431$ & $\begin{array}{l}1 / 2 \text { wages in } \\
\text { excess of } 1 / 4 \\
\text { WBA }\end{array}$ & $\begin{array}{l}\text { Weighted } \\
\text { schedule of } \\
\text { BPW to HQW }\end{array}$ & $8-28$ & $\begin{array}{l}\$ 1,000 \text { in } \\
\text { current or } \\
\text { preceding } \\
\text { year }\end{array}$ & $\$ 27,000$ & $\begin{array}{l}0.82 \% \\
6.12 \% \\
\text { InAvg } \%\end{array}$ \\
\hline NE & $\begin{array}{l}\$ 3,868 \text { in BP; } \\
\$ 1,850 \text { in } \mathrm{HQW} \\
\text { and wages in at } \\
\text { least } 1 \text { other qtr } \\
\text { of } \$ 800\end{array}$ & $1 / 2$ AWW & $\$ 70$ & $\$ 354$ & $1 / 4 \mathrm{WBA}$ & $\begin{array}{l}\text { Lesser of } 26 \\
\times \text { WBA or } 1 / 3 \\
\text { BPW }\end{array}$ & $14-26$ & $\begin{array}{l}20 \text { weeks or } \\
\$ 1,500 \text { in any } \\
\text { qtr }\end{array}$ & $\$ 9,000$ & $\begin{array}{l}0.00 \% \\
8.66 \% \\
2.50 \%\end{array}$ \\
\hline NV & $\begin{array}{l}1 \frac{1}{2} \times \mathrm{HQW} \text { in } \mathrm{BP} \\
\text { and } \$ 400 \text { in } \mathrm{HQ} \text {; } \\
\text { or wages in } 3 \text { of } 4 \\
\text { qtrs in } \mathrm{BP} \text { and } \\
\$ 400 \text { in } \mathrm{HQ}\end{array}$ & 1/25 HQW & $\$ 16$ & $\$ 396$ & $1 / 4$ wages & $\begin{array}{l}\text { Lesser of } 26 \\
\times \text { WBA or } 1 / 3 \\
\text { BPW }\end{array}$ & & $\begin{array}{l}\$ 225 \text { in any } \\
\text { qtr }\end{array}$ & $\$ 26,400$ & $\begin{array}{l}0.25 \% \\
5.40 \% \\
2.95 \%\end{array}$ \\
\hline $\mathrm{NH}$ & $\begin{array}{l}\$ 2,800 ; \$ 1,400 \text { in } \\
\text { each of } 2 \text { qtrs }\end{array}$ & $\begin{array}{l}1 \%-1.1 \% \text { annual } \\
\text { wages }\end{array}$ & $\$ 32$ & $\$ 427$ & $30 \%$ WBA & $\begin{array}{l}\text { Uniform } \\
\text { duration }\end{array}$ & & $\begin{array}{l}20 \text { weeks or } \\
\$ 1,500 \text { in any } \\
\text { qtr }\end{array}$ & $\$ 14,000$ & $\begin{array}{l}0.01 \% \\
7.00 \% \\
3.70 \%\end{array}$ \\
\hline NJ & $\begin{array}{l}20 \text { weeks } \\
\text { employment at } 20 \\
x \text { State hourly } \\
\text { minimum wage or } \\
1,000 \times \text { State } \\
\text { hourly minimum } \\
\text { wage }\end{array}$ & $\begin{array}{l}60 \% \text { of claimant's } \\
\text { AWW + DA }\end{array}$ & $\begin{array}{l}\$ 87- \\
100\end{array}$ & $\$ 611$ & $\begin{array}{l}\text { Greater of } \\
20 \% \text { WBA } \\
\$ 5\end{array}$ & $\begin{array}{l}100 \% \text { base } \\
\text { weeks } \\
\text { worked in } \\
\text { base year up } \\
\text { to } 26\end{array}$ & $1-26$ & $\begin{array}{l}\$ 1,000 \text { in any } \\
\text { year }\end{array}$ & $\$ 30,300$ & $\begin{array}{l}0.50 \% \\
5.80 \% \\
2.80 \%\end{array}$ \\
\hline NM & $\begin{array}{l}\$ 1,749.54 \text { in } \\
\text { HQW and wages } \\
\text { in at least } 1 \text { other } \\
\text { qtr }\end{array}$ & $\begin{array}{l}53.5 \% \text { of AWW } \\
\text { paid in BP qtr } \\
\text { in which wages } \\
\text { were highest }\end{array}$ & $\begin{array}{l}\$ 74- \\
111\end{array}$ & $\begin{array}{l}\$ 397- \\
447\end{array}$ & 1/5 WBA & $\begin{array}{l}\text { Lesser of } 26 \\
\times \text { WBA or } \\
60 \% \text { BPW }\end{array}$ & $16-26$ & $\begin{array}{l}20 \text { weeks or } \\
\$ 450 \text { in any } \\
\text { qtr }\end{array}$ & $\$ 22,400$ & $\begin{array}{l}0.05 \% \\
5.40 \% \\
2.00 \%\end{array}$ \\
\hline NY & $\begin{array}{l}11 \frac{1}{2} \times \mathrm{HQW} ; \\
\$ 1,600 \text { in } \mathrm{HQ}\end{array}$ & $\begin{array}{l}1 / 26 \mathrm{HQW} \text { unless } \\
\mathrm{HQW} \leq \$ 3,575 \\
\text { then, } 1 / 25 \mathrm{HQW}\end{array}$ & & & $\begin{array}{l}\text { None. All } \\
\text { employment } \\
\text { affects WBA }\end{array}$ & $\begin{array}{l}\text { Uniform } \\
\text { duration }\end{array}$ & 26 & $\begin{array}{l}\$ 300 \text { in any } \\
\text { qtr }\end{array}$ & $\$ 8,500$ & $\begin{array}{l}1.50 \% \\
9.90 \% \\
4.10 \% \\
\end{array}$ \\
\hline NC & $\begin{array}{l}6 \times \text { AWW; wages } \\
\text { in } 2 \text { qtrs of BP }\end{array}$ & 1/26 HQW & & $\$ 522$ & $\begin{array}{l}10 \% \mathrm{AWW} \\
\text { in } \mathrm{HQ}\end{array}$ & $\begin{array}{l}(B P W / \\
\text { HQW)x } \\
82 / 3\end{array}$ & $13-26$ & $\begin{array}{l}20 \text { weeks or } \\
\$ 1,500 \text { in any } \\
\text { qtr }\end{array}$ & $\$ 20,400$ & $\begin{array}{l}0.24 \% \\
6.84 \% \\
1.20 \%\end{array}$ \\
\hline ND & $\begin{array}{l}11 / 2 \times \text { HQW; } \\
\text { wages in } 2 \text { qtrs }\end{array}$ & $\begin{array}{l}1 / 65 \text { of wages in } 2 \\
\mathrm{HQs}+1 / 2 \text { wages in } \\
3^{\text {rd }} \mathrm{HQ}\end{array}$ & $\$ 43$ & $\$ 470$ & $60 \%$ WBA & $\begin{array}{l}\text { Weighted } \\
\text { schedule of } \\
\text { BPW to HQW }\end{array}$ & $12-26$ & $\begin{array}{l}20 \text { weeks or } \\
\$ 1,500 \text { in any } \\
\text { qtr }\end{array}$ & $\$ 27,900$ & $\begin{array}{l}0.20 \% \\
10.00 \% \\
1.37 \%\end{array}$ \\
\hline $\mathrm{OH}$ & $\begin{array}{l}20 \text { weeks } \\
\text { employment with } \\
\text { wages averaging } \\
27.5 \% \text { of State } \\
\text { AWW; wages in } 2 \\
\text { qtrs }\end{array}$ & $\begin{array}{l}1 / 2 \text { claimant's AWW } \\
\text { +DA of } \$ 1-\$ 139 \\
\text { based on } \\
\text { claimant's AWW } \\
\text { and number of dep }\end{array}$ & $\$ 111$ & $\begin{array}{l}\$ 400- \\
539\end{array}$ & 1/5 WBA & $\begin{array}{l}20 \times \text { WBA + } \\
1 \times \text { WBA for } \\
\text { each quali- } \\
\text { fying week in } \\
\text { excess of } 20\end{array}$ & $20-26$ & $\begin{array}{l}20 \text { weeks or } \\
\$ 1,500 \text { in any } \\
\text { qtr }\end{array}$ & $\$ 9,000$ & $\begin{array}{l}0.70 \% \\
9.60 \% \\
2.70 \%\end{array}$ \\
\hline OK & $\begin{array}{l}\$ 1,500 \text { and } 1 \frac{1}{2} x \\
\text { HQW }\end{array}$ & 1/23 HQW & $\$ 16$ & $\$ 368$ & $\$ 100$ & $\begin{array}{l}\text { Weighted } \\
\text { schedule of } \\
\text { BPW to HQW }\end{array}$ & $18-26$ & $\begin{array}{l}20 \text { weeks or } \\
\$ 1,500 \text { in any } \\
\text { qtr }\end{array}$ & $\$ 19,100$ & $\begin{array}{l}0.30 \% \\
7.50 \% \\
1.00 \%\end{array}$ \\
\hline OR & $\begin{array}{l}\text { BPW } \geq \$ 1,000 \\
\text { and BPW } \geq 1 \frac{1}{2} x \\
\text { HQW; or } 500 \\
\text { hours of } \\
\text { employment in } \\
\text { BP }\end{array}$ & $1.25 \% \mathrm{BPW}$ & $\$ 118$ & $\$ 507$ & $\begin{array}{l}1 / 3 \text { WBA or } \\
10 \times \$ 8.50 \\
\text { (i.e., the } \\
\text { State } \\
\text { minimum } \\
\text { wage) } \\
\end{array}$ & $\begin{array}{l}\text { Lesser of } 26 \\
\times \text { WBA or } 1 / 3 \\
\text { BPW }\end{array}$ & $3-26$ & $\begin{array}{l}18 \text { weeks or } \\
\$ 1,000 \text { in any } \\
\text { qtr }\end{array}$ & $\$ 33,000$ & $\begin{array}{l}2.20 \% \\
5.40 \% \\
3.30 \%\end{array}$ \\
\hline
\end{tabular}




\begin{tabular}{|c|c|c|c|c|c|c|c|c|c|c|}
\hline & \multicolumn{7}{|c|}{ BENEFITS } & \multirow{3}{*}{$\begin{array}{l}\text { COVERAGE } \\
\text { Size of Payroll } \\
\text { (Length of } \\
\text { Employment/ } \\
\text { Wages Paid) }^{6}\end{array}$} & \multicolumn{2}{|c|}{ TAXES } \\
\hline & \multirow{2}{*}{$\begin{array}{c}\text { Earnings/ } \\
\text { Employment } \\
\text { Needed in Base } \\
\text { Period to Qualify }{ }^{1}\end{array}$} & \multirow{2}{*}{$\begin{array}{l}\text { Computation of } \\
\text { Weekly Benefit } \\
\text { Amount }\end{array}$} & \multicolumn{2}{|c|}{$\begin{array}{l}\text { Weekly Benefit } \\
\text { Amount }^{2}\end{array}$} & \multirow{2}{*}{$\begin{array}{c}\text { Weekly } \\
\text { Earnings } \\
\text { Disregarded }^{3}\end{array}$} & \multirow{2}{*}{$\begin{array}{l}\text { Calculation of } \\
\text { Number of } \\
\text { Benefit } \\
\text { Weeks }^{4}\end{array}$} & \multirow{2}{*}{$\begin{array}{l}\text { Number } \\
\text { of } \\
\text { Benefit } \\
\text { Weeks }^{5}\end{array}$} & & \multirow{2}{*}{$\begin{array}{c}2012 \\
\text { Wages } \\
\text { Subject } \\
\text { to Tax }\end{array}$} & \multirow{2}{*}{$\begin{array}{c}2011 \\
\text { Minimum \& } \\
\text { Maximum } \\
\text { Rates }^{7} \\
\text { New } \\
\text { Employer }^{\text {Rate }}{ }^{8} \\
\end{array}$} \\
\hline & & & $\begin{array}{l}\text { Mini- } \\
\text { mum }\end{array}$ & $\begin{array}{l}\text { Maxi- } \\
\text { Mum }\end{array}$ & & & & & & \\
\hline PA & $\begin{array}{l}\$ 800 \text { in } \mathrm{HQ} ; \\
\$ 1,320 \text { in } \mathrm{BP} ; \text { at } \\
\text { least } 20 \% \text { of } \\
\text { BPW outside } \mathrm{HQ} ; \\
16 \text { credit weeks in } \\
\text { BP }\end{array}$ & $\begin{array}{l}1 / 23-1 / 25 \mathrm{HQW}+\$ 5 \\
\text { for } 1 \mathrm{dep} ; \$ 3 \text { for } 2^{\text {nd }} \\
\text { dep }\end{array}$ & $\$ 35-43$ & $\begin{array}{l}\$ 573- \\
581\end{array}$ & $\begin{array}{l}\text { Greater of } \\
\$ 6 \text { or } 40 \% \\
\text { WBA }\end{array}$ & $\begin{array}{l}\text { At least } 16 \\
\text { credit weeks } \\
\text { for minimum, } \\
18 \text { for } \\
\text { maximum }\end{array}$ & 16 or 26 & Any size & & $\begin{array}{l}2.68 \% \\
10.82 \% \\
3.70 \%\end{array}$ \\
\hline PR & $\begin{array}{l}40 \times \text { WBA; } \$ 280 \\
\text { minimum; } \$ 77 \text { in } \\
1 \text { qtr; wages in } 2 \\
\text { qtrs }\end{array}$ & 1/11-1/26 HQW & $\$ 7$ & $\$ 133$ & WBA & $\begin{array}{l}\text { Uniform } \\
\text { duration }\end{array}$ & 26 & Any size & $\$ 7,000$ & $\begin{array}{l}2.40 \% \\
5.40 \% \\
3.30 \%\end{array}$ \\
\hline RI & $\begin{array}{l}11 / 2 \times \text { HQW. } 200 \\
\times \text { minimum hourly } \\
\text { wage in } 1 \text { qtr and } \\
400 \times \text { minimum } \\
\text { hourly wage in } \\
\text { BP; or } 1,200 x \\
\text { minimum hourly } \\
\text { wage in BP }\end{array}$ & $\begin{array}{l}4.62 \% \mathrm{HQW}+ \\
\text { greater of } \$ 15 \text { or } \\
5 \% \text { of the benefit } \\
\text { rate per dep, } \\
\text { capped at the } \\
\text { greater of } \$ 50 \text { or } \\
25 \% \text { of WBA }\end{array}$ & $\begin{array}{l}\$ 68- \\
118\end{array}$ & $\begin{array}{l}\$ 566- \\
707\end{array}$ & 1/5 WBA & $36 \%$ BPW & $8-26$ & & $\begin{array}{l}\$ 19,600 \\
\text { or } \\
\$ 21,100 \\
\text { for high } \\
\text { tax } \\
\text { group } \\
\text { em- } \\
\text { poyers } \\
\end{array}$ & $\begin{array}{l}1.69 \% \\
9.79 \% \\
2.46 \%\end{array}$ \\
\hline SC & $\begin{array}{l}11 / 2 \times \mathrm{HQW} ; \\
\$ 4,455 \text { minimum; } \\
\$ 1,092 \text { in } \mathrm{HQ}\end{array}$ & 1/20 HQW & $\$ 42$ & $\$ 326$ & $1 / 4$ WBA & $1 / 3 \mathrm{BP}$ & $13-2$ & $\begin{array}{l}20 \text { weeks or } \\
\$ 1,500 \text { in any } \\
\text { qtr }\end{array}$ & $\$ 12,000$ & $\begin{array}{l}0.10 \% \\
11.28 \% \\
2.24 \%\end{array}$ \\
\hline SD & $\begin{array}{l}\$ 728 \text { in } \mathrm{HQ} ; 20 \mathrm{x} \\
\text { WBA outside } \mathrm{HQ}\end{array}$ & 1/26 HQW & $\$ 28$ & $\$ 323$ & $\begin{array}{l}1 / 4 \text { wages } \\
\text { over } \$ 25\end{array}$ & & $15-26$ & $\begin{array}{l}20 \text { weeks or } \\
\$ 1,500 \text { in any } \\
\text { qtr }\end{array}$ & $\$ 12,000$ & $\begin{array}{l}0.00 \% \\
9.50 \% \\
1.20 \%\end{array}$ \\
\hline TN & $\begin{array}{l}40 \times \text { WBA; } \\
\$ 780.01 \text { avg } \\
\text { wages in highest } \\
2 \text { qtrs; BPW } \\
\text { outside HQW } \geq \\
\text { the lesser of } 6 \times \\
\text { WBA or } \$ 900\end{array}$ & $\begin{array}{l}1 / 26 \text { of avg } 2 \\
\text { highest qtrs }\end{array}$ & $\$ 30-80$ & $\begin{array}{l}\$ 275- \\
325\end{array}$ & $\begin{array}{l}\text { Greater of } \\
\$ 50 \text { or } 1 / 4 \\
\text { WBA }\end{array}$ & $\begin{array}{l}\text { Lesser of } 26 \\
\times \text { WBA or } 1 / 4 \\
\text { BPW }\end{array}$ & $13-26$ & $\begin{array}{l}20 \text { weeks or } \\
\$ 1,500 \text { in any } \\
\text { qtr }\end{array}$ & $\$ 9,000$ & $\begin{array}{l}0.50 \% \\
10.00 \% \\
2.70 \%\end{array}$ \\
\hline $\mathrm{TX}$ & $\begin{array}{l}37 \times \text { WBA; wages } \\
\text { in at least } 2 \text { qtrs }\end{array}$ & 1/25 HQW & $\$ 61$ & $\$ 426$ & $\begin{array}{l}\text { Greater of } \\
\$ 5 \text { or } 1 / 4 \\
\text { WBA }\end{array}$ & $27 \%$ BPW & $10-26$ & $\begin{array}{l}20 \text { weeks or } \\
\$ 1,500 \text { in any } \\
\text { qtr }\end{array}$ & $\$ 9,000$ & $\begin{array}{l}0.78 \% \\
8.25 \% \\
2.70 \%\end{array}$ \\
\hline UT & $\begin{array}{l}\$ 3,200 \text { in BP and } \\
1 \frac{1}{2} \times \mathrm{HQW}\end{array}$ & $1 / 26 \mathrm{HQW}-\$ 5$ & & $\$ 467$ & $30 \%$ WBA & $\begin{array}{l}27 \% \\
\text { BPW/WBA }\end{array}$ & $10-26$ & Any size & $\$ 29,500$ & $\begin{array}{l}0.40 \% \\
9.40 \% \\
\text { InAvg } \%\end{array}$ \\
\hline VT & $\begin{array}{l}\$ 2,203 \mathrm{HQW}+ \\
\mathrm{BPW} \geq 40 \% \\
\mathrm{HQW}\end{array}$ & $\begin{array}{l}\text { Wages in the } 2 \\
\text { highest qtrs } \\
\text { divided by } 45\end{array}$ & & $\$ 425$ & $\begin{array}{l}\text { Greater of } \\
30 \% \text { WBA or } \\
\$ 40\end{array}$ & $\begin{array}{l}\text { Lesser of } 26 \\
\times \text { WBA or } \\
46 \% \text { BPW }\end{array}$ & $21-26$ & $\begin{array}{l}20 \text { weeks or } \\
\$ 1,500 \text { in any } \\
\text { qtr }\end{array}$ & $\$ 16,000$ & $\begin{array}{l}1.30 \% \\
8.40 \% \\
1.00 \%\end{array}$ \\
\hline VA & $\begin{array}{l}\$ 2,700 \text { in highest } \\
2 \text { qtrs of BP }\end{array}$ & $\begin{array}{l}1 / 50 \text { of the } 2 \\
\text { highest qtrs }\end{array}$ & $\$ 54$ & $\$ 378$ & $\$ 50$ & $\begin{array}{l}\text { See table in } \\
\text { law }\end{array}$ & $12-26$ & $\begin{array}{l}20 \text { weeks or } \\
\$ 1,500 \text { in any } \\
\text { qtr }\end{array}$ & $\$ 8,000$ & $\begin{array}{l}0.77 \% \\
6.87 \% \\
3.17 \%\end{array}$ \\
\hline VI & $\begin{array}{l}11 / 2 \times \mathrm{HQW} \text { and } \\
\$ 858 \text { in } \mathrm{HQ} \text {; or } \\
\$ 858 \text { in } \mathrm{HQ} \text { and } \\
39 \times \text { WBA in } \mathrm{BP}\end{array}$ & & $\$ 33$ & $\$ 495$ & $\begin{array}{l}25 \% \text { in } \\
\text { excess of } \\
\$ 15\end{array}$ & 1/3 BPW & $13-26$ & Any size & $\$ 23,700$ & $\begin{array}{l}0.10 \% \\
9.00 \% \\
3.00 \%\end{array}$ \\
\hline WA & $\begin{array}{l}680 \text { hours; wages } \\
\text { in BP or alternate } \\
\mathrm{BP}\end{array}$ & $\begin{array}{l}3.85 \% \text { of avg of } \\
\text { high } 2 \text { qtrs in BP }\end{array}$ & $\$ 138$ & $\$ 583$ & $\begin{array}{l}1 / 4 \text { of wages } \\
\text { over } \$ 5\end{array}$ & $\begin{array}{l}\text { Lesser of } 26 \\
\times \text { WBA or } 1 / 3 \\
\text { BPW }\end{array}$ & $1-26$ & Any size & $\$ 38,200$ & $\begin{array}{l}0.49 \% \\
6.00 \% \\
\text { InAvg } \% \\
\end{array}$ \\
\hline WV & $\begin{array}{l}\$ 2,200 \text { and } \\
\text { wages in } 2 \text { qtrs }\end{array}$ & $\begin{array}{l}55 \% \text { of } 1 / 52 \text { of } \\
\text { median wages in } \\
\text { worker's wage } \\
\text { class }\end{array}$ & $\$ 24$ & $\$ 424$ & $\$ 60$ & $\begin{array}{l}\text { Uniform } \\
\text { duration }\end{array}$ & 26 & $\begin{array}{l}20 \text { weeks or } \\
\$ 1,500 \text { in any } \\
\text { qtr }\end{array}$ & $\$ 12,000$ & $\begin{array}{l}1.50 \% \\
7.50 \% \\
2.70 \%\end{array}$ \\
\hline wi & $\begin{array}{l}35 \times \text { WBA and } 4 \times \\
\text { WBA outside } H Q\end{array}$ & $\begin{array}{l}4 \% \mathrm{HQW} \text { up to } \\
\text { maximum WBA }\end{array}$ & $\$ 54$ & $\$ 363$ & $\begin{array}{l}\$ 30 \text { plus } \\
33 \% \text { of } \\
\text { wages in } \\
\text { excess of } \\
\$ 30\end{array}$ & $\begin{array}{l}\text { Lesser of } 40 \\
\text { X BPW or } 26 \\
\text { X WBR }\end{array}$ & $4-26$ & $\begin{array}{l}20 \text { weeks or } \\
\$ 1,500 \text { in any } \\
\text { qtr }\end{array}$ & $\$ 13,000$ & $\begin{array}{l}0.27 \% \\
9.80 \% \\
3.60 \%\end{array}$ \\
\hline
\end{tabular}




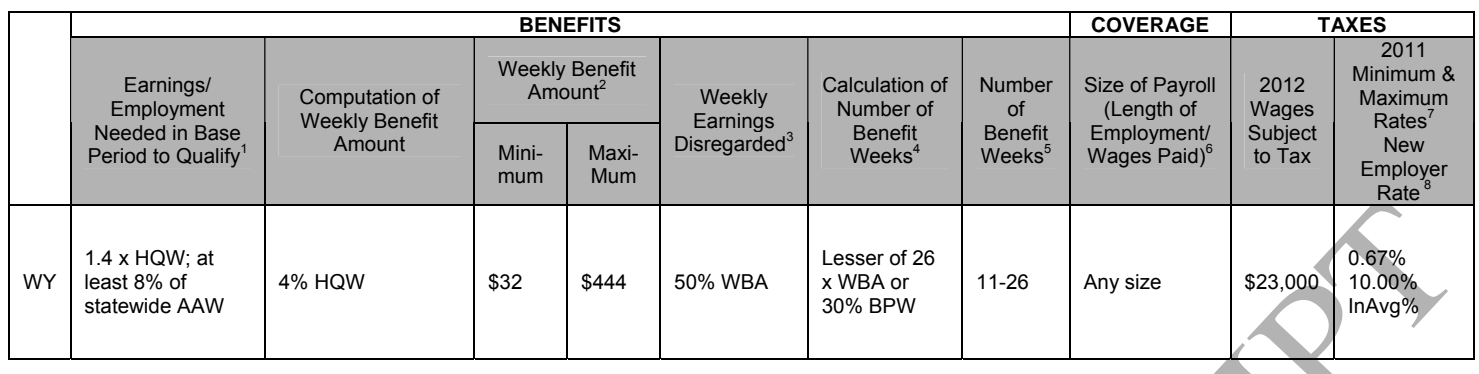

This document is prepared for general reference and may not reflect all the details of a State's law. It is posted on the Web site below. Consult the State agency or the State law for authoritative information. More detailed information may be found in the Comparison of State Unemployment Insurance Laws, which also includes information on Temporary Disability Insurance Programs, at http://www.oui.doleta.gov/unemploy/statelaws.asp.

KEY:
Avg - Average
BPW - Base Period Wages
DA - Dependents Allowance
MBA - Maximum Benefit Amount
">" - Greater Than or Equal To
Qtrs - Quarters

$$
\begin{aligned}
& \text { AAW - Average Annual Wage } \\
& \text { CQ - Calendar Quarter } \\
& \text { HQ - High Quarter } \\
& \text { WBA - Weekly Benefit Amount } \\
& \text { " } \leq \text { " - Less Than or Equal To } \\
& \text { "x" - Times }
\end{aligned}
$$

OTHER PROVISIONS OF LAW:

Waiting Week - Most States require a 1-week waiting period where the claimant must meet all eligibility conditions before benefits are payable. The following States do not require a waiting week: CT, DE, GA, IA, MD, MI, NV, NJ, VT (until 7/1/12), and WY. The waiting week may be paid after a specified period of unemployment in AL, MO, TN, and TX. In some States, it may be suspended under certain conditions.

Base Periods - Almost all qualifying earnings are determined using a BP consisting of the first 4 of the last 5 completed CQs. A few States use a different BP. In the following States, more recent earnings may be used in an alternative BP under certain conditions: AK, AR, CA (effective 04/01/12) CO, CT, DE, DC, GA, HI, ID, IL, IA, KS, ME, MD, MA, MI, MN, MT, NE, NV, NH, NJ, NM, NY, NC, OH, OK, OR, RI, SC, SD, TN, UT, VT, VA, VI, WA, WV, and WI.

\section{FOOTNOTES:}

Reflects basic qualifying formula. Some States have alternative qualifying formul

2 When two amounts given, higher includes DA; the higher figure for both the minimum and maximum WBAs includes DA for the maximum number of deps. If state has a DA and only one amount is given, the maximum is the same with or without the allowance. The total amount of DA payable in any week is limited by a cap. CO and MN do not pay DA. The lower amount is based on HQWs, and the higher amount is based on total BPWs.

${ }^{3}$ This column lists the amount of weekly earnings that are disregarded (will not reduce the WBA). However, earnings in excess of those listed will be deducted from the WBA, resulting in a reduced payment.

${ }^{4}$ For States that use earnings, further calculation is needed to derive the number of benefit weeks--take the amount obtained from the formula listed (which is the claimant's MBA) and divide it by the claimant's WBA. States with uniform duration do not have to calculate the number of benefit weeks since it is fixed at 25 or 26 weeks. In MO, when calculating $1 / 3$ BPW, BPW are limited to $26 \times$ WBA for each quarter.

${ }^{5}$ Lists number of benefit weeks for only the regular program for total unemployment. In States with uniform duration, all eligible claimants receive the same ${ }^{5}$ Lists number of benefit weeks for only the regular program for total unemployment. In States with uniform duration, all eligible claimants receive the same
number of benefit weeks (in IL the maximum amount payable cannot exceed one's BPW, resulting in some claimants being paid less than 26 weeks). For number of benefit weeks (in IL the maximum amount payable cannot exceed one's BPW, resulting in some claimants being paid less than 26 weeks). For
FL the maximum number of weeks annually decreases from 23 with each half percent decline in the avg unemployment rate below $10.5 \%$ during the $3^{\text {rd }} \mathrm{CQ}$ FL the maximum number of weeks annually decreases from 23 with each half percent decline in the avg unemployment rate below $10.5 \%$ during the
of the preceding year; however, the maximum number of weeks cannot fall below 12 when the avg unemployment rate is less than $5 \%$. For WA the of the preceding year; however, the maximum number of weeks cannot fall below 12 when the avg unemployment rate is less than $5 \%$. For WA the
maximum number of benefit weeks decreases from 30 to the lesser of 26 or $1 / 3$ BPW if the State unemployment rate falls to $6.8 \%$ or below. When MA is maximum number of benefit weeks decreases from 30 to the lesser of 26 or $1 / 3 \mathrm{BPW}$ if the State unemployment rate falls to $6.8 \%$ or below. When MA is
paying extended benefits and/or emergency unemployment compensation, the maximum number of weeks of regular benefits is 26 . For WI, with some paying extended benefits and/or emergency unemployment compensation, the maximum number of weeks of regular benefits is 26 . For WI, with some
limited exceptions, individuals with significant ownership interest in family partnerships, LLCs and corporations, and certain of their family members, are limited exceptions, individuals with significant ownership interest in family partnerships, LLCs and corporations, and certain of their family members, are
limited to 4 weeks of regular UI benefits. In some States, additional weeks of benefits are payable under limited circumstances such as high unemployment, limited to 4 weeks of regular UI benefits. In some States, addi

Continuation of approved training, or workforce dislocations.
${ }_{6}^{6}$ Coverage is determined by the size of the employing unit's payroll or the number of days or weeks worked during a $\mathrm{CY}$ and applies to employing units who, ${ }^{6}$ Coverage is determined by the size of the employing unit's payroll or the number of days or weeks worked during a $\mathrm{CY}$ and applies to employing units who,
during any $C Q$ in the current or immediately preceding $\mathrm{CY}$, paid wages of $\$ 1,500$ or more, or to employing units who employ one or more workers on at least 1 day in each of 20 weeks during the current or immediately preceding CY; such employing units are liable for taxes, and the workers accrue benefit rights. For those States with "Any size," all workers are covered regardless of payroll size or weeks worked. States may have different thresholds for agricultural, domestic, and nonprofit employing units.

${ }^{7}$ Rates apply only to experience rated employers and do not include applicable non UI taxes, surtaxes, penalties, or surcharges. In most States, rate year 2011 begins on January 1, 2011, and ends on December 31, 2011. In NH, NJ, TN, and VT rate year 2011 begins on July 1, 2011, and ends on June 30, 2012. Tax rates for 2012 will be posted in the July 2012 issue. For ME there is an additional $0.06 \%$ for the Competitive Skills Scholarship Fund on all employer rates. The rates for IL include the fund building surcharge.

${ }^{8}$ New employer rate shown is the basic rate. Higher rates may apply depending on industry classification and/or other factors: AR (employers can elect to receive rate based on rate schedule), CO, DE (construction employers pay an avg industry rate), DC, IA ( $9.0 \%$ construction employers), IL (4.1\% construction employers which includes the fund building surcharge), KS (6.0\% construction employers), KY (foreign \& domestic construction firms receive maximum rate), MA ( $8.62 \%$ new construction employers), ME (predetermined yield), MD (foreign contractors assigned avg industry rate, and in 2011 new construction employers headquartered in another state pay a $13.3 \%$ avg industry rate), MI (construction employers receive industry rate), MN (high experience rating industries are assigned a rate of $9.69 \%$ plus base rate, assessments, and fees), MT, MO (greater of $3.51 \%$ or InAvg), NE, NJ, NY (highest rate assigned to employers with positive account balances or $3.4 \%$, whichever is less), ND, OH (new construction employers pay InAvg), PA (new rate assigned to employers with positive account balances or $3.4 \%$, whichever is less), ND, OH (new construction employers pay InAvg), PA (new
construction employers pay $9.7 \%)$, SD (6.0\% construction employers), TN, TX, UT, VT (construction employers pay InAvg), WA ( $90 \%$ of InAvg), WV (construction \& foreign entities pay 8.5\%), WI (larger employers \& new construction employers pay higher rate), and WY (InAvg, but not less than 1.0\%). NJ and LA rates depend on rate schedule in effect. In RI new employers pay an additional $0.21 \%$ Job Development Fund.

If you have any questions, please contact Loryn Lancaster at 202-693-2994 or Agnes Wells at 202-693-2996. 